\title{
Aspectos bioecológicos de Harmonia axyridis (Coleoptera: Coccinẹllidae), con especial énfasis en la susceptibilidad a insecticidas: implicancias a nivel ecológico
}

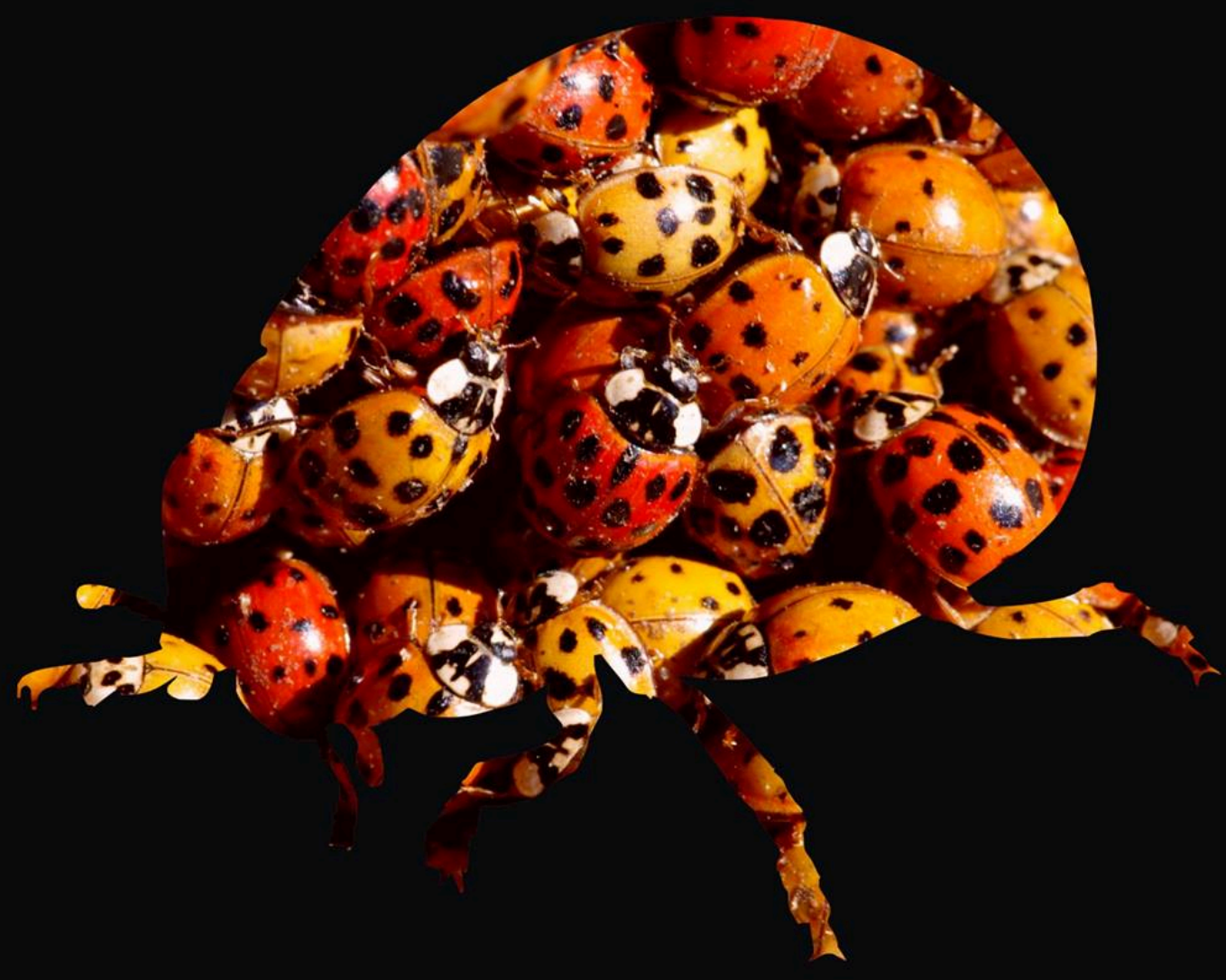

Lic. Luciana Mirande 2015

Director: Dra. M.Inés Schneider Codirector: Dr. Nicolas Desneux 


\section{Agradecimientos}

En primer lugar quiero agradecer a la Facultad de Ciencias Naturales y Museo y a la Universidad Nacional de La Plata, por brindar a los estudiantes de grado la posibilidad gratuita de realizar estudios de doctorado.

También quiero agradecer al Consejo Nacional de Investigaciones Científicas y Tecnológicas (CONICET). Sin la beca otorgada por esta institución, este trabajo de tesis no hubiera sido posible.

Al Centro de Estudios Parasitológicos y de Vectores, por brindarme su lugar de trabajo y demás instalaciones para realizar esta investigación.

A mi directora de tesis, la Dra. Marcela Inés Schneider, y mi codirector de beca, el Dr. Nicolas Desneux, por su apoyo durante estos años.

A la Estación Experimental Ing. Agr. Julio Hirschhörn de la Facultad de Ciencias Agrarias y Forestales, UNLP, por permitirme realizar el muestreo de los insectos.

A Gisela Lamas, docente del curso "Taller de metodología de investigación y elaboración de tesis". Por brindarme aportes que fueron significativos para mi formación.

A los profesionales del Cepave. Graciela Minardi por su profesionalidad al ofrecerme su ayuda con el análisis estadístico. Guillermo Reboredo por su colaboración en los muestreos de campo. Y a Luis Giambelluca por su esmero y dedicación en obtener fotografías de alta calidad que se muestran en este trabajo.

A todos los compañeros del Cepave, con quienes he compartido charlas, mates y almuerzos.

A mis compañeros de laboratorio. En especial a Mar y Emi, porque además de charlas científicas, hemos compartido momentos de la vida. En el último año, el 99\% de las 
charlas fueron sólo científicas, estoy muy agradecida de haber compartido con ellas esta etapa.

A Julia Rouaux, amiga, colega y diseñadora de la tapa de esta tesis. Por contestar a todas mis preguntas y ofrecerme los mejores consejos.

A los amigos que conocí durante mi estadía en Francia. Los españoles Rebeca y Ricardo, el chileno Rodrigo y el tano Michelle. Fueron la compañía más hermosa.

También quiero agradecer a todas aquellas personas que me acompañaron durante todos este tiempo.

A mis amigas de Villa, La Plata y Berazategui. ¡A todas ellas! Por acompañarme, escucharme y preguntarme siempre: ¿cómo andan las vaquitas?

A toda mi familia. Hermanos, tíos, primos y sobrinitos hermosos. En especial, a mi hermana Ale y prima Mechi, por estar siempre a la par. Y a mis padres, por acompañarme en cada decisión que tome. 


\section{Índice}

Resumen

Páginas

Abstract

vii

$x i$

Capítulo 1 - Introducción General 1

El Manejo Integrado de Plagas en los agroecosistemas 2

Insecticidas convencionales utilizados para el control de plagas agrícolas $\quad 4$

Insecticidas biorracionales, una alternativa para el control de plagas 8

Toxicidad de insecticidas sobre enemigos naturales 11

Beneficios y riesgos asociados al control biológico 12

Harmonia axyridis, ubicación sistemática y ciclo de vida 14

Origen y distribución de Harmonia axyridis 16

Posibles causas del éxito de la invasión de Harmonia axyridis 17

Capítulo 2 - Objetivos e Hipótesis

Objetivo General 22

Objetivos específicos $\quad 22$

Hipótesis específicas $\quad 22$

Capítulo 3 - Materiales y Métodos Generales 24

Área de colecta $\quad 25$

Metodología de recolección de coccinélidos $\quad 26$

Colonias de insectos en laboratorio $\quad 27$

Cría de Harmonia axyridis y Eriopis connexa $\quad 27$

Cría de Rhopalosiphum padi 28

Condiciones de cría de insectos y bioensayos $\quad 29$

Cría y obtención de coccinélidos para bioensayos 30

Capítulo 4 - Parámetros biológicos y demográficos de Harmonia axyridis 32

Introducción 33

Materiales y Métodos $\quad 34$

Tabla de vida de dos sexos por estado y edad 35

$\begin{array}{ll}\text { Análisis estadístico } & 37\end{array}$

Resultados 38

Tiempo de desarrollo y longevidad de adultos 38

Supervivencia 38

Expectativa de vida 41 
Parámetros reproductivos 43

Parámetros demográficos $\quad 44$

Discusión 45

Capítulo 5 - Susceptibilidad de Harmonia axyridis a los insecticidas: 50

azadiractina, piriproxifén, acetamiprid y cipermetrina

Introducción 51

Materiales y métodos 53

Bioensayos de toxicidad 53

Bioensayos de toxicidad sobre el estado de huevo 55

Bioensayos de toxicidad sobre larvas del segundo y cuarto estadio 56 larval y estado pupa

Análisis estadístico $\quad 57$

Resultados 58

Bioensayos de toxicidad sobre el estado de huevo 58

Emergencia de larvas expuestas en el estado de huevo 58

Supervivencia de larvas-pupas expuestas en el estado de huevo 59

Fecundidad y fertilidad de hembras expuestas en el estado de huevo 60

Bioensayos de toxicidad sobre el segundo estadio larval 61

Supervivencia de larvas-pupas expuestas en el segundo estadio larval 61

Fecundidad y fertilidad de hembras expuestas en el segundo estadio 64 larval

Bioensayos de toxicidad sobre el cuarto estadio larval 65

Supervivencia de larvas-pupas expuestas en el cuarto estadio larval 65

Fecundidad y fertilidad de hembras expuestas en el cuarto estadio 68 larval

Bioensayos de toxicidad sobre el estado de pupa 69

Emergencia de adultos expuestos en el estado de pupa 69

Fecundidad y fertilidad de hembras expuestas en el estado de pupa

Discusión 73

Capítulo 6 - Interacción intragremio entre Harmonia axyridis y Eriopis connexa 81

Introducción 82

Materiales y métodos 86

Condiciones generales de bioensayos de interacción IGP 86

Bioensayos de interacción IGP en ausencia de presa 86

Bioensayos de interacción IGP con diferentes densidades de presas 88

Bioensayos de interacción IGP con presas contaminadas con insecticidas $\quad 89$ 
Análisis estadístico 90

Resultados 91

Bioensayos de interacción IGP en ausencia de presa 91

$\begin{array}{ll}\text { Supervivencia } & 91\end{array}$

Peso de larvas $\quad 93$

Bioensayos de interacción IGP con diferente densidad de presas 94

Supervivencia 94

$\begin{array}{ll}\text { Peso de pupas } & 97\end{array}$

Bioensayos de interacción IGP con presas contaminada con insecticidas $\quad 99$

Supervivencia 99

Discusión 103

Capítulo 7 - Conclusiones 106

$\begin{array}{ll}\text { Referencias } & 109\end{array}$ 


\section{Resumen}

El Manejo Integrado de Plagas (MIP) es un paradigma que promueve la integración de diferentes estrategias, de bajo impacto sobre el ambiente, para prevenir y controlar poblaciones de organismos plagas por debajo de un nivel que no genere un daño económico al cultivo. Entre las estrategias del MIP se encuentran el uso de insecticidas biorracionales y el control biológico.

El uso de insecticidas es el método más empleado para el control de plagas en los agroecosistemas. Los insecticidas convencionales son los más utilizados por su efectividad de control; sin embargo, debido a su alta toxicidad muchos de estos compuestos han sido prohibidos o su uso ha sido restringido, en varios países del mundo. Los insecticidas biorracionales representan una alternativa al uso de los insecticidas de amplio espectro. Su mayor selectividad hacia los organismos plaga y bajo impacto sobre organismos benéficos y el medio ambiente, hacen que el uso de estos compuestos sea compatible con otras estrategias empleadas en programas de MIP. A su vez, la evaluación de la toxicidad de los insecticidas sobre organismos benéficos provee información útil para el desarrollo de los programas de MIP y su continuidad a largo plazo.

El control biológico involucra la utilización de enemigos naturales (depredadores, parasitoides y patógenos), de forma temporal o permanente, para reducir la densidad de las plagas por debajo del nivel de daño económico. Los enemigos naturales pueden ser nativos o introducidos desde otra región. En los últimos 125 años, alrededor de 2700 especies de enemigos naturales han sido importadas, criadas y liberadas para el control de plagas a nivel mundial. Muchos de estos casos de introducción resultaron exitosos, desde el punto de vista del control biológico. Sin embargo, se han reportado efectos negativos causados por agentes de control biológico exóticos, sobre organismos no blanco, por competir por el espacio, presa u hospedador, participar en interacciones de depredación intragremio, etc.

Harmonia axyridis Pallas (Coleoptera: Coccinellidae) es un depredador nativo de Asia, introducido en muchos países del mundo como agente de control biológico. El número de introducciones e individuos involucrados, su capacidad de dispersión, plasticidad para 
desarrollarse en un amplio rango de ambientes, hábito de alimentación generalista y su rol dominante en interacciones intragremio, han sido algunos de los factores que han contribuido al éxito de la invasión de esta especie. Además, $H$. axyridis puede convertirse en plaga de cultivos frutales, generando daños a frutos, y ocasionar molestias al hombre al invadir edificaciones, e incluso causar alergias. Este coccinélido ha sido categorizado como un agente exótico altamente riesgoso, según la Organización Internacional de Control Biológico (IOBC) y Unión Europea. Desde la introducción de esta especie en la Argentina en el año 1996, no se han realizado estudios de evaluación de riesgo ambiental que midan el impacto de esta especie sobre poblaciones de enemigos naturales nativos, presentes en los agroecosistemas.

En este trabajo de tesis doctoral se estudiaron los parámetros biológicos y demográficos de $H$. axyridis. Se evaluó su susceptibilidad a los insecticidas biorracionales, azadiractina, piriproxifén y acetamiprid, y al insecticida convencional, cipermetrina. Además, se evaluó la interacción intragremio entre los coccinélidos $H$. axyridis y Eriopis connexa en presencia y ausencia de presa, y con presa contaminada con azadiractina, piriproxifén, acetamiprid y cipermetrina. El mantenimiento de las colonias de los coccinélidos y el áfido Rhopalosiphum padi L, así como los bioensayos, se llevaron a cabo en laboratorio en condiciones controladas de temperatura $25 \pm 5{ }^{\circ} \mathrm{C}$, humedad $75 \pm 5 \%$ HR y fotoperiodo de 16: $8 \mathrm{~h} \mathrm{L:} \mathrm{O.}$

A través del estudio de los parámetros biológicos y demográficos de $H$. axyridis se obtuvieron los siguientes resultados. El tiempo de desarrollo inmaduro de $H$. axyridis fue de 17,21 $( \pm 0,11)$ días. El 55\% de los individuos alcanzaron el estado adulto, la proporción de sexos fue 0,47, sesgada hacia los machos, y la longevidad de los adultos fue significativamente diferente entre hembras $(61,87 \pm 4,09)$ y machos $(80,26 \pm 3,68)$. Las curvas de supervivencia específica por estado y edad $(S x j)$ y de expectativa de vida (exj), mostraron los mayores valores de reducción de supervivencia al inicio del ciclo de vida (huevo y primer estadio larval). El periodo de preoviposición adulto fue de 7,09 $( \pm 0,28)$ días. La curva de fecundidad específica $(f x j)$ se caracterizó por presentar numerosos picos a los largo del período reproductivo. La fecundidad y fertilidad promedio de cada hembra, 
a lo largo de su vida, fue de $824,28( \pm 94,91)$ huevos y 562,087 ( $\pm 70,60)$ larvas, respectivamente. Cuando se evaluaron los parámetros demográficos, se obtuvieron los siguientes resultados: $r=0,14( \pm 0,005), R o=232,66( \pm 39,011), \lambda=1,19( \pm 0,002)$ y $T=$ $36,41( \pm 0,662)$.

En la evaluación de la susceptibilidad de H. axyridis hacia los diferentes insecticidas, los efectos de los mismos dependieron del estado de desarrollo ensayado, el insecticida y las concentraciones empleadas.

Azadiractina causó una baja toxicidad sobre el estado de huevo y pupa, solo se registraron efectos letales y subletales en los tratamientos en los que se emplearon la MCRC (48 mg ia./L) y diluciones del 50\% (24 mg ia./L). Sin embargo, los efectos sobre el segundo y cuarto estadio larval fueron más notorios

Piriproxifén resultó ser altamente tóxico sobre el estado de huevo y pupa, reduciendo la emergencia de larvas y adultos a todas las concentraciones ensayadas. Este insecticida produjo una reducción de la supervivencia de larvas del segundo estadio aunque no ocasionó efectos subletales, además, resultó ser inocuo para larvas del cuarto estadio.

Acetamiprid y cipermetrina resultaron ser altamente tóxicos para todos los estados de desarrollo de $H$. axyridis. Ambos insecticidas produjeron una gran reducción de la supervivencia de huevos, larvas y pupas.

Cuando se evaluó la interacción intragremio entre $H$. axyridis y $E$. connexa en ausencia de presa los valores del nivel de depredación intragremio (IGP) indicaron un alto índice de interacción entre ambas especies. Por otro lado, los valores del índice de simetría de IGP demostraron que la dirección de la interacción favoreció a $H$. axyridis en la mayoría de los tratamientos. En los bioensayos con diferente densidad de presa, se observó el mismo patrón. Es este caso la densidad de presas representó un factor clave que intervino en dicha interacción. En los bioensayos con presa tratada con los diferentes insecticidas, azadiractina y piriproxifén causaron una reducción de la supervivencia de los individuos y, al mismo tiempo, influyeron en la interacción IGP, favoreciendo al depredador, $H$. axyridis. Por otro lado, debido a la alta toxicidad de los insecticidas acetamiprid y cipermetrina, no se pudieron evaluar los efectos de estos compuestos sobre dicha interacción. 
Este tipo de estudio permitió obtener valiosa información sobre la biología de la población local de $H$. axyridis, presente en el CHFP, su susceptibilidad a diferentes insecticidas y la interacción intragremio con E. connexa. Estos resultados permiten conjeturar el impacto potencial del depredador invasivo sobre este coccinélido nativo. 


\begin{abstract}
Integrated Pest Management (IPM) is a paradigm that promotes the use of different strategies of low impact on the environment, to prevent and control pests' populations below a certain level which does not generate economical crop damage. Among the strategies of IPM, biorational insecticides and biological control were developed.
\end{abstract}

Nowadays, the use of insecticides is the most common method around the world for controlling pests in agroecosystems. Among them, conventional insecticides are the most commonly used because of its control effectiveness. However, due to its high toxicity many of these compounds have been prohibited or restricted in several countries.

Biorational insecticides emerged in the '90s as an alternative to broad-spectrum insecticides. The high selectivity of these compounds to pests and the low impact on beneficial organisms and environment, make them consistent with other IPM strategies.

Toxicity assays of insecticides on beneficial organisms provide essential knowledge for the development of IPM programs and its long-term continuity.

Biological control involves the use of natural enemies (predators, parasitoids and pathogens) to reduce temporarily or permanently, the density of pests below the economic injury level. The selected natural enemies can be native or introduced from another region. In the past 125 years, about 2700 species of natural enemies have been imported, reared and released for pest control, worldwide. Several cases of successful biological control programs were reported. However, negative effects of exotic biological control agents, were also reported on non-target organisms, i.e. competition for space, prey or host, intraguild predation interactions, etc.

Harmonia axyridis Pallas (Coleoptera: Coccinellidae) is a predator native from Asia, introduced in many countries as a biological control agent. Some of the factors that have been contributed to the success of its invasion are: the numerous introductions of this predator over the world, the number of individuals involved, their dispersal ability, plasticity to develop in a wide range of environments, generalist feeding, and its dominant role in intraguild predation interaction. Moreover, $H$. axyridis could become an economically significant pest in fruit trees, causing damage to the fruits, as well as being 
annoying to humans/people for invade their buildings and even cause allergies. This coccinellid has been categorized as a highly risk exotic agent, according to the International Organization for Biological Control (IOBC) and the European Union. Harmonia axyridis was introduced in Argentina in 1996. Since then, there have been no studies of environmental risk assessment to measure the impact of this species to populations of native natural enemies, also present in the agroecosystem.

In this dissertation, biological and demographic parameters of $H$. axyridis were studied. Susceptibility of $H$. axyridis to the biorational insecticides, azadirachtin, pyriproxifen, acetamiprid, and the conventional insecticide, cypermethrin were evaluated. Besides, the intraguild interactions between $H$. axyridis and Eriopis connexa in absence and presence of prey were performed, and also treated prey with azadirachtin, acetamiprid, pyriproxifen, and cypermethrin. The rearing of the coccinellid and the aphid Rhopalosiphum padi, and the bioassays, were carried out in laboratory, under controlled conditions of temperature $25 \pm 5{ }^{\circ} \mathrm{C}$, humidity $75 \pm 5 \% \mathrm{HR}$ and photoperiod of $16: 8 \mathrm{~h} \mathrm{~L}: \mathrm{D}$.

Through biological and demographic parameters studies in $H$. axyridis, the following results were obtained. The immature developmental time of $H$. axyridis was $17.21( \pm 0.11)$ days. $55 \%$ of the individuals reached the adult stage, the sex ratio was 0.47 , biased towards males, and adult longevity was significantly different between females (61.87 \pm $4.09)$ and males $(80.26 \pm 3.68)$. The age-stage specific survival rate $(S x j)$ and the age-stage life expectancy (exj), showed that the highest values of mortality were recorded on eggs and first instar larvae. The oviposition period was $7.09( \pm 0.28)$ days. The age-stage specific fecundity $(f x j)$ was characterized by numerous peaks along the reproductive period. The average fecundity and fertility of each female, throughout his life, was $824.28( \pm 94.91)$ eggs and $562.087( \pm 70.60)$ larvae, respectively. When demographic parameters were evaluated, the following results were obtained: $R o=232.66( \pm 39.011), r=0.14( \pm 0.005)$, $\lambda=1.19( \pm 0.002)$ and $T=36.41( \pm 0.662)$.

In the evaluation of the susceptibility of $H$. axyridis to insecticides, the effects depended on developmental stage, insecticide evaluated, and concentrations employed. 
Azadirachtin caused low toxicity to eggs and pupae, lethal and sublethal effects were only registered with the MFRC (48 mg a.i./L) and dilutions of 50\% (24 mg a.i./L). However, the effects on the second and fourth larval stage were more evident.

Pyriproxifen was highly toxic to egg and pupae, the emergence of larvae and adults were reduced with all tested concentrations. Although there was a reduction on the survival of the second larval stage, this insecticide did not cause sublethal effects, and in addition it proved to be harmless to the fourth larval stage.

Acetamiprid and cypermethrin was highly toxic to all developmental stages of $H$. axyridis. Both insecticides produced a high reduction in survivorship of eggs, larvae and pupae.

When intraguild interaction was assessed, between $H$. axyridis and $E$. connexa, in the absence of prey bioassays, level values of intraguild predation (IGP) indicated a high rate of interaction between both species. On the other hand, the index symmetry values of IGP demonstrated that the interaction was asymmetric in favor of $H$. axyridis in most of treatments. The same pattern was observed in the bioassays with different prey density. In this case, prey density was the key factor in the interaction. In the bioassays with treated prey with different insecticides, azadirachtin and pyriproxifen caused a reduction in the survival and at the same time, they influenced the IGP interaction, in favor to the predator $H$. axyridis. Furthermore, due to the high toxicity of cypermethrin and acetamiprid, the effects of these compounds over the interaction, could not be evaluated.

This study allows obtaining valuable information about the biology of $H$. axyridis local population, in the CHFP, its susceptibility to different insecticides and the intraguild interaction with $E$. connexa. These results permit to speculate about the potential impact of the invasive predator on the native coccinelid. 
Capítulo 1

\section{Introducción General}




\section{El Manejo Integrado de Plagas en los agroecosistemas}

Los sistemas agrícolas son ecosistemas artificiales, manipulados por el hombre con un fin productivo. Estos sistemas de producción, en general, están diseñados para maximizar el rendimiento y la rentabilidad de la producción. Como resultado, se producen cambios en la estructura y función del ecosistema natural. Desde el punto de vista agroecológico, los sistemas agrícolas son considerados agroecosistemas. Se los estudia de manera más amplia, incluyendo el conjunto de interacciones físicas, químicas, biológicas, ecológicas y culturales que ocurren en ellos, con el fin de obtener una producción sustentable de alimentos (Altieri \& Nicholls 2000; Gliessman et al. 2007).

Para garantizar el éxito de la actividad productiva en los agroecosistemas es fundamental proteger a los cultivos del daño que pueden ocasionarles las plagas. Un manejo adecuado de las mismas se logra a través del Manejo Integrado de Plagas (MIP) (Kogan 1998; Fiedler et al. 2008). El MIP se refiere a "un sistema de toma de decisiones para la selección y el uso de estrategias de manera conjunta para el control de plagas. Este tipo de manejo se basa en el análisis del costo/beneficio, teniendo en cuenta los intereses y el impacto en los productores, la sociedad y el ambiente" (Kogan 1998).

Según lo establecido en el tratado de la Convención Internacional de Protección Fitosanitaria, en el año 1997, una plaga es "cualquier especie, raza o biotipo vegetal o animal o agente patógeno dañino para las plantas o productos vegetales" (FAO 2000).

Por otro lado, el MIP reconoce que una especie fitófaga puede actuar o no como plaga de un cultivo o producto de almacenamiento, dependiendo de las condiciones existentes en el agroecosistema. De esta manera, se identifican las especies fitófagas que pueden ejercer un daño a la producción y se establecen el nivel de daño económico (NDE) y el umbral económico (UE) para cada población en particular. El NDE corresponde a la densidad de una población de individuos fitófagos que causa un daño económico, no tolerado por el productor. El UE es una densidad poblacional menor al NDE; cuando se 
alcanza este valor, se recomienda aplicar una medida de control (Fiedler et al. 2008; Maleki \& Damavandian 2015).

Entre las principales plagas de los agroecosistemas se incluyen: insectos, ácaros, nematodos, hongos, virus, bacterias, moluscos, roedores, aves, arvenses, etc. (Van Driesche et al. 2007).

EI MIP propone el uso conjunto de diferentes estrategias para mantener a los organismos fitófagos por debajo del NDE. Entre ellas se encuentran la selección de variedades resistentes de plantas (cultivos mejorados y plantas genéticamente modificadas), prácticas culturales entre las que se incluyen rotación, aumento de la diversidad de cultivos y uso de cultivos trampa, control biológico, control químico a través del uso de insecticidas biorracionales, técnicas basadas en principios biológicos (uso de feromonas) y control autocida (ej.: técnica de macho estéril) (Kogan \& Waheed 1999; Fiedler et al. 2008).

El control biológico consiste en la utilización de enemigos naturales, de forma temporal o permanente, para reducir la densidad de las plagas por debajo del NDE. Esta estrategia de control de plagas ocasiona un bajo o nulo impacto sobre el ambiente, es de aplicación fácil y segura y en muchos casos permite reducir costos económicos (Van Driesche et al. 2007).

Los enemigos naturales son organismos taxonómicamente diversos e incluyen depredadores (Araneae y Acari, e insectos de los órdenes: Thysanoptera, Heteroptera, Neuroptera, Coleoptera, Diptera e Hymenoptera), parasitoides (Hymenoptera y Diptera) y patógenos (hongos, virus, bacterias, protozoarios y nematodos) (Van Driesche et al. 2007; Jacas \& Urbaneja 2009).

Existen distintos tipos de control biológico. El control biológico por conservación consiste en la manipulación del ambiente para favorecer y potenciar la permanencia y actividad de los enemigos naturales en el agroecosistema. Entre las prácticas que se llevan 
a cabo se encuentran: el manejo del suelo, cultivos y arvenses, suministro de refugios, presas u hospederos alternativos, uso de insecticidas biorracionales, etc. Los tipos de control biológico clásico y neoclásico implican la importación de un enemigo natural, desde otra región, para controlar una plaga exótica o nativa, respectivamente. El control biológico aumentativo comprende liberaciones de enemigos naturales en el cultivo. Existen dos tipos de liberaciones, inundativas e inoculativas. En la primera de ellas, se llevan a cabo una o más liberaciones masivas durante el ciclo del cultivo, esperando que los enemigos naturales controlen a la plaga sin que se establezcan en el sistema. En las liberaciones inoculativas, los enemigos naturales son liberados periódicamente en cultivos de edad temprana. La finalidad es que los mismos se establezcan, multipliquen y su descendencia continúe con el control de la plaga (Eilenberg 2006; Van Driesche et al. 2007).

Insecticidas convencionales utilizados para el control de plagas agrícolas

Los insecticidas convencionales, denominados también plaguicidas, son compuestos de síntesis, utilizados comúnmente para controlar plagas agrícolas. Estos productos químicos se encuentran entre los más utilizados en el mundo y forman parte de los compuestos más peligrosos para el ser humano (Ahmed Azmi \& Naqvi 2011; Arias et al. 2011). Desde su lanzamiento al mercado y durante varias décadas estos productos fueron utilizados sin considerarse su toxicidad, dosis recomendadas, densidad poblacional de la plaga, presencia de organismos benéficos, etc. (Devine et al. 2008). El desconocimiento por parte de la sociedad acerca del impacto de estos insecticidas sobre el ambiente y el hombre, junto con el ocultamiento de esta información por parte de las empresas privadas y el marketing empleado por las mismas, facilitaron la difusión y masificación de estos productos (Stenersen 2004; Devine et al. 2008).

El primer insecticida sintético ampliamente utilizado fue el DDT. Este compuesto, perteneciente al grupo de los organoclorados, comenzó a emplearse en 1939 para 
combatir el mosquito transmisor de la malaria y otras plagas asociadas a la peste bubónica, tripanosomiasis y tifus (Stenersen 2004).

Los insecticidas organoclorados ejercen su mecanismo de acción sobre el sistema nervioso central, se unen a receptores de los canales de cloro e impide la entrada de estos iones a las neuronas. Debido a que la función del cloro es atenuar la transmisión del impulso nervioso, se provoca una excitación anormal, convulsiones y muerte del organismo (Casida \& Durkin 2013). Estos compuestos presentan una alta persistencia en el ambiente y esto se debe a la estabilidad de su estructura química, se estima que el tiempo medio de degradación es de 15 a 30 años (Ahmed Azmi \& Naqvi 2011). Los insecticidas organoclorados son transportados a grandes distancias por el agua y el viento y, debido a su capacidad lipofílica, se incorporan fácilmente en las cadenas tróficas, se acumulan en los seres vivos y se magnifican, alcanzándose concentraciones mayores de estos compuestos en los niveles tróficos superiores (Sijm et al.2007). Se han encontrado residuos de estos compuestos en verduras, frutos, lácteos, leche materna, torrente sanguíneo y otros tejidos de seres humanos (Lorenzati et al. 2003; Ahmed Azmi \& Naqvi 2011).

En la década de 1940, surgen los insecticidas organofosforados. Estos compuestos también ejercen su acción sobre el sistema nervioso central, pero en este caso actúan fosforilando e inhibiendo la enzima acetilcolinesterasa. Esta enzima cataliza la reacción responsable de la interrupción del impulso nervioso, al desligar la molécula del neurotransmisor, acetilcolina, del receptor de la membrana posináptica. Por lo tanto, se genera la transmisión de impulsos continuos, provocando contracciones rápidas de los músculos, hiperexcitación y finalmente la muerte (Casida \& Durkin 2013). Los insecticidas organofosforados han alcanzado un gran éxito en el mercado mundial por su alta efectividad sobre plagas y menor persistencia en el ambiente, con respecto a los insecticidas organoclorados, y nula acumulación en los seres vivos. Sin embargo, estos productos, utilizados también como fungicidas y herbicidas, son altamente tóxicos para 
animales vertebrados, organismos benéficos y el hombre (Gupta 2006; Fernández et al. 2010).

Los insecticidas carbamatos son compuestos que surgen a finales de la década de 1940. Estos productos presentan un mecanismo de acción similar al de los insecticidas organofosforados. Sin embargo la unión del principio activo a la enzima acetilcolineterasa es de manera reversible (Casida \& Durkin 2013). Los carbamatos presentan un espectro de acción amplio y son utilizados como insecticidas, herbicidas y fungicidas. Si bien el tiempo de degradación en el ambiente es menor con respecto a los compuestos organoclorados y organofosforados, resultan ser altamente tóxicos para mamíferos, otros vertebrados, organismos benéficos y el hombre (Gupta 2006).

Los insecticidas piretroides son compuestos cuyo principio activo deriva del crisantemo (Chrysanthemum cinerariawfolium Vis, Asteraceae). Estos productos comenzaron a sintetizarse en la década de 1970 y desde el año 1980 han sido comercializados masivamente, a nivel mundial. Los piretroides presentan una alta efectividad sobre plagas en concentraciones muy bajas. Estos compuestos interfieren en la actividad de los canales de sodio y potasio del sistema nervioso, ocasionando una prolongación y aumento en la intensidad del impulso nervioso. Esto genera hiperexcitabilidad, convulsiones y la muerte del individuo (Casida \& Durkin 2013).

Entre los insecticidas piretroides, la cipermetrina es uno de los productos más utilizados en Argentina para el control plagas de los órdenes: Hemiptera, Diptera, Lepidoptera, Coleoptera, etc. Este insecticida actúa por contacto sobre la planta, su acción sobre los insectos es por contacto e ingestión y además presenta poder de volteo (CASAFE 2013-2015). El amplio rango organismos plaga que son controlados con este insecticida puede explicar su baja selectividad hacia enemigos naturales (Rimoldi et al. 2007). Si bien la cipermetrina y otros insecticidas piretroides presentan baja toxicidad en mamíferos y no se acumulan en el ambiente, son tóxicos para muchas especies de organismos benéficos (Rimoldi et al. 2007; 2008; Fogel 2012; Wakeling et al. 2012; Benamú et al. 2013). 
Los cuatro grupos de insecticidas convencionales mencionados anteriormente presentan un modo de acción similar, al intervenir todos ellos en el funcionamiento del sistema nervioso de los organismos afectados (Casida \& Durkin 2013). El uso de estos compuestos de manera constante y en altas dosis genera una presión de selección sobre individuos fitófagos. De esta manera, se favorece el desarrollo resistencia, generando organismos que no se ven afectados frente a la exposición de un insecticida en particular. Además, también puede generarse resistencia cruzada. En este caso los organismos resistentes a un insecticida específico, adquieren resistencia a otro compuesto que esté relacionado toxicológicamente y al cual no han sido expuestos (Ahmed Azmi \& Naqvi 2011). Otro fenómeno que surge como consecuencia del uso masivo de estos compuestos es la aparición de plagas secundarias. Estas son poblaciones de individuos fitófagos que en un principio no ocasionaban un daño económico sobre el cultivo, pero que, dada la disminución de poblaciones de plagas primarias con quienes competían y/o por la reducción de poblaciones de enemigos naturales que regulaban sus poblaciones, se convirtieron en plagas (Cloyd 2006).

En el año 1996, la Agencia Medio Ambiental de los Estados Unidos (EPA; por sus siglas en inglés) elaboró una lista de productos altamente tóxicos y prohibió su uso en ese país. Desde entonces, cada vez son más los insecticidas altamente tóxicos prohibidos o restringidos en ese y otros países del mundo. En la actualidad, los insecticidas organoclorados, organofosforados y carbamatos forman parte del grupo denominados "Contaminantes Orgánicos Persistentes" (COPs). La comercialización de estos productos constituye un riesgo para la salud del hombre y del ambiente, dado que estas son sustancias químicas peligrosas que pueden acumularse en los compartimentos ambientales: agua, suelo, aire, biota; y ocasionar daños en el ser humano (Colombo et al. 2005; 2011; Pórfido 2014).

En la Argentina, el Servicio Nacional de Sanidad y Calidad Agroalimentaria (SENASA), a partir del 1 de julio del 2013, prohibió la elaboración, formulación y comercialización del endosulfán. Este compuesto se convirtió en el último organoclorado producido en este 
país. Sin embargo, continúan comercializándose insecticidas altamente tóxicos, como metamidofós, fenitorión, malatión y clorpirifós, pertenecientes al grupo de los organofosforados y carbofurán y aldicarb, del grupo de los carbamatos (Pórfido 2014).

Los insecticidas empleados para el control de plagas agrícolas, proveen un gran beneficio para el ser humano, si se los utiliza correctamente. Sin embargo, el uso excesivo o mal uso de estos compuestos puede provocar problemas de contaminación en el ambiente, ocasionando pérdidas de la biodiversidad (Arias et al. 2011). La falta o mal uso de equipos de aplicación y elementos de protección, por parte de trabajadores asociados al uso o fabricación de insecticidas ha provocado envenenamientos agudos o crónicos en estas personas (Bulacio et al. 2007). Además, la acumulación de residuos de insecticidas en granos, frutos, lácteos, etc. podría incidir negativamente en su comercialización y afectar la salud de los consumidores (Devine et al. 2008; Ahmed Azmi \& Naqvi 2011).

Insecticidas biorracionales, una alternativa para el control de plagas

Los insecticidas biorracionales surgen en la década de 1990 como una alternativa al uso de insecticidas convencionales. Son compuestos sintéticos o naturales que derivan de microorganismos, plantas o minerales. También pueden ser sustancias similares o idénticas a otras que se encuentran en la naturaleza (O’Farrill \& Gaud 2007).

Estas sustancias controlan efectivamente a la plaga, se degradan rápidamente, son de bajo impacto ambiental y presentan baja toxicidad hacia organismos benéficos, vertebrados y el hombre. Todas estas características hace que su uso sea recomendable en programas de MIP (O’Farrill \& Gaud 2007; Horowitz et al. 2009).

Los insecticidas biorracionales constituyen una gran diversidad de productos químicos, entre los que se incluyen, bioplaguicidas de origen botánico, reguladores de crecimiento (IGR; por sus siglas en inglés), neonicotinoides y bioplaguicidas de origen microbiano, procedentes de bacterias, hongos, nematodos y virus (O'Farrill \& Gaud 2007; Horowitz et al. 2009). En la actualidad, existen controversias respecto a esta clasificación, 
tal como se mencionará más adelante, los insecticidas neonicotinoides no serían categorizados como insecticidas biorracionales (Nauen \& Denholm 2005).

A continuación, se describen aquellos grupos de insecticidas biorracionales que fueron evaluados en este trabajo de tesis. Los bioplaguicidas de origen botánico son compuestos que presentan una o más moléculas de principio activo, de origen vegetal. En general, estas sustancias representan metabolitos secundarios que participan en la defensa química de las plantas contra organismos herbívoros y patógenos (Isman 2008). El insecticida botánico más conocido y utilizado en la Argentina es la azadiractina. El principio activo de este insecticida es una molécula tetranortriterpenoide del tipo limonoide que se extrae de las semillas del árbol neem (Azadirchta indica A. Juss, Meliaceae). La azadiractina es utilizada en los cultivos para controlar trips, mosca blanca, áfidos, minadores, cochinillas, ácaros y langostas, entre otros (CASAFE 2015).

El insecticida azadiractina bloquea la liberación de la ecdicsona u hormona de la muda por parte de las glándulas protorácicas. Esta hormona regula desarrollo de los insectos, ciclo de muda y diferenciación de tejidos imaginales durante la fase de pupa (Mordue 2004; Cloyd 2006). Además, este insecticida tiene efecto repelente y fagodisuasivo en insectos, al estimular los quimiorreceptores presentes en los tarsos, piezas bucales y cavidad oral, bloquea mecanismos de alimentación y activa mecanismos de disuasión (Mordue 2004).

La azadiractina presenta baja persistencia en el ambiente debido a su alta tasa de fotodegradación (Isman 2006). Si bien este producto no genera ningún daño en humanos y vertebrados, la toxicidad de este insecticida sobre enemigos naturales y polinizadores (abejas y abejorros) es discutida (Isman 2006; Desneux 2007; Haramboure et al. 2009; Francesena et al. 2013).

Los insecticidas IGR abarcan productos cuyo principio activo interviene en el crecimiento y desarrollo de los insectos, e incluyen a los insecticidas miméticos de la hormona juvenil, antagonistas de la hormona de la muda e inhibidores de la síntesis de la quitina. Algunos de los insecticidas utilizados en la Argentina son piriproxifén, metopreno, 
halofenozida, metoxifenocida, diflubenzurón y novalurón (Pórfido 2014). Estos compuestos son muy eficaces para el control de orugas, gorgojos, moscas blancas y otros sucsopicadores (CASAFE 2015).

El piriproxifén es un insecticida mimético de la hormona juvenil. Esta hormona, sintetizada en los cuerpos alados, es la encargada de mantener los caracteres inmaduros durante la fase preimaginal. Además, en adultos interviene en el metabolismo de las proteínas de vitelo y en el desarrollo de los folículos ováricos y glándulas sexuales accesorias. El piriproxifén al actuar como agonista de esa hormona interviene en el desarrollo de los estados inmaduros, presenta efecto ovicida y en adultos altera la fisiología reproductiva (Horowitz et al. 2009). La toxicidad de los insecticidas IGRs sobre enemigos naturales es muy variable y depende, entre otros factores, de la especie ensayada, insecticida empleado, estado de desarrollo evaluado y tiempo de exposición (Cloyd 2006; Schneider et al. 2007).

Los insecticidas neonicotinoides surgieron en la década de 1990. El principio activo de estos compuestos presenta una composición química similar a la nicotina. En la Argentina productos comúnmente comercializados son el acetamiprid, imidacloprid, tiacloprid y tiametoxán (Pórfido 2014).

El insecticida acetamiprid es utilizado para controlar áfidos, moscas blancas, chicharritas, minadores, ácaros, coleópteros del suelo, etc. Este producto tienen acción traslaminar y sistémica sobre la planta y actúa tanto por contacto e ingestión sobre la plaga (CASAFE 2015). Al igual que los demás insecticidas neonicotinoides, actúa sobre el sistema nervioso central de los insectos. La unión de la molécula del principio activo a los receptores de la acetilcolina, de manera persistente, causa la prolongación y aumento del estímulo nervioso, provocando hiperexcitación, convulsiones, parálisis y muerte del organismo (Casida \& Durkin 2013).

Los neonicotinoides han sido considerados durante más de una década insecticidas de bajo riesgo ambiental, especialmente por su baja toxicidad a mamíferos (Tomizawa \& 
Casida 2003). Sin embargo, en la actualidad su categorización dentro del grupo de los insecticidas biorracionales está siendo reconsiderada (EPA 2015). Numerosos estudios demuestran la toxicidad de estos compuestos sobre enemigos naturales, polinizadores y vertebrados (Nauen \& Denholm 2005; Horowitz et al. 2009; Gentz et al. 2010; Whitehorn et al. 2012; Fogel et al. 2013).

\section{Toxicidad de insecticidas sobre Enemigos Naturales}

La evaluación del efecto de los insecticidas biorracionales y de amplio espectro, sobre organismos benéficos ha sido objeto importante de investigación desde la década del 1990. Estos estudios permiten seleccionar y recomendar el uso de ciertos compuestos en programas de MIP y, además, contribuyen con el registro de nuevas materias activas (Desneux et al. 2005; Stark et al. 2007).

La Organización Internacional de Control Biológico (IOBC; por sus siglas en inglés), a través del grupo de trabajo de la Región Paleártica, denominado "Plaguicidas y Organismos Benéficos", propone un sistema de evaluación que consiste en la exposición de organismos benéficos a residuos de insecticidas. Se aplica un esquema secuencial, incluyendo etapas de laboratorio, semicampo y campo. Esta evaluación se centra en el estudio de efectos letales, aunque también se evalúan algunos efectos subletales relacionado con la capacidad benéfica del agente de control biológico, como ser el parasitismo, fecundidad, fertilidad, etc. (Hassan et al. 1994; Boller et al. 2005).

El primer nivel consiste en estudios de laboratorio. Se clasifica a los insecticidas, dependiendo de la reducción ocasionada sobre la supervivencia o capacidad benéfica de los organismos, en las siguientes cuatro categorías: 1- inocuo (<30\%); 2 - levemente tóxico (30-80\%); 3- moderadamente tóxico (80-98\%) y 4- tóxico (> 98\%). Los insecticidas incluidos dentro de la categoría 1, son sugeridos para programas de MIP. Si son incluidos en las categorías 2, 3 y 4 se recomienda realizar estudios en el siguiente nivel. El segundo nivel involucra estudios en condiciones de semicampo, en este caso las categorías de evaluación son: 1 - inocuo (< 25\%); 2- levemente tóxico (25-50\%); 3- moderadamente 
tóxico (50-75\%) y 4- tóxico (>75\%). Los insecticidas incluidos en la categoría 1 o 2 son aceptados para su uso en programas de MIP, si pertenecen a la categoría 3 se requieren estudios de campo y los incluidos en la categoría 4 son considerados incompatibles con programas de MIP. En los estudios de campo, las categorías de clasificación son las mismas que las propuestas para los estudios de semicampo. Aquellos insecticidas pertenecientes a la clase 1 y 2 son recomendados y los incluidos en la clase 3 y 4 son considerados incompatibles para su uso en programas de MIP (Hassan 1994).

El nivel de laboratorio representa la peor situación de exposición de un organismo. Los individuos de campo podrían no entrar en contacto con los insecticidas o encontrar refugios, migrar, elegir la presa u hospedero, etc. Además, podrían estar expuestos a concentraciones menores de insecticidas, producto de la degradación de los mismos en el ambiente (Desneux et al. 2005; Zhang et al. 2011)

Stark \& Banks (2003) destacan la importancia de estudiar los efectos subletales de los organismos benéficos expuestos a insecticidas. Los efectos subletales son aquellos efectos que alteran la fisiología, bioquímica y aspectos comportamentales de los individuos que logran sobrevivir a la exposición de un insecticida, ya sea a la concentración recomendada de campo o inferiores a esta (Desneux et al. 2007). Por lo tanto, aquellos individuos que sobreviven a la exposición de un insecticida pueden haber sufrido daños, reflejados en alteraciones en el tiempo de desarrollo, longevidad, fecundidad y fertilidad. Además, otros factores como la movilidad, búsqueda y captura de presas, parasitismo, etc. pueden verse afectados (Desneux 2005; Cloyd 2006; Schneider et al. 2009; Fogel 2012).

\section{Beneficios y riesgos asociados al control biológico}

El control biológico clásico involucra la introducción de un enemigo natural originario del área nativa de la plaga, por lo tanto, ambas especies comparten una historia evolutiva en común. El control biológico neoclásico, también llamado de nueva asociación, implica la importación de un enemigo natural para controlar una plaga nativa. En este 
caso, las especies no presentan interacción previa y no existe una relación evolutiva entre ellas (Van Driesche et al. 2007). Ambos tipos de control se basan en el principio ecológico que establece que un enemigo natural exótico ejerce un control de la plaga más efectivo respecto a los enemigos naturales nativos (O'Connel et al. 2012).

En los últimos 125 años, alrededor de 2700 especies de enemigos naturales han sido importadas, criadas y liberadas para el control de plagas a nivel mundial (van Lenteren et al. 2008; Cock et al. 2010). Muchos casos de introducción han resultado exitosos desde el punto de vista del control biológico. Un ejemplo de ellos fue la importación del coccinélido Rodolia cardinalis Mulsant de Australia a California, en el año 1888, para el control de Icerya purchasi Maskell (Hemiptera: Coccoidea), plaga primaria de los cítricos (Hoy 2000). Otro caso exitoso de introducción fue la del parasitoide asiático Anagyrus kamali Moursi (Hymenoptera: Encyrtidae) en el Caribe, en la década del 1990. Este parasitoide logró un control efectivo del piojo harinoso rosado, Maconellicoccus hirsutus Green (Hemiptera: Coccoidea), plaga de cítricos, cacao, algodón y plantas ornamentales (Kairo et al. 2000).

Sin embargo, cuando se producen importaciones de enemigos naturales las nuevas asociaciones que se generan entre especies locales y exóticas, pueden interferir e incluso desestabilizar las interacciones preexistentes (Ragsdale et al. 2011). Existen casos de introducción de enemigos naturales que han ocasionado efectos negativos sobre otros organismos no blanco, por participar en interacciones intragremio al competir por el espacio, presa u hospedador o intervenir en la depredación intragremio (IGP; por sus siglas en inglés). Las interacciones IGP ocurren cuando dos especies, que comparten un recurso potencialmente limitante, interactúan tróficamente, alimentándose entre sí (Polis \& McCormick 1989; Lucas et al. 1998). Entre algunos ejemplo de especies de enemigos naturales exóticos que han ocasionado efectos secundarios en las regiones donde han sido introducidos, se encuentran la especie asiática Harmonia axyridis Pallas y la especie paleártica Coccinella septempunctata L (Coleoptera: Coccinellidae) en Estados Unidos. La introducción de ambas especies ha sido asociada a la declinación de poblaciones de coccinélidos nativos (Koch 2003). Otro caso se encuentra representado por la introducción 
de Orius insidiousus Say (Hemiptera: Anthocoridae) en Europa, quien parece competir y desplazar poblaciones del antocórido nativo Orius laevigatus Fieber (Tommasini et al. 2002).

La IOBC junto a la Unión Europea han desarrollado un programa de evaluación de riesgo ambiental que informa sobre la importación y liberación de agentes de control biológico. Mide el impacto que generan las especies introducidas y evalúa aspectos de establecimiento, dispersión, rango de presas u hospedadores, etc. (Van Lenteren et al. 2003; 2008). Este programa, en función de los parámetros mencionados anteriormente, establece una clasificación y define a $H$. axyridis como un enemigo natural altamente riesgosos (Van Lenteren et al. 2008).

Harmonia axyridis, ubicación sistemática y ciclo de vida

Harmonia axyridis es una especie perteneciente a la familia Coccinellidae, la cual se compone de aproximadamente 6000 especies e incluye aquellos individuos conocidos vulgarmente como mariquitas, chinitas o vaquitas (Nedvěd \& Kovář 2012). Los adultos presentan el cuerpo redondeado y convexo, miden menos de $10 \mathrm{~mm}$ de longitud $\mathrm{y}$, al igual que el resto de los coleópteros, se caracterizan por presentar el primer par de alas transformadas en escudos denominados élitros. Estos forman una armadura que protege la parte posterior del tórax, incluido el segundo par de alas. Son características las coloraciones vistosas, generalmente presentan élitros rojos o amarillos con manchas negras (Nedvěd \& Kovář 2012).

Los coccinélidos son depredadores tanto en la fase adulta como larvaria. Se encuentran comúnmente en una gran variedad de ecosistemas agrícolas y muchas especies toman importancia por actuar como enemigos naturales efectivos de áfidos, ácaros y otros organismos plaga de importancia económica de los órdenes Lepidoptera y Coleoptera (Weber \& Lundgren 2009; Nedvěd \& Honěk 2012). 
Harmonia axyridis fue descripta por primera vez como Coccinella axyridis, por Pallas en 1773, numerosas sinonimias fueron propuestas y finalmente, en 1915 y 1943, Jacobson y Timberlake, respectivamente, designaron el nombre de Harmonia como género para esta especie (Koch 2003).

Este coccinélido presenta un ciclo de vida con metamorfosis completa, atravesando el estado de huevo, larva (cuatro estadios), pupa y adulto (El-Sebaey \& El-Gantiry 1999).

Los huevos presentan forma oval, su largo es aproximadamente de $1,2 \mathrm{~mm}$ y son puestos en masas formando plastones, esto es característico de la familia Coccinellidae. Aquellos de menos de 24 horas de edad presentan coloración amarilla y antes de emerger las larvas estas se hacen visibles a través del corion, dándole al huevo una coloración gris oscura (El-Sebaey \& El-Gantiry 1999; Nedvěd \& Honěk 2012).

Las larvas neonatas tienen una longitud de alrededor de $2 \mathrm{~mm}$ y son de color negro. Cuando emergen se localizan alrededor de los huevos, alimentándose de estos, e incluso de otras larvas. El canibalismo es común entre los individuos de esta y otras especies de coccinélidos y es característico de todos los estadios larvales e incluso de los adultos, quienes se alimentan de huevos (El-Sebaey \& El-Gantiry 1999; Nedvěd \& Honěk 2012).

Las larvas del segundo estadio se diferencian de las del primero, por presentar en las regiones dorsolaterales del primer o primer y segundo segmento abdominal una coloración anaranjada. En la larva del tercer estadio estas regiones se extienden hacia el quinto segmento abdominal. Además, esta última presenta en el abdomen estructuras cuticulares en forma de espinas (El-Sebaey \& El-Gantiry 1999; Nedvěd \& Honěk 2012).

Las larvas del cuarto estadio, con una longitud promedio de $9 \mathrm{~mm}$, presentan una coloración similar a las larvas del estadio anterior, aunque las estructuras cuticulares están más acentuadas. Cuando esta larva culmina su desarrollo deja de alimentarse, permanece inmóvil y se fija al sustrato por su último segmento abdominal dando lugar al estado de 
pupa. Esta presenta la superficie lisa y su coloración es anaranjada con puntos negros (ElSebaey \& El-Gantiry 1999; Nedvěd \& Honěk 2012).

Los adultos presentan el cuerpo moderadamente convexo, con una longitud de 7 $\mathrm{mm}$ de largo y $5 \mathrm{~mm}$ de ancho. Su color es muy variable, se han citado más de ochenta morfotipos. En general, son de coloración roja o anaranjada, con manchas negras que varían en número, de cero a veinte. También existen individuos completamente negros o negros con manchas rojas o anaranjadas (Koch 2003). La pigmentación de los élitros está asociada a la herencia genética. Además, la alimentación recibida durante la etapa inmadura y la temperatura a la cual han sido expuestas son factores que influyen en la coloración (Bezzerides et al. 2007).

Los adultos de $H$. axyridis, presentan dimorfismo sexual. La presencia del labro y prosterno pigmentado son características asociadas a las hembras. En los machos, estas estructuras no presentan coloración. Otra característica es el margen distal del quinto esternito abdominal, este es convexo en las hembras y cóncavo en los machos. Si bien estas características no son exactas, representan un patrón y constituyen una herramienta útil para distinguir entre individuos de diferente sexo (Mc Cornack et al. 2007). Además, las hembras grávidas se diferencian de los machos por presentar el abdomen de mayor tamaño y visible, ya que los élitros no alcanzan a cubrirlo.

\section{Origen y distribución de Harmonia axyridis}

Harmonia axyridis es una especie nativa de China, Japón, Korea, Mongolia y el este de Rusia. Esta especie ha sido introducida como agente de control biológico en muchos países del mundo (Lombaert et al. 2010; Brown et al. 2011). La primera introducción fue llevada a cabo en Estados Unidos, en 1916, para el control clásico de áfidos y cóccidos (Gordon 1985). Luego, se realizaron varias introducciones en diferentes estados de ese país, entre los años 1964 y 1982. Sin embargo, esta especie no se ha considerado establecida hasta el año 1988. En Méjico y Canadá, se produjo su introducción intencional 
en el año 1991 y en el presente se encuentra establecida exitosamente en esos países (Koch \& Tederson 2008).

En Europa, H. axyridis fue introducida por primera vez en Ucrania, en 1964, para el control de áfidos de árboles frutales (Katsoyannos et al. 1997). A partir de 1995, esta especie comenzó a comercializarse y desde entonces expandió su rango de distribución. Actualmente, se encuentra en la mayoría de los países del continente europeo (Brown et al. 2008; 2011). A partir de la década de 2000, H. axyridis fue introducida en varios países de África. En la actualidad se considera establecida en Egipto, Túnez, Lesoto, Kenia y Sudáfrica (Brown et al. 2008; 2011).

En Sudamérica, la primera introducción de $H$. axyridis se realizó en la Argentina, en el año 1996, por el INTA Mendoza, para el control de pulgones del duraznero (Saini 2004). En el año 2001, este depredador exótico se encontró en Buenos Aires y, actualmente, es común su presencia en cultivos hortícolas del Cinturón Hortiflorícola Platense (CHFP) (Saini 2004; Strassera et al. 2013). Su presencia también ha sido señalada en las provincias de Santa Fe, Entre Ríos, La Rioja y San Luis, (Zumoffen et al. 2010; Manfrino et al. 2011; Montero 2014). En Chile, H. axyridis fue introducida en el año 1998, sin embargo, no hay registros de su establecimiento hasta el año 2003. Desde entonces, existen registros de este coccinélido en varias localidades de la región central del país (Grez et al. 2010). Aunque no se conocen las causas de la llegada de $H$. axyridis a otros países de Sudamérica, la distribución de esta especie asiática incluye también: Brasil, Uruguay, Ecuador, Colombia, Venezuela, Paraguay y Perú (de Almeida \& da Silva 2002; González \& Kondo 2012; Kondo \& González 2013).

\section{Posibles causas del éxito de la invasión de Harmonia axyridis}

El establecimiento de una especie exótica en una nueva región depende en gran medida de la dispersión antropogénica. Cuando se produce la introducción de un agente de control biológico, la cantidad de importaciones que se realizan y el número de 
individuos involucrados, son factores claves que intervienen en el éxito de su establecimiento. A su vez, el transporte accidental de individuos con el comercio de frutos, vegetales, flores, etc., también juega un rol importante en la dispersión de especies entre diferentes regiones del mundo (De Clercq et al. 2011).

Otro factor importante es la dispersión de la propia especie. $H$. axyridis es un volador activo, con una alta capacidad de movilidad en respuesta a la densidad de presa (Koch 2003). A su vez, en los coccinélidos, la cantidad y calidad de presas que ingieren tiene un gran efecto en la reproducción y, por lo tanto, en el desarrollo de la población. Los progenitores localizan colonias de presas y realizan la postura de huevos, de esta forma se reduce la búsqueda de alimento por parte de la progenie (Tauber \& Tauber 1993; Phoofolo et al. 2008).

Harmonia axyridis es conocida por transportarse hacia sitios de invernadero y formar agregaciones de cientos o miles de individuos en las estaciones de otoño e invierno (Koch et al. 2003). Estos sitios están representados por ambientes naturales, como grietas de rocas y cortezas de árboles, y por ambientes intervenidos por el hombre. Esto podría conferirle una ventaja al aumentar la supervivencia durante las estaciones de bajas temperaturas. Estos hábitos se han detectado en su región de origen y nuevas áreas de introducción. Cuando $H$. axyridis invade casas y otras edificaciones, puede convertirse en una plaga doméstica, causando molestias por ocupar y dañar muebles y paredes e incluso causar alergias al hombre (Koch et al. 2006).

Esta especie asiática habita en una gran variedad de ambientes que incluyen zonas arbóreas, ribereñas, pastizales, praderas y sistemas agrícolas y urbanos (Majerus et al. 2006). Además, H. axyridis se desarrolla favorablemente en un amplio rango de temperatura y presenta una gran capacidad de adaptación a nuevos ambientes y redes tróficas (Adriaens et al. 2008; Brown et al. 2011). Esta especie ha sido registrada en cultivos de lechuga, tomate, alcaucil, pimiento, berenjena, repollo, alfalfa, trigo. También su presencia es habitual en producciones frutales de ciruelo, cerezo, duraznero, almendro, 
manzano y cítricos, entre otros (Manfrino et al. 2011; Strassera et al. 2013; Montero 2014; Strassera com. pers.).

Harmonia axyridis es un depredador generalista de áfidos y otros artrópodos de los grupos: Tetranichidae, Psyllidae, Coccoidea, Chrysomelidae, Curculionidae y Lepidoptera. También se alimenta de polen, néctar y frutos, lo cual representa alimento suplementario y favorece la supervivencia de la población, cuando la presa es escasa o no está disponible (Koch 2003). Se han encontrado ejemplares de esta especie alimentándose de frutos en producciones de uvas, manzanas, duraznos, ciruelas, frambuesas, etc. En ciertos casos, $H$. axyridis podría actuar como plaga, generando daños a frutos o convirtiéndose en contaminante en la elaboración de vino y alimentos (Pickering et al. 2005; Galvan et al. 2009).

Harmonia axyridis ha generado efectos adversos sobre poblaciones de enemigos naturales y otros organismos benéficos en las regiones donde ha sido introducida. Esta especie invasiva ha generado desequilibrios en las cadenas tróficas, por competir por los recursos e intervenir en interacciones IGP (van Lenteren et al. 2003; Pervez \& Omkar 2006; Alhmedi et al. 2010). En Estados Unidos se han realizado estudios a campo evaluando la abundancia de diferentes especies de coccinélidos a lo largo de varios años. Los mismos han demostrado que mientras la abundancia de $H$. axyridis ha aumentado, otras especies de coccinélidos nativos han declinado sus poblaciones. Entre ellas se encuentran Cycloneda munda Say, Chilocorus stigma Say, Cycloneda sanguinea L., Coccinella transversoguttata Faldermann e Hippodamia tredecimpunctata L. (Colunga Garcia \& Gage 1998; Michaud 2002; Alyokhin \& Sewell 2004). En Europa, Pell et al. (2008) reportaron que los coccinélidos Adalia bipunctata L y $C$. septempunctata han sido desplazados por $H$. axyridis. Por otro lado, estudios en laboratorio han demostrado la ocurrencia de interacción intragremio entre $H$. axyridis y otros enemigos naturales afidófagos, como ser Chrysoperla carnea Stephens (Neuroptera: Chrysopidae), Aphidoletes aphidimyza Rondani (Dipetra: Cecidomyiidae) y Podisus maculiventris Say (Heteroptera: Pentatomidae). Los resultados a favor del coccinélido exótico indican que las poblaciones 
a campo de estos enemigos naturales podrían verse afectadas (Phoofolo \& Obrycki 1998; Lanzoni et al. 2004; Pell et al. 2008). En la Argentina, desde la introducción de este coccinélido en el año 1996, no se han llevado a cabo estudios que evalúen el impacto de esta especie sobre poblaciones de enemigos naturales nativos presentes en los agroecosistemas (Saini 2004). 
Capítulo 2

\section{Objetivos e hipótesis}




\section{Objetivo General}

El objetivo general de este trabajo de tesis fue ampliar el conocimiento sobre la biología de la población local de Harmonia axyridis presente en el Cinturón Hortiflorícola Platense (CHFP), evaluar su susceptibilidad a diferentes insecticidas y estudiar la interacción con el coccinélido Eriopis connexa Germar.

\section{Objetivos específicos}

1- Estudiar los parámetros biológicos (tiempo de desarrollo, supervivencia, longevidad, fecundidad y fertilidad) y demográficos (tasa intrínseca de crecimiento natural, tasa reproductiva neta, tasa finita de crecimiento y tiempo generacional) de $H$. axyridis.

2- Evaluar la susceptibilidad de H. axyridis a los insecticidas biorracionales, azadiractina, piriproxifén y acetamiprid, y al insecticida convencional, cipermetrina.

3- Comparar la interacción intragremio entre H. axyridis y E. connexa, en presencia y ausencia de presa.

4- Analizar los efectos de los insecticidas biorracionales, azadiractina, piriproxifén y acetamiprid, y el insecticida convencional cipermetrina, sobre la interacción intragremio entre $H$. axyridis y E. connexa.

\section{Hipótesis específicas}

El primer objetivo fue descriptivo y no presentó hipótesis asociada. Las hipótesis específicas relacionadas con los demás objetivos fueron:

1. H. axyridis muestra menor susceptibilidad a los insecticidas biorracionales, azadiractina, piriproxifén y acetamiprid, con respecto al insecticida convencional, cipermetrina.

2. Existe interacción intragremio entre $H$. axyridis y $E$. connexa y dicha interacción favorece al depredador exótico. 
3. Los insecticidas biorracionales, azadiractina, piriproxifén y acetamiprid, influyen en la interacción intragremio entre $H$. axyridis y $E$. connexa, favoreciendo al depredador exótico. 
Capítulo 3

\section{Materiales y Métodos Generales}




\section{Área de colecta}

El Cinturón Hortiflorícola Platense (CHFP) es la región hortícola más importante de la provincia Buenos Aires. Se ubica en el noreste de la provincia y comprende la zona sur del llamado "Cinturón Verde Bonaerense". Abarca los partidos de La Plata, Berazategui y Florencio Varela y se concentra en las localidades de La Plata, Los Hornos, Abasto, Lisandro Olmos, Etcheverry, Colonia Urquiza y El Peligro (CHFB 2005; Ringuelet 2008) (Figura 3.1 b).

La región del CHFP cuenta con un área de 5.308,5 ha cultivadas, de las cuales el $80 \%$ corresponden a cultivos bajo cubierta (CHFB 2005; García 2011). La tecnología de invernáculo, representada por estructuras de madera recubiertas con polietileno, presenta como ventaja un mayor control del ambiente que se refleja en un mayor rédito de la actividad productiva. Sin embargo, la adopción de esta tecnología ha generado una creciente demanda y dependencia por el uso de productos agroquímicos (García 2011).

En esta región, el manejo sanitario de plagas se lleva a cabo principalmente a través del control químico, utilizando insecticidas convencionales, con aplicaciones periódicas, llevadas a cabo por calendario. Sin embargo, también existen otros tipos de producción como la agroecológica y, en menor medida, la producción orgánica. Uno de los aspectos del manejo agroecológico se basa en priorizar el monitoreo de individuos fitófagos y enemigos naturales antes de realizar la aplicación de insecticidas, y a su vez, emplear aquellos insecticidas que generan un menor daño a los organismos no blanco y el ambiente. En la Provincia de Buenos Aires, la superficie cultivada con hortalizas bajo manejo orgánico es de 6300 ha (DNIyCA-SENASA, 2015), en donde se lleva a cabo el monitoreo periódico de plagas y organismos benéficos y los insecticidas que se utilizan para el control de plagas son bioplaguicidas de origen botánico y microbiológico (Strassera 2009; Rouaux 2015). 


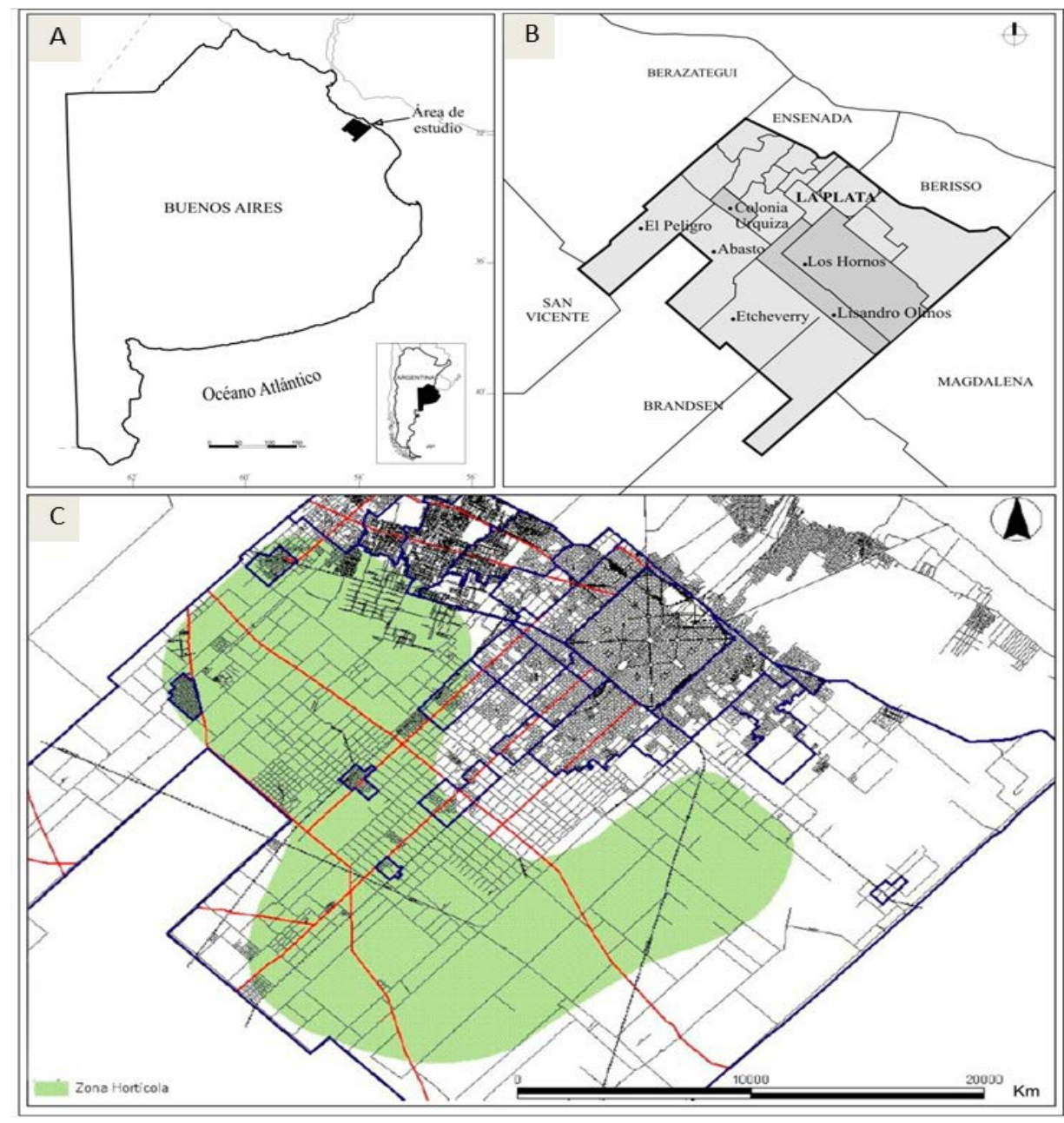

Figura 3.1. A y B: Ubicación del Partido de La Plata y de sus localidades (Colonia Urquiza, Los Hornos, Abasto, Lisandro Olmos, Etcheverry y El Peligro) (Rouaux 2015); C: Plano del Partido de La Plata donde se muestra, en verde, la ubicación de las áreas dedicadas a la horticultura (Ringuelet 2008).

\section{Metodología de recolección de coccinélidos}

La colecta de los coccinélidos, Harmonia axyridis y Eriopis connexa, fueron Ilevados a cabo en el CFHP, durante los meses de marzo y abril de 2011. Se recolectaron manualmente ejemplares de diferentes estados de desarrollo en cultivos de alcaucil 
(Cynara cardunculus L., Asteraceae), lechuga (Lactuca sativa L., Asteraceae), tomate (Solanum lycopersicum L., Solanaceae), pimiento (Capsicum annuum L., Solanaceae), berenjena (Solanum melongena L., Solanaceae) y repollo (Brassica oleracea L., Brassicaceae). Se priorizaron aquellos cultivos con manejo orgánico, con el fin de recolectar individuos libres de residuos de insecticidas.

Los individuos se colocaron en recipientes plásticos, de $10 \mathrm{~cm}$ de diámetro y $10 \mathrm{~cm}$ de alto, ventilados con tela de "voile". Los mismos se colocaron en conservadoras para su traslado al laboratorio. Las especies fueron corroboradas, contrastando el material recolectado con las descripciones de Guillermo González (www.coccinellidae.cl), y luego confirmadas por él. Los ejemplares recolectados fueron criados durante 30 días en cuarentena para evitar la ocurrencia de patologías y parasitismo que pudieran condicionar luego su cría. Una vez transcurrido este tiempo, los individuos fueron multiplicados y la progenie se utilizó para iniciar la colonia en el laboratorio. Para mantener la variabilidad alélica de las poblaciones, se incorporó material biológico de ambas especies de depredadores, dos veces al año, siguiendo las recomendaciones de Mackauer (1976).

\section{Colonias de insectos en laboratorio}

\section{Cría de Harmonia axyridis y Eriopis connexa}

Los individuos adultos de $H$. axyridis y $E$. connexa fueron criados en recipientes cilíndricos de plástico, de $18 \mathrm{~cm}$ de diámetro y $20 \mathrm{~cm}$ de alto, ventilados con tela de "voile" (Figura 3.2). Se dispusieron alrededor de 30 individuos por recipiente y se utilizó como alimento pulgón de la avena, Rhopalosiphum padi L. (Hemiptera: Aphididae), pasas de uva y dieta artificial a base de carne e hígado de vaca y azúcares. La misma fue suministrada, cada dos días, a través de esferas realizadas con Parafilm ${ }^{\circledR}$ (Figura 3.2). Además, se colocaron trozos de papel como sustrato de oviposición y bebederos con agua. Éstos últimos, consistieron en recipientes de $40 \mathrm{ml}$ a los que se les realizó un orificio en su parte superior y se les colocó un trozo de material tipo esponja. 
Dos veces por semana, los individuos fueron acondicionados. Se los colocó en un recipiente limpio con alimento y agua. Cuando se encontraron huevos, los mismos fueron separados y dispuestos en cápsulas plásticas de Petri de $6 \mathrm{~cm}$ de diámetro y $1,5 \mathrm{~cm}$ de alto.

Las larvas emergidas fueron colocadas, como máximo en número de 20 , en recipientes cilíndricos de plástico, de $18 \mathrm{~cm}$ de diámetro y $20 \mathrm{~cm}$ de alto, ventilados con tela de "voile". Estas se alimentaron con R. padi, dieta artificial y pasas de uva. Debido al canibalismo que ocurre naturalmente entre individuos de muchas especie de coccinélidos (Nedvěd \& Honěk 2012), se colocaron en el interior de los recipientes trozos de papel para suministrarles a los individuos un espacio de refugio. Los individuos que superaron el estado de pupa y alcanzaron el estado adulto fueron utilizados para iniciar una nueva cohorte de la colonia.

\section{Cría de Rhopalosiphum padi}

La cría del pulgón $R$. padi se llevó a cabo sobre plantines de trigo, Triticum estivum L., Poaceae, variedades cultivadas ACA 901/908. Los clones de áfidos fueron suministrados por la Dra. Mónica Ricci de la Facultad de Ciencias Agrarias y Forestales (UNLP). El material fue analizado con las claves de Olsen et al. (1993). Las semillas de trigo fueron provistas por el Ing. Armando Junquera (Asociación de Cooperativas Argentinas).

Las semillas se colocaron para su germinación en recipientes con agua durante 6-8 h. Una vez escurridas se colocaron, formando una capa ligera, en bandejas de $15 \times 15 \times 5$ $\mathrm{cm}$, fueron cubiertas con film plástico y se mantuvieron en el bioterio durante 48-72 h. Aquellas semillas que presentaron emergencia de raíces fueron colocadas en macetas de plástico de $6 \mathrm{~cm}$ de diámetro y $6 \mathrm{~cm}$ de alto, utilizándose como sustrato tierra fértil y perlita en proporción 3: 1. Posteriormente, las plántulas fueron colocadas en recipientes plásticos, de $13 \mathrm{~cm}$ de alto x $30 \mathrm{~cm}$ de largo x $23 \mathrm{~cm}$ de ancho, ventilados con tela de 
"voile" (Figura 3.2). Dos veces por semana, se retiraron plantines para su uso en la cría de los depredadores o bioensayos, y se colocaron nuevas plántulas.

\section{Condiciones de cría de insectos y bioensayos}

La cría de los coccinélidos, $H$. axyridis y E. connexa, R. padi y los bioensayos, se llevaron a cabo en un bioterio, bajo condiciones controladas de temperatura, $25 \pm 2{ }^{\circ} \mathrm{C}$, humedad, $75 \pm 5 \% \mathrm{HR}$, y fotoperiodo, 16: $8 \mathrm{~h} \mathrm{L:} \mathrm{O.}$
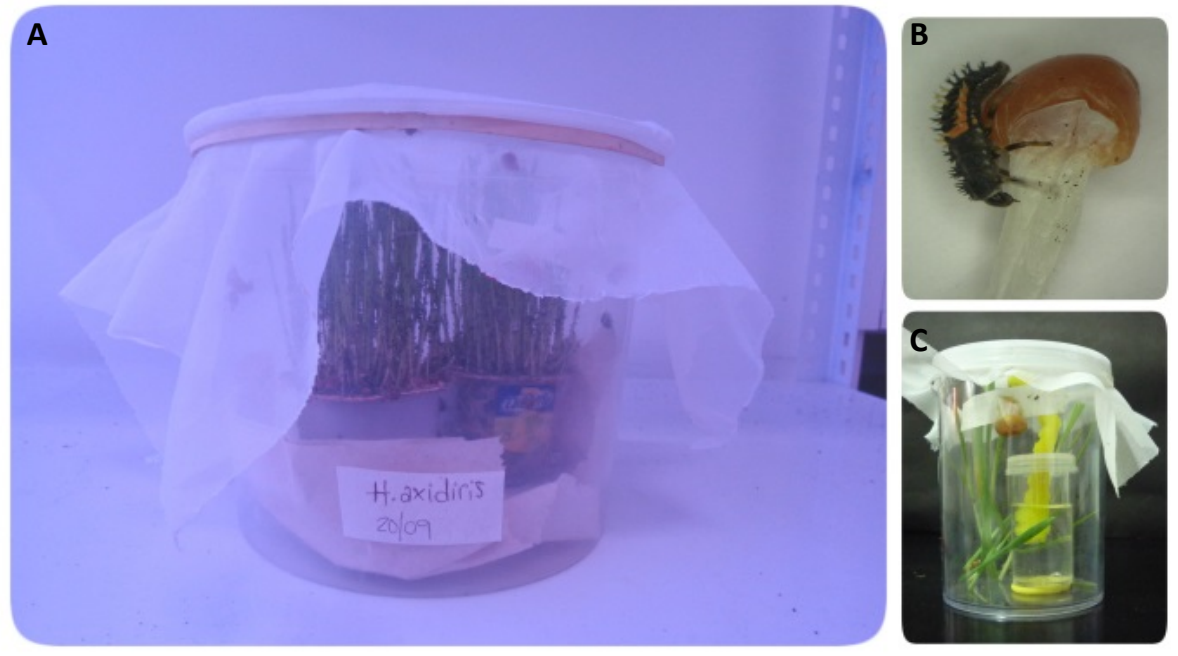

$$
\text { D }
$$

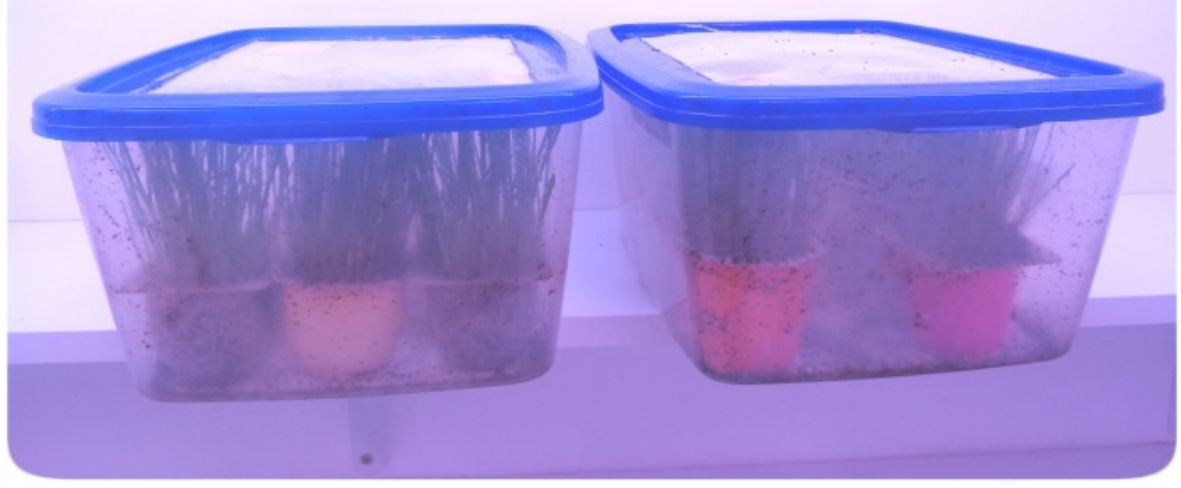

Figura 3.2. A: Cría de adultos de Harmonia axyridis. B: Larva del cuarto estadio de $H$. axyridis alimentándose de dieta artificial C: Arena de hembras Cl grávidas. D: Cría de Rhopalosiphum padi sobre plantines de trigo. 
La obtención de individuos para bioensayos se realizó siguiendo la metodología descripta para la cría de coccinélidos, con algunas variantes dependiendo del estado de desarrollo que se deseó conseguir. El diagrama general se ilustra en la Figura 3.3.

Se seleccionaron individuos adultos de entre 15 y 30 días de edad de los recipientes de cría. Éstos se colocaron en grupos de 20 en recipientes plásticos de $18 \mathrm{~cm}$ de diámetro y $20 \mathrm{~cm}$ de alto, ventilados con una tela de "voile" y se les suministró como alimento $R$. padi ad libitum y dieta artificial. Se escogieron adultos jóvenes para aprovechar al máximo su potencial reproductivo. Una vez transcurridos 7 días, se retiraron las hembras grávidas, identificadas por presentar el abdomen de mayor tamaño y élitros levantados. Las mismas se colocaron individualmente en recipientes cilíndricos de plástico, de $6 \mathrm{~cm}$ de diámetro y $10 \mathrm{~cm}$ de alto, ventilados con tela de "voile", en los que se colocaron trozos de papel como sustrato de oviposición (Figura 3.2. C). Se realizó un control diario para suministrar el alimento y recolectar los huevos.

Los huevos fueron destinados para bioensayos o, cuando se deseó obtener un estado de desarrollo más avanzado, los mismos fueron llevados al bioterio. Las larvas del primer estadio fueron individualizadas en cápsulas de Petri, de $6 \mathrm{~cm}$ de diámetro y 1,5 cm de alto, y controladas diariamente para asegurar la higiene, suministrar alimento y contabilizar las ecdisis. De igual manera, las pupas se controlaron cada $24 \mathrm{~h}$ para registrar la emergencia de adultos. Aquellos individuos que no se emplearon en los bioensayos se incorporaron nuevamente a la colonia. 


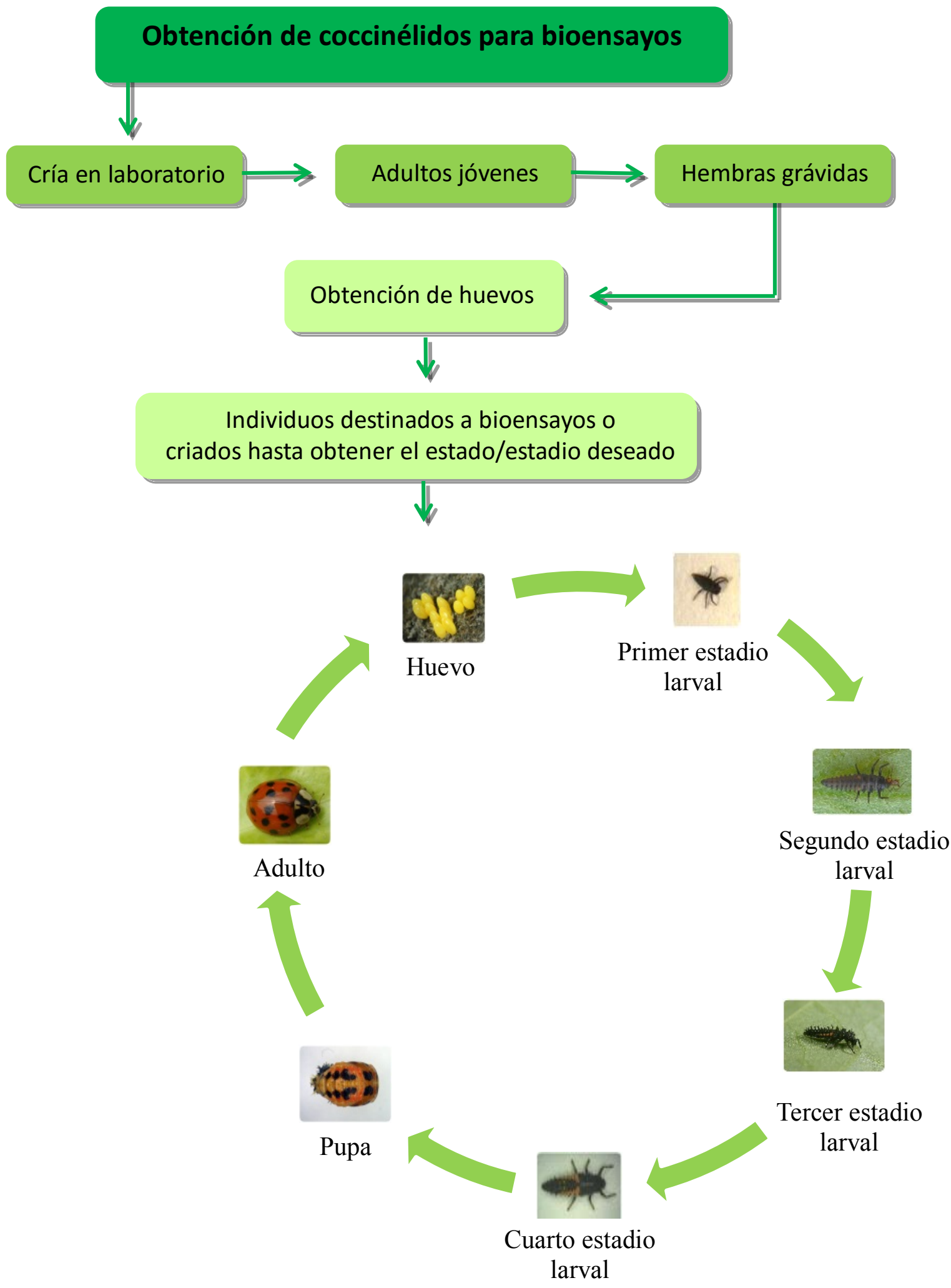

Figura 3.3. Diagrama general de cría y obtención de coccinélidos para bioensayos. Las fotos del ciclo de vida corresponden a los diferentes estados de desarrollo de Harmonia axyridis. 
Capítulo 4

\section{Parámetros biológicos y demográficos de Harmonia axyridis}




\section{Introducción}

Las tablas de vida brindan información cuantitativa sobre la supervivencia y reproducción de una población animal y, a partir de ellas, se pueden establecer los parámetros demográficos (Rabinovich 1980). Estos son indicadores de distintos aspectos de la biología de una población y permiten inferir sobre las fluctuaciones en su desarrollo y crecimiento (Pianka 1983).

Los estudios de tablas de vida horizontal tradicionales o específicas por edad describen el crecimiento potencial de una población a partir de una cohorte, es decir, individuos de la misma edad cronológica. Además, asume que todos los individuos, a una determinada edad, se encuentran en el mismo estado de desarrollo (Leslie 1945, Birch 1948; Rabinovich 1980; Chi \& Liu 1985; Chi 1988).

Sin embargo, desde el punto de vista ecológico, es importante evaluar la superposición de los diferentes estados de desarrollo e incluir en el estudio a los individuos machos de la población (Chi 1988; Chi \& Liu 1985). Los insectos presentan una tasa de desarrollo diferencial que se refleja en el fenómeno de superposición entre los diferentes estados de desarrollo. Esto se debe a la variabilidad natural existente entre los individuos de una población y a factores externos como la temperatura, luz, humedad, disponibilidad de alimento, etc. Cuando se evalúan los diferentes estados de desarrollo de un organismo benéfico depredador y se consideran a ambos sexos, se pueden encontrar variaciones en cuanto a la longevidad y tiempo de desarrollo de los mismos, cantidad de presas requerida, etc. (Silva et al. 2013; Yu et al. 2005; 2013).

Chi y Liu (1985) desarrollaron un estudio de tabla de vida horizontal denominado "tabla de vida de dos sexos por estado y edad". El beneficio de utilizar este modelo es que incluye a los individuos de ambos sexos y aquellos que no alcanzan el estado adulto. Por otro lado, considera la variabilidad existente entre los estados de desarrollo. Las tablas de vida de dos sexos, por estado y edad, han sido empleadas en estudios biológicos, ecológicos y ecotoxicológicos, de insectos y ácaros, tanto plagas como enemigos naturales (Chi \& Su 2006; Schneider et al. 2009; Chi \& Yang 2003; Jha et al. 2014). 
El objetivo de este capítulo fue:

- Estudiar parámetros biológicos (tiempo de desarrollo, supervivencia, longevidad, fecundidad y fertilidad) y demográficos (tasa intrínseca de crecimiento natural, tasa reproductiva neta, tasa finita de crecimiento y tiempo generacional) de $H$. axyridis.

\section{Materiales y Métodos}

El estudio de tabla de vida se llevó a cabo bajo condiciones controladas de temperatura, humedad y fotoperiodo $\left(25 \pm 2{ }^{\circ} \mathrm{C}, 75 \pm 5 \% \mathrm{HR}, 16: 8 \mathrm{~h} \mathrm{~L}\right.$ : O). El experimento se inició con un total de 88 huevos, de $<24$ h de edad. Los mismos se extrajeron de la colonia de coccinélidos para bioensayos.

Una vez emergidas las larvas se colocaron individualmente en cápsulas de Petri, de 6 $\mathrm{cm}$ de diámetro y $1,5 \mathrm{~cm}$ de alto. Diariamente se les suministró como alimento pulgón $R$. padi ad libitum y dieta artificial. Se registró la supervivencia diaria de cada individuo y se determinó el tiempo de desarrollo de cada estado inmaduro, incluyendo aquellos que no alcanzaron el estado adulto.

Cuando emergieron los adultos, los mismos fueron sexados siguiendo la metodología de Mc Cornack et al. (2007). La proporción de sexos se calculó de la siguiente manera:

Proporción de sexo $q$ = número de adultos $q /$ número total de adultos

Se formaron 23 parejas y se las colocó individualmente en recipientes cilíndricos de plástico, de $6 \mathrm{~cm}$ de diámetro y $10 \mathrm{~cm}$ de alto, ventilados con tela de "voile". En cada arena se colocó papel como sustrato de oviposición, bebederos con agua, pulgón ad libitum y dieta artificial. Se realizó un control diario para suministrar el alimento y retirar los huevos. 
Se registró la longevidad de los adultos y el número de huevos/hembra/día y larvas emergidas/hembra/día de cada hembra para calcular la fecundidad y fertilidad diaria, respectivamente.

Tabla de vida de dos sexos por estado y edad

Los datos de la historia de vida de $H$. axyridis fueron analizados a través del modelo de tabla de vida de dos sexos, por estado y edad (Chi \& Liu 1985; Chi 1988). Para esto, se utilizó el software TWOSEX MSCHART, versión 2015.016 (Chi 2012).

A partir de los datos de supervivencia y fecundidad, este modelo elabora diferentes matrices de múltiples filas y columnas. El estudio se inicia con la construcción de una matriz $\mathrm{N}$ representada por $k$ filas y $m$ columnas, donde $k$ representa las diferentes edades de la población y $m$ los diferentes estados de desarrollo. En este trabajo de tesis, son los siguientes: huevo, primer, segundo, tercer y cuarto estadio larval, pupa y adulto (hembras y machos por separados). Los diferentes valores de la matriz nij constituyen los individuos a la edad $i$ y estado $j$. El tamaño total de la población queda representado por:

$$
N t=\sum n i j
$$

Conociendo la estructura por estado y edad de una población a un tiempo $t$, se puede inferir sobre el desarrollo poblacional en un tiempo $t+1$. Luego de un intervalo de tiempo $t$, un individuo de edad $i$ y estado $\mathrm{j}$ puede desarrollarse a la edad $i+1 \mathrm{y}$ permanecer en el mismo estado $j$, desarrollarse hacia el estado $j+1$, o morir.

Los parámetros biológicos obtenidos, fueron los siguientes:

- Tasa de supervivencia específica por edad y estado (Sxj). Muestra la probabilidad de un individuo de sobrevivir a la edad $x$ y estado $j$. 
- Tasa de supervivencia $(/ x)$. Corresponde a la proporción de la cohorte que sobrevive desde el nacimiento hasta la edad $x$.

- Expectativa de vida por edad y estado (exj). Indica el tiempo total, en días, que le queda por vivir a un individuo de edad $x$ y estado $j$.

-Expectativa de vida a la edad $x(e x)$. Indica el tiempo total, en días, que le queda por vivir a un individuo de edad $x$.

- Fecundidad específica por edad (fxj). Representa el número promedio de descendientes producido por un individuo hembra a la edad $x$.

Para la estimación de los parámetros demográficos, este modelo se basa en la fórmula de la tasa intrínseca de crecimiento natural ( $r$ ), propuesta por Lotka (1913) y descripta a continuación. El error estándar de cada uno de los parámetros demográficos se estimó a través del test de Bootstrap.

$$
\sum e^{-r x} l x m x=1
$$

Los parámetros demográficos se estimaron de la siguiente manera (Chi \& Liu 1985; Chi 1988):

- Tasa intrínseca de crecimiento natural o tasa instantánea de incremento poblacional $(r)$. Es una medida de la tasa instantánea de cambio del tamaño de la población.

$$
\sum e^{-r x} l x m x=\sum\left(e^{-r x}\right) \sum S x j f x j=1
$$

- Tasa reproductiva neta o tasa de reemplazo por generación $\left(R_{0}\right)$. Corresponde al número promedio de descendientes producidos por hembra durante toda su vida. 


$$
R_{0}=\sum l x m x=\sum S x j f x j
$$

- Tasa finita de crecimiento. Es la tasa de cambio del tamaño de la población en un período finito de tiempo $(\lambda)$.

$$
\lambda=e^{r}
$$

- Tiempo generacional (T). Es el tiempo promedio, en días, entre dos generaciones sucesivas. En este caso, al tratarse de una población con generaciones discretas, este valor se calcula de huevo a huevo.

$$
T=\frac{\ln R_{0}}{r}=\frac{\ln \left(\sum S x j f x j\right)}{r}
$$

\section{Análisis estadístico}

El tiempo de desarrollo de huevo a pupa y huevo a adulto, así como la longevidad de adultos entre hembras y machos se comparó a través del análisis de dos muestras independientes, utilizando el test $\mathrm{t}$ de Student para datos paramétricos y el test $\mathrm{U}$ Mann Whitney para datos no paramétricos. Para comprobar la normalidad de los datos y la homocedasticidad de las varianzas, los mismos fueron sometidos al test de Shapiro-Wilk y de Levene, respectivamente. Si alguna de los supuestos no se alcanzaron, los datos fueron transformados en escala logarítmica: $y=\log (x+1)$. Los datos transformados fueron sometidos nuevamente a la comprobación de los supuestos de normalidad y homocedasticidad. Se utilizó el programa estadístico XLSTAT.exe 2014. El nivel de significancia elegido fue $\alpha=0,05$. 


\section{Resultados}

Tiempo de desarrollo y longevidad de adultos

El tiempo de desarrollo de huevo a pupa $(U=309 ; P=0,62)$ y de huevo a adulto $(U=$ 320; $P=0,40$ ) no mostró diferencias significativas entre hembras y machos. La proporción de sexos fue 0,47, sesgada hacia los machos. Las hembras presentaron valores de longevidad menores, con respecto a los machos, observándose diferencias significativas ( $t$ $=3,47 ; P<0,001)$ (Tabla 4.1).

Tabla 4.1. Tiempo de desarrollo y longevidad (días) de Harmonia axyridis alimentada con Rhopalosiphum padi y dieta artificial. Media ( \pm ES).

\begin{tabular}{lcc}
\hline & $\mathbf{n}$ & Tiempo de desarrollo \\
\hline Huevo & 88 & $3,28( \pm 0,05)$ \\
Primer estadio larval & 74 & $1,72( \pm 0,06)$ \\
Segundo estadio larval & 53 & $1,29( \pm 0,07)$ \\
Tercer estadio larval & 51 & $2,28( \pm 0,08)$ \\
Cuarto estadio larval & 50 & $3,92( \pm 0,11)$ \\
Pupa & 48 & $4,75( \pm 0,06)$ \\
Huevo a pupa (hembras) & 23 & $12,46( \pm 0,90)$ \\
Huevo a pupa (machos) & 25 & $12,44( \pm 0,10)$ \\
Huevo a adulto hembras) & 23 & $17,21( \pm 0,51)$ \\
Huevo a adulto (machos) & 25 & $17,20( \pm 0,91)$ \\
Huevo a adulto & 48 & $17,21( \pm 0,11)$ \\
\hline & $\mathbf{n}$ & Longevidad \\
\hline Adulto & 48 & $70,72( \pm 3,07)$ \\
Hembra & 23 & $61,87( \pm 4,09)$ \\
Macho & 25 & $80,26( \pm 3,68)$ \\
\hline
\end{tabular}

\section{Supervivencia}

La curva de supervivencia específica por estado y edad (Sxj) de los estados inmaduros mostró los mayores valores de reducción de supervivencia al inicio del ciclo de vida (huevo y primer estadio larval). Los huevos presentaron un valor de supervivencia aproximado del $80 \%$ y las larvas del primer estadio un valor cercano al $60 \%$. Este 
parámetro no presentó mayores fluctuaciones en los demás estadios larvales y estado de pupa. Alrededor del $55 \%$ de los individuos alcanzaron el estado adulto (Figura $4.1 \mathrm{~A}$ ).

La emergencia adulta, de ambos sexos, ocurrió el día 16 del ciclo de vida. Las curvas Sxj de adultos presentaron un patrón similar, sin embargo las hembras de la cohorte obtuvieron valores menores para esta tasa. La supervivencia de las hembras comenzó a decrecer el día 45 , se registró un descenso abrupto el día 83 y luego continuó disminuyendo hasta alcanzar el valor de 0, el día 115. En el caso de los machos, la supervivencia comenzó a descender a partir del día 65, se registró una reducción abrupta el día 102 y luego continuó decreciendo hasta el día 125 correspondiendo con la muerte del último individuo (Figura 4.1 B).

La curva de supervivencia por edad $(I x)$ presenta una importante disminución en los primeros días del ciclo de vida, que corresponde al estado de huevo y al primer estadio larval. Luego la supervivencia se mantiene aproximadamente constante para comenzar a declinar de forma gradual a partir del día 45, que corresponde al incremento de la mortalidad en adultos de ambos sexos. Este descenso si bien es gradual muestra una disminución el día 84, para continuar hasta el día 125 que muere el último individuo de la cohorte. Esta curva presenta una forma semejante a una curva de tipo II (Deevey 1947) (Figura 4.2). 

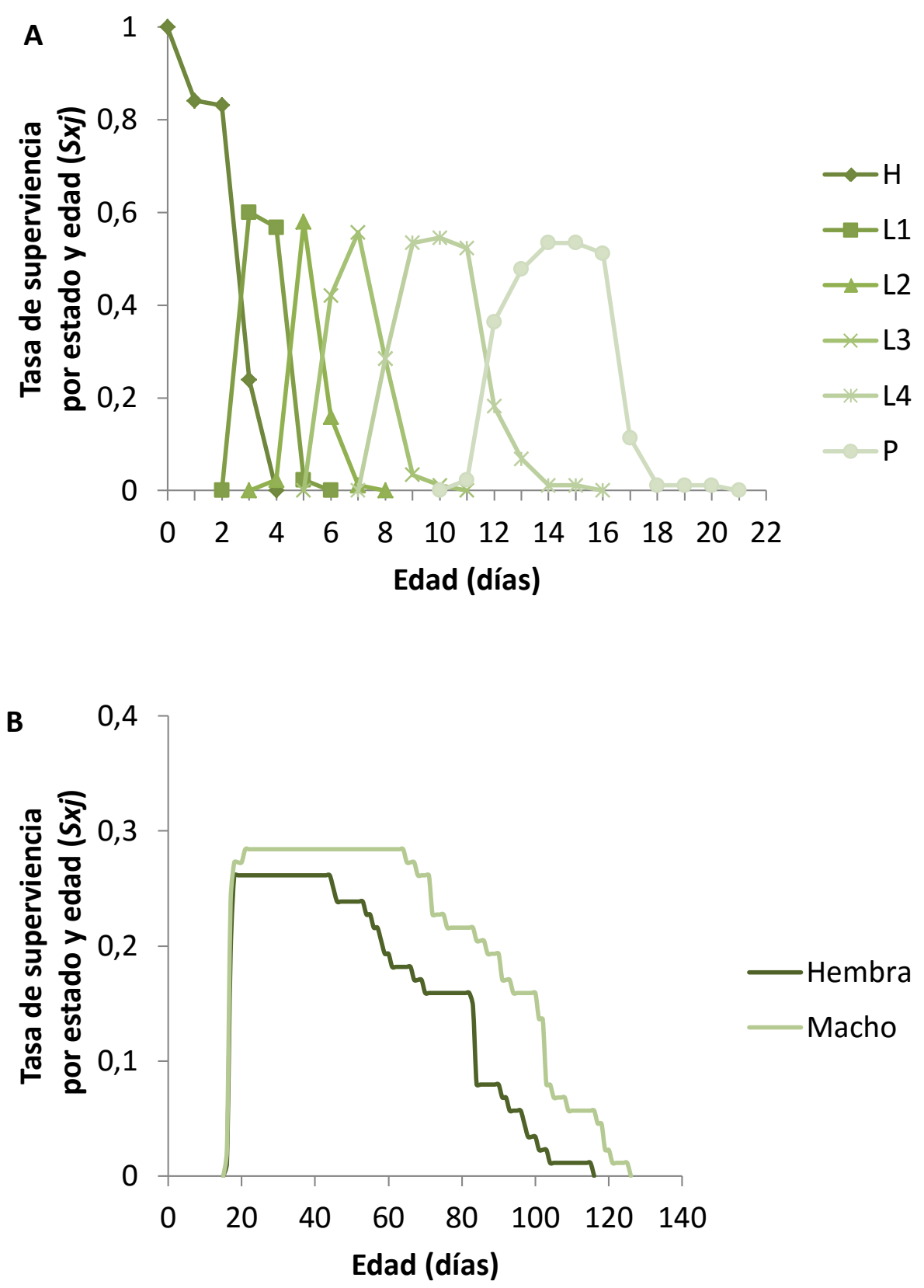

Figura 4.1. Tasa de supervivencia específica por estadio y edad (Sxj) de Harmonia axyridis alimentada con Rhopalosiphum padi y dieta artificial. H, L1, L2, L3, L4 y P = huevo, primer, segundo, tercer, cuarto estadio larval y pupa. A: estados inmaduros. B: estado adulto. 


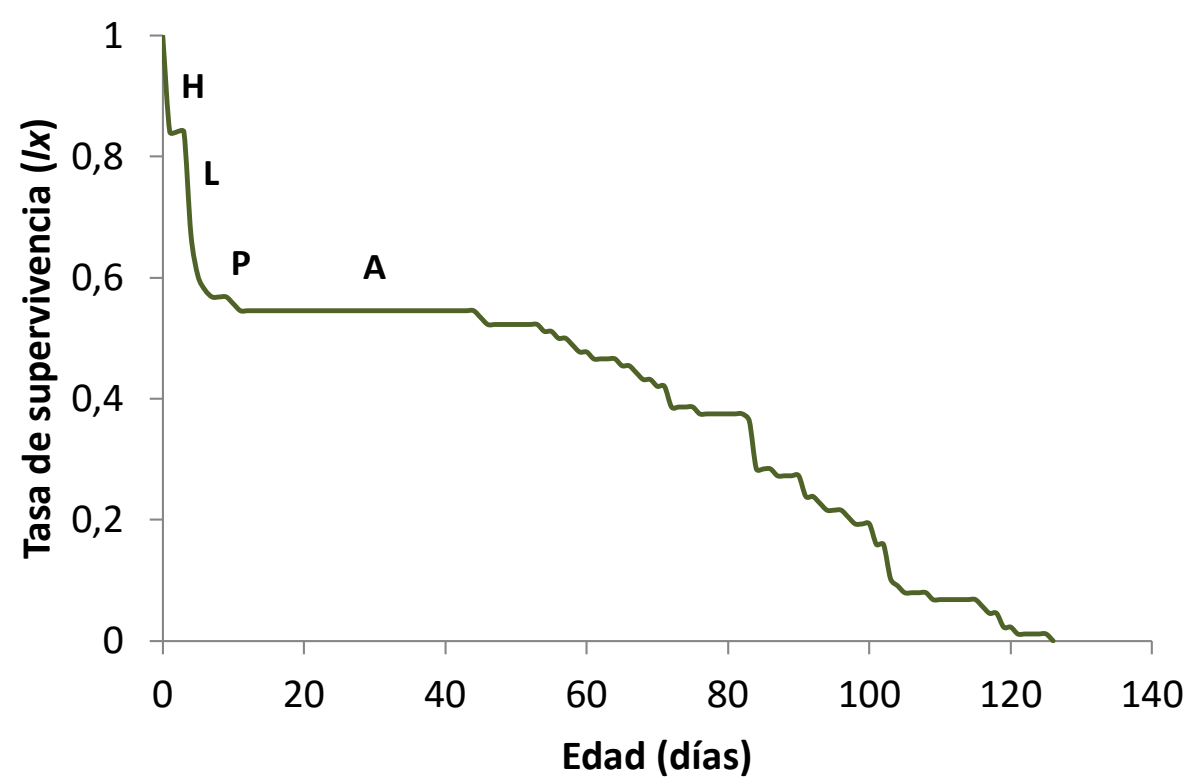

Figura 4.2. Tasa de supervivencia $(I x)$ de Harmonia axyridis alimentada con Rhopalosiphum padi y dieta artificial. H, L, P y A = huevo, larva, pupa y adulto.

\section{Expectativa de vida}

La curva de expectativa de vida por estado y edad (exj) de los estados inmaduros mostró los menores valores los primeros cuatro días del experimento, que correspondieron con el estado de huevo y larvas del primer estadio. Sin embargo, hacia el quinto día, este estadio larval alcanzó el máximo valor para este parámetro. En los demás estadios larvales y estado de pupa, la curva exj mantuvo valores relativamente constantes (Figura $4.3 \mathrm{~A})$.

Las curvas exj de adultos de ambos sexos presentan características similares. Ambas comenzaron decreciendo proporcionalmente y luego lo continuaron haciendo de manera irregular. La expectativa de vida de las hembras fue de aproximadamente un $20 \%$ menor, con respecto a la de los machos (Figura 4.3 B).

Los valores máximos de expectativa de vida (ex) fueron de 77,06 y 76,66 y se alcanzaron a los días 6 y 11, respectivamente. Esto correspondió con el segundo y cuarto estadio larval. Posteriormente, se observó un descenso durante el estado adulto hasta llegar a cero el día 126 (Figura 4.4). 

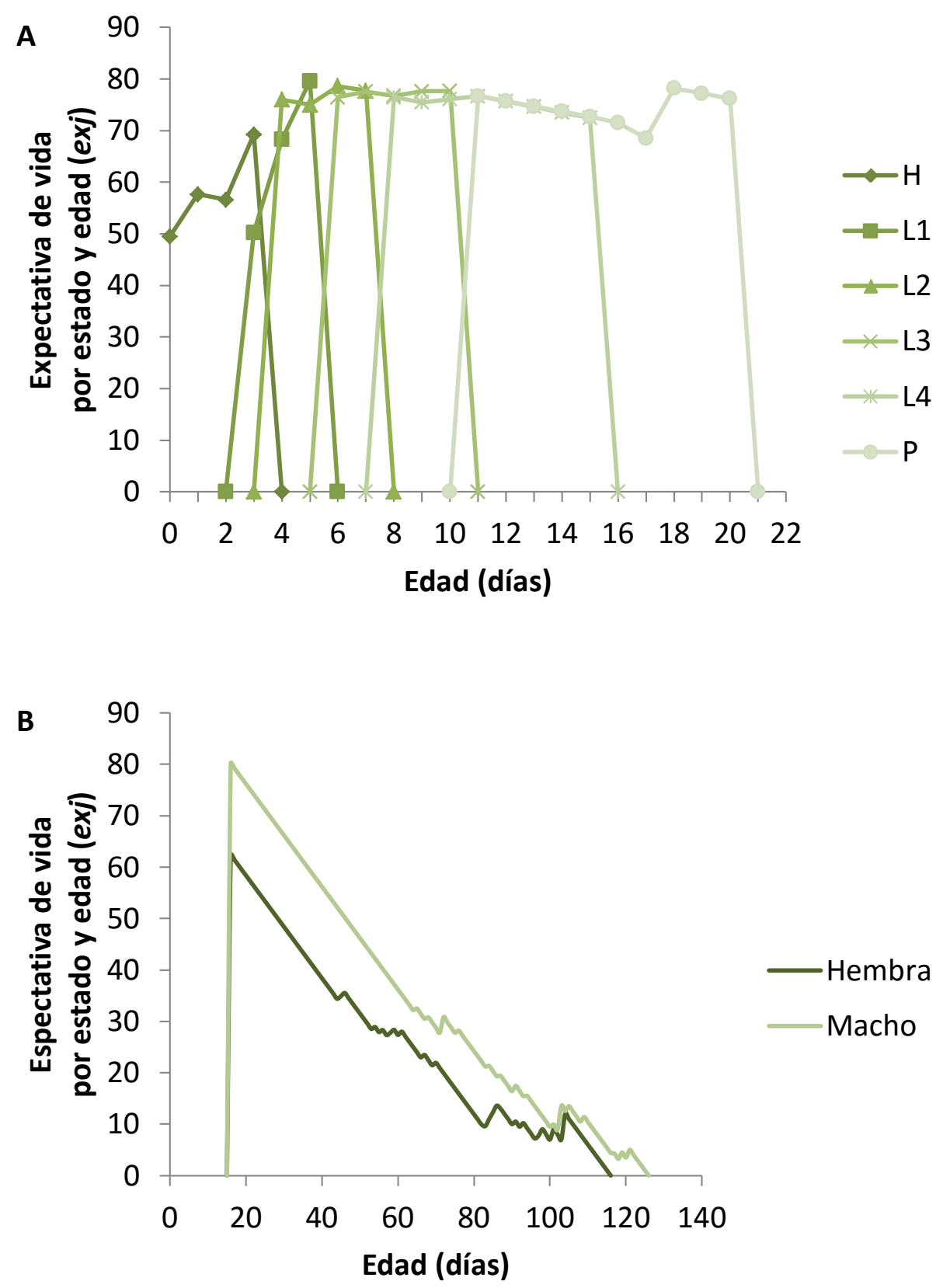

Figura 4.3. Expectativa de vida (días) $(S x j)$ de Harmonia axyridis alimentada con Rhopalosiphum padi y dieta artificial. H, L1, L2, L3, L4 y $\mathrm{P}=$ huevo, primer, segundo, tercer, cuarto estadio larval y pupa. A: estados inmaduros. B: estado adulto. 


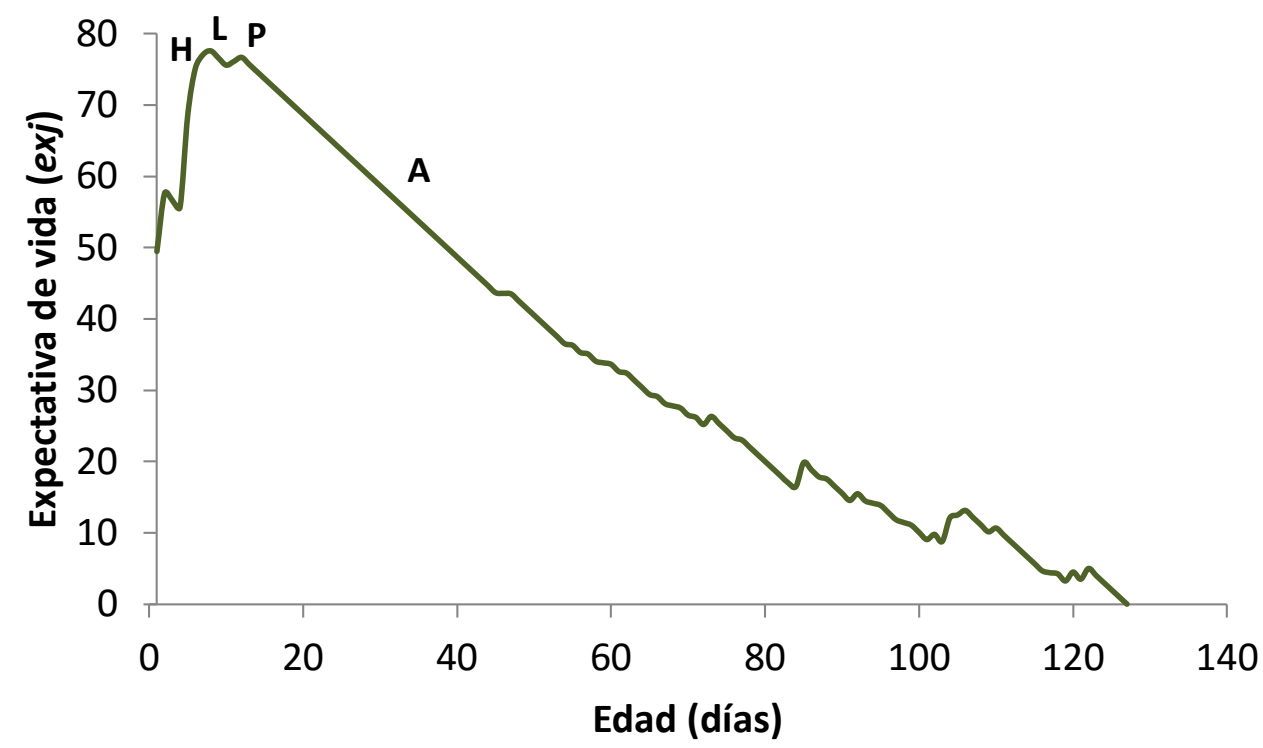

Figura 4.4. Expectativa de vida (días) (ex) de Harmonia axyridis alimentada con Rhopalosiphum padi y dieta artificial. H, L, P y A = huevo, larva, pupa y adulto.

\section{Parámetros reproductivos}

El periodo de preoviposición fue de 7,09 $( \pm 0,28)$ días. La fecundidad y fertilidad promedio por hembra fue 824,28 ( \pm 94,91) huevos y 562,087 $( \pm 70,60)$ larvas, respectivamente.

Esta curva de fecundidad específica $(f x j)$ se caracteriza por presentar numerosos picos a lo largo del todo el periodo reproductivo. Los valores máximos de oviposición se observaron entre los días 24 y 46. Desde el día 47, y hasta el día 80, se registraron valores menores y a partir del día 81 se observó una reducción abrupta de este parámetro. El día 98 se produjeron las últimas posturas de la cohorte (Figura 4.5). 


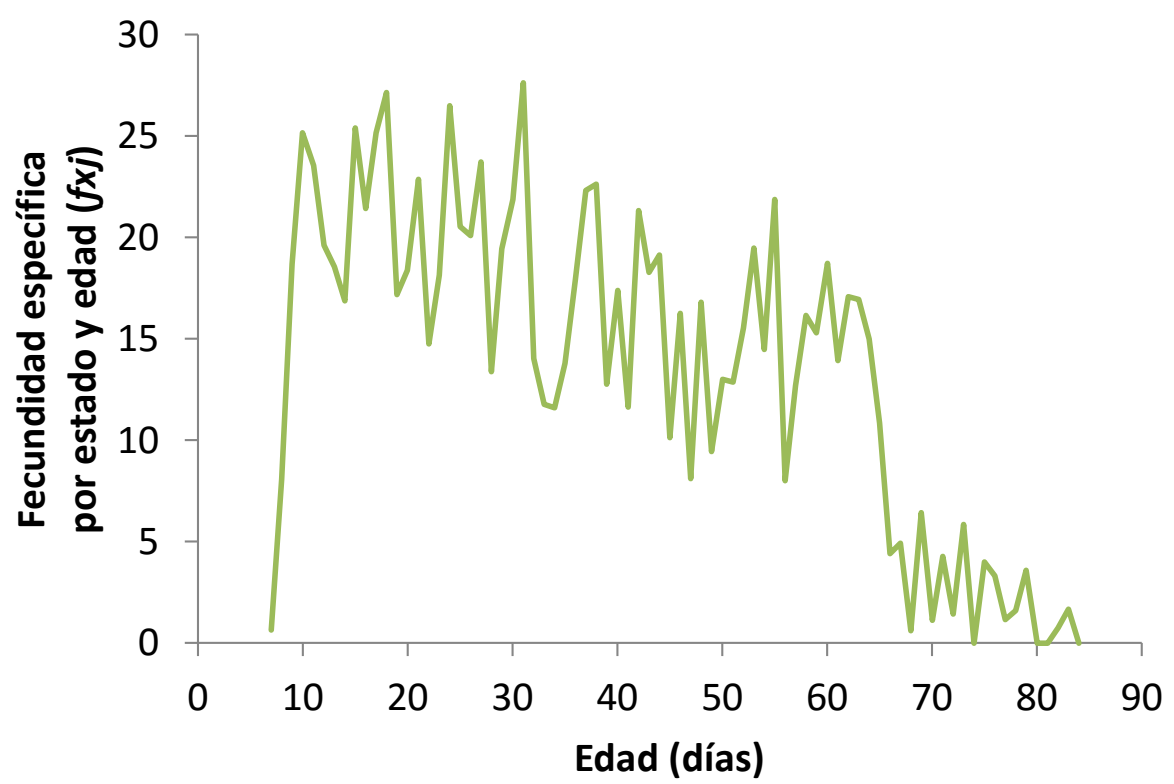

Figura 4.5. Fecundidad específica $(f x j)$ de Harmonia axyridis alimentada con Rhopalosiphum padi y dieta artificial.

Parámetros demográficos

En la Tabla 4.2 se muestran los parámetros demográficos de Harmonia axyridis.

Tabla 4.2. Parámetros demográficos de Harmonia axyridis alimentada con Rhopalosiphum padi y dieta artificial. Media ( \pm ES). $r$ (días ${ }^{-1}$ ), Ro (individuos/hembra), $\lambda$ y $T$ (días).

\begin{tabular}{lc}
\hline Tasa intrínseca de crecimiento natural $(\boldsymbol{r})$ & $0,14( \pm 0,005)$ \\
Tasa reproductiva neta $(\boldsymbol{R o})$ & $232,66( \pm 39,011)$ \\
Tasa finita de crecimiento $(\lambda)$ & $1,19( \pm 0,002)$ \\
Tiempo generacional $(\boldsymbol{T})$ & $36,41( \pm 0,662)$ \\
\hline
\end{tabular}




\section{Discusión}

En este trabajo de tesis $H$. axyridis alcanzó el estado adulto en 17 días. Abdel Salam \& Abdel Baky (2001) registraron un valor ligeramente superior cuando esta especie fue alimentada con huevos del lepidóptero Sitotroga cerealella Olivier. En otros estudios en los que H. xyridis fue alimentada con el pulgón Myzus persicae Sulzer también se registró un tiempo de desarrollo preimaginal superior al alcanzado en este trabajo (Lanzoni et al. 2004). Por otro lado, se observó un tiempo de desarrollo inferior para los coccinélidos Hippodamia variegata Goeze utilizando como presa el pulgón Aphis fabae Scop (Farhadi et al. 2011) y Lemnia biplagiata Swartz alimentada con el áfido Aphis gossypii Glover (Yu et al. 2005). Cuando Duarte \& Zenner de Polanía (2009a) evaluaron diferentes aspectos del depredador Eriopis connexa alimentada con los áfidos M. persicae y Toxoptera aurantii Boyer de Fonscolombe, bajo diferentes condiciones de temperatura, este coccinélido a $25^{\circ} \mathrm{C}$ completó la etapa inmadura de desarrollo, tardando cinco días más que $H$. axyridis en este trabajo.

Como es de esperar, la tasa de supervivencia y expectativa de vida son parámetros estrechamente relacionados. Sin embargo, el análisis de cada uno de ellos, por separado, permite conocer en mayor detalle la cohorte en estudio. El estado de huevo y primer estadio larval de $H$. axyridis presentaron los menores valores de supervivencia (Sxj). Este patrón es característico de muchas especies de insectos y otros animales (Rabinovich 1980) y se observó en los coccinélidos Harmonia dimidiata Fabricius utilizando como presa al pulgón A. gossypii (Yu et al. 2013), H. variegata (Farhadi et al. 2011) y E. connexa alimentados con los áfidos M. persicae y T. aurantii (Duarte \& Zenner de Polanía 2009b). Además, en el presente trabajo, el 54,55\% del total de los individuos iniciales alcanzaron el estado adulto. Lanzoni et al. (2014) registraron un valor ligeramente inferior para $H$. axyridis, en cambio, Abdel Salam \& Abdel Baky (2001) observaron valores cercanos al 80\% para esta especie, alimentada con huevos de un lepidóptero plaga. En otros trabajos, se registraron valores del $65,90 \%$ y $50 \%$ para $H$. variegata (Farhadi et al. 2011) y E. connexa (Duarte \& Zenner de Polanía 2009a), respectivamente. 
Los adultos de ambos sexos de $H$. axyridis presentaron un patrón de supervivencia similar. La curva comenzó con forma de meseta, que se extendió casi treinta días, y continuó con un descenso gradual, presentando algunos puntos pronunciados de caída. Además, las hembras mostraron valores menores de longevidad con respecto a los machos. Esto también se observó en $E$. connexa (Duarte \& Zenner de Polanía 2009a), $H$. dimidiata (Yu et al. 2013) y $H$. variegata (Farhadi et al. 2011). Esta tendencia en comúnmente observada en diferentes especies de coccinélidos. La menor longevidad que suelen presentar las hembras, con respecto a los machos, se relaciona con el costo energético que deben enfrentar durante el periodo reproductivo (Nedvěd \& Honěk 2012).

En el presente estudio, los individuos de $H$. axyridis durante la segunda y tercer semana de vida de los adultos, y coincidiendo con el período de mayor fecundidad, presentaron los valores máximos de supervivencia. Por el contrario Duarte \& Zenner de Polanía (2009b) registraron una reducción de la supervivencia del $25 \%$ en la primera fase del estado adulto, entre los días 20 y 33 de vida, que incluye el tiempo de preoviposición e inicio de oviposición.

En los coccinélidos los parámetros reproductivos, como la fecundidad, fertilidad y el periodo de preoviposición, están influenciados por el tamaño del cuerpo, edad, frecuencia de cópula, densidad poblacional, entre otros. Además, la cantidad y calidad de alimento son factores claves que podrían generar distintas respuestas entre diferentes poblaciones (Nedvěd \& Honěk 2012). En ensayos de laboratorio los individuos en general son alimentados ad libitum durante el ciclo completo de vida (Yu et al. 2013). En el presente trabajo, además, se les suministró a los individuos como alimento suplementario dieta artificial en base a proteínas y azúcares. En condiciones de campo, si bien la disponibilidad de presa es variada, los individuos invierten más energía en el proceso de búsqueda y, posiblemente, la cantidad de presa ingerida no sea suficiente para expresar al máximo su potencial reproductivo (Nedvěd \& Honěk 2012). A pesar de esto, es valioso realizar estudios de tabla de vida y conocer el crecimiento potencial de las plagas y sus enemigos naturales, estimar los posibles escenarios e interacciones que ocurren entre estos en los 
agroecosistemas, e inferir sobre la evolución de estas poblaciones (Yu et al. 2013; Jha et al. 2014).

El periodo de preoviposición fue menor para $H$. axyridis en este estudio $(7,09)$ con respecto a los obtenidos por Abdel Salam \& Abdel Baky $(2001)(8,01)$. Cuando se comparó el periodo de preoviposición con otros coccinélidos, se observó que S. subvillosus presentó un valor similar $(7,04)$ (Atlihan \& Chi 2008), en cambio $H$. variegata inició la fase reproductiva unos días antes (3,4) (Farhadi et al. 2011).

Harmonia axyridis mostró picos periódicos de oviposición con una tendencia descendente hacia el final del ciclo de vida. Cuando se analizaron los datos en crudo de la fecundidad diaria de cada hembra, se observaron picos de oviposición seguidos por periodos de no oviposición. Este mismo patrón se observó en L. biplagiata (Yu et al. 2005), H. dimidiata (Yu et al. 2013) y E. connexa (Duarte Gómez et al. 2013) y es común entre los coccinélidos afidófagos (Borges et al. 2013).

Cuando se comparó la fecundidad de $H$. axyridis, a lo largo de toda su fase adulta, con respecto a otras especies de coccinélidos, se observó que la fecundidad presenta el siguiente patrón: $H$. variegata $>$ L. biplagiata $>H$. axyridis $>H$. dimidiata $>E$. connexa $(\mathrm{Yu}$ et al. 2005; 2013; Duarte \& Zenner de Polanía 2009b; Farhadi et al. 2011). La mayor diferencia se observó con E. connexa; $H$. axyridis produjo una cantidad de huevos siete veces mayor.

Con respecto a los valores de fertilidad, este parámetro no fue obtenido en los trabajos mencionados anteriormente. En este trabajo de tesis, aproximadamente el $68 \%$ de los huevos de $H$. axyridis eclosionaron. Es común entre los coccinélidos la producción de huevos infértiles, debido al bajo volumen o calidad del esperma, o no viables, donde un embrión se desarrolla por un tiempo pero la larva no emerge del huevo. Los huevos que no eclosionan son considerados huevos tróficos y sirven como alimento a larvas recién emergidas. Además, en muchos huevos viables no se produce la emergencia de larvas debido al canibalismo que ocurre por parte de las larvas o adultos (Nedvěd \& Honěk 2012). 
El valor de la tasa reproductiva neta estimado para $H$. axyridis indica que, en las condiciones de este bioensayo, cada hembra durante toda su vida es capaz de producir 232 individuos. Este coccinélido criado con S. cerealella obtuvo valores mayores (Abdel Salam \& Abdel Baky 2001) y se ha registrado un valor menor de esta tasa para S. subvillosus (Atlihan \& Chi 2008). Por otro lado, Duarte \& Zenner de Polanía (2009b) registraron para E. connexa un valor de $R o=16,07$ individuos. Los autores sostienen que un valor bajo de este parámetro representaría una ventaja para E. connexa con respecto a otros coccinélidos. En condiciones de campo, las poblaciones de esta especie, al presentar un crecimiento poblacional lento, no requerirían un alto crecimiento poblacional de su presa. De esta forma, este depredador regularía la densidad de su propia población, sin extinguir su alimento. Si se compara el valor de Ro de $E$. connexa con el obtenido en este trabajo para $H$. axyridis, la diferencia es muy amplia. En condiciones de campo al cabo de una generación, 36,3 días para $H$. axyiris y 38,47 días para $E$. connexa (Duarte \& Zenner de Polanía 2009b), la población del depredador exótico estaría representada por un número mucho mayor de individuos. Por lo tanto, si la disponibilidad de presa disminuye, podría generarse un escenario de competencia favorable para la especie exótica y, además, el número e intensidad de las interacciones de depredación intragremio podría verse aumentado. Por otro lado, la falta de disponibilidad de alimento no sería una desventaja para $H$. axyridis debido a su alta dispersión y habilidad para buscar presas y alimento alternativo (Phoofolo et al. 2008).

Comparar los valores de la tasa intrínseca de crecimiento y la tasa finita de crecimiento de ambas especies permite estimar el desarrollo potencial de cada población. $H$. axydiris presentó valores de $r=0,14$ días $^{-1}$ y $\lambda=1,19$ días, mientras que para $E$. connexa Duarte Gómez \& Zenner de Polanía (2009b) encontraron valores de $r=0,07$ días $^{-1}$ y $\lambda=1,08$ días. Posiblemente, si en condiciones de campo se produjera un aumento abrupto de la densidad poblacional de la presa, el depredador exótico tendría mayor capacidad de respuesta al aumentar diferencialmente el tamaño de su población y aprovechar al máximo la presa disponible. En cambio la población de $E$. connexa sufriría un menor incremento y, por lo tanto, el desarrollo de su población estaría en desventaja. 
Como ya se ha mencionado a lo largo de esta discusión las condiciones de cría y alimentación de $H$. axyridis en este trabajo respecto a las recibidas por E. connexa por otros autores fueron diferentes. Muchos factores como ser el fotoperiodo, temperatura, humedad, tipo y cantidad de presa, variedad del cultivo, etc. pueden afectar los parámetros biológicos y demográficos (Phoofolo et al. 2008; Duarte \& Zenner de Polanía 2009a; Gugole Ottaviano et al. 2013; Silva et al. 2013). Sin embargo, los resultados obtenidos en este estudio y su comparación con estudios similares desarrollados para $E$. connexa, quien representa el coccinélido más abundante de la región Neotropical, muy comúnmente encontrado en el Cinturón Hortiflorícola Platense (CHFP) y otros agroecosistemas de la Argentina (Strassera et al. 2013; Tulli et al. 2013; Montero 2014), permiten conjeturar el impacto potencial del depredador invasivo sobre este coccinélido nativo. 


\section{Capítulo 5}

Toxicidad de los insecticidas: azadiractina, piriproxifén, acetamiprid y cipermetrina, sobre Harmonia axyridis 


\section{Introducción}

El uso de insecticidas convencionales de amplio espectro para el control de plagas es la práctica más común en la Argentina y en otros países del mundo. Sin embargo, a través de numerosos estudios abordados desde diferentes disciplinas, como ser la agroecología, entomología, ecología de poblaciones, etc., se ha demostrado el impacto negativo que estos compuestos causan sobre el ambiente, organismos no blanco y el hombre (Gliessman et al. 2007; Arias et al. 2011). En la actualidad, existe preocupación por parte de la sociedad consumidora, habitantes cercanos a las zonas productivas y trabajadores asociados a la producción, transporte y aplicación de insecticidas, acerca del uso de estos compuestos (Devine et al. 2008; Pórfido 2014).

En programas de MIP, los insecticidas biorracionales son una alternativa al uso de insecticidas convencionales para el control de plagas. Con ellos, se busca reducir los niveles poblacionales de las plagas por debajo del nivel de daño económico y ocasionando el menor impacto posible sobre organismos no blanco, el ambiente y la salud del hombre. Entre los organismos no blanco se encuentran los enemigos naturales (depredadores, parasitoides y patógenos), polinizadores (abejas y abejorros) y fauna en general (otros invertebrados y vertebrados) (Kogan \& Waheed 1999; Horowitz et al. 2009).

Como se mencionó en la introducción general de esta tesis la toxicidad de los insecticidas biorracionales azadiractina y piriproxifén sobre la fauna benéfica es variable, dependiendo de la especie ensayada, estado/estadio de desarrollo evaluado, concentración del insecticida empleada, modo de exposición, etc.

En estudios de laboratorio en lo que se evaluó la toxicidad de la azadiractina sobre el coccinélido Cycloneda sanguínea se demostró una baja toxicidad de este insecticida sobre el estado de huevo. A todas las concentraciones ensayadas (10, 50 y $100 \mathrm{mg}$. i.a/L) la reducción en la supervivencia fue aproximadamente del $20 \%$, respecto al control. Además, no se observaron diferencias significativas en la emergencia de adultos, probablemente esto se debe a la metabolización y / o excreción del ingrediente activo durante el desarrollo preimaginal. Cuando larvas del primer y cuarto estadio fueron expuestas a este 
insecticida, la supervivencia se redujo significativamente cuando se emplearon las dos máximas concentraciones (Cosme et al. 2007). Kraiss \& Cullen (2008) obtuvieron resultados similares de toxicidad de este insecticida botánico sobre larvas del primer y tercer estadio de H. axyridis, resultando los efectos sobre el primer estado de desarrollo más notorios. Sin embargo, no se observaron efectos subletales sobre los parámetros reproductivos de los individuos expuestos durante la etapa inmadura.

Con respecto a piriproxifén, se ha demostrado que este IGR es tóxico para ciertas especies de coccinélidos. Este insecticida ocasionó una alta mortalidad de huevos de Serangium japonicum Chapin, observándose un 3,3\% y $17.3 \%$ de supervivencia cuando los mismos fueron expuestos a concentraciones de 100 y 200 mg i.a./L. Además, a ambas concentraciones piriproxifén afectó la supervivencia de larvas del cuarto estadio y la fecundidad de adultos (Li et al. 2015). Fogel (2012) demostró una baja toxicidad de este insecticida sobre huevos de Eriopis connexa, sin embargo, piriproxifén afectó la supervivencia de larvas y pupas del coccinélidos, ocasionando efectos subletales. Se observaron malformaciones en los adultos expuestos en durante el estado de pupa y, además, se registró una disminución de la fecundidad y fertilidad de los individuos expuestos durante la fase preimaginal. En otros estudios se corrobora también la reducción ocasionada por piriproxifén sobre los parámetros reproductivos del coccinélido Rodolia cardinalis (Grafton Cardwell \& Gu 2003). Por otro lado, cuando adultos el coccinélido Delphastus catalinae Horn fueron alimentados con huevos de Bemisia tabaci Gennadius (Hemiptera: Aleyrodidae) previamente contaminados con piriproxifén, no se registró una disminución en la supervivencia y tampoco se observaron efectos en el periodo de preoviposición y en la producción de huevos viables (Liu \& Stansly 2004). Otros trabajos demuestran la inocuidad de este insecticida sobre adultos de $H$. axyridis (Koch 2003), Cryptolaemus montrouzieri Mulsant (Cloyd \& Dockinson 2006) y Coccinella septempunctata (Bozsik 2006).

La categorización de los neonicoitnoides como insecticidas biorracionales está siendo reconsiderada debido a la toxicidad que ejercen estos compuestos sobre enemigos 
naturales, polinizadores y vertebrados (Nauen \& Denholm 2005; Horowitz et al. 2009). Youn et al. 2003 evaluaron en laboratorio la toxicidad del acetamiprid sobre huevos, larvas, pupa y adultos de $H$. axyridis. Este insecticida afectó drásticamente la supervivencia de todos los estados de desarrollo evaluados. Otros estudios demuestran la alta toxicidad que ocasiona este insecticida sobre diferentes especies de coccinélidos, entre las que se encuentran E. connexa (Fogel et al. 2013) Cheilomenes sp (Awasthi et al. 2013) y Cryptolaemus montrouzieri Mulsant (Cloyd \& Dockinson 2006).

Los insecticidas convencionales de amplio espectro resultan más tóxicos a organismos benéficos con respecto a los insecticidas biorracionales (Rimoldi et al. 2012). El insecticida cipermetrina interfiere en el sistema nervioso central de un amplio rango de coccinélidos entre los que se encuentran, H. axyridis (Michaud \& Grant 2003), E. connexa (Fogel 2012), Hippodamia convergens Guerin-Meneville (Kaakeh 1996) y Coccinella undecimpunctata L. (Ahmad et al. 2011).

El objetivo asociado a este capítulo fue:

- Determinar la susceptibilidad de H. axyridis a los insecticidas biorracionales, azadiractina, piriproxifen y acetamiprid, y al insecticida convencional, cipermetrina.

La hipótesis propuesta fue:

- Harmonia axyridis muestra menor susceptibilidad a los insecticidas biorracionales, azadiractina, piriproxifén y acetamiprid con respecto al insecticida convencional, cipermetrina.

\section{Materiales y métodos}

Bioensayos de toxicidad

Los compuestos evaluados en los diferentes bioensayos se detallan en la Tabla 5.1, así como el nombre comercial, pureza, máxima concentración recomendada a campo (MCRC) en la Argentina y empresa fabricante (CASAFE 2013-2015). Para todos los estados 
del depredador fueron evaluadas el $100 \%$ de la MCRC y diluciones del $50 \%, 25 \%$ y $12,5 \%$, detalladas en la Tabla 5.2. El estudio de diferentes diluciones intentó representar concentraciones menores a las que los individuos están expuestos en condiciones de campo, producto de la degradación de los insecticidas luego de su aplicación (Desneux et al. 2005; Zhang et al. 2011).

Tabla 5.1. Insecticidas empleados en los estudios de toxicidad sobre Harmonia axyridis. $\mathrm{p} / \mathrm{v}=\%$ peso del i.a/volumen total del insecticida; $\mathrm{p} / \mathrm{p}=\%$ peso del i.a /peso total del insecticida; i.a = ingrediente activo.

\begin{tabular}{ccccc}
\hline $\begin{array}{c}\text { Ingrediente } \\
\text { activo }\end{array}$ & $\begin{array}{c}\text { Nombre } \\
\text { comercial }\end{array}$ & Pureza & MCRC (mg i.a/L) & $\begin{array}{c}\text { Empresa } \\
\text { fabricante }\end{array}$ \\
\hline Azadiractina & Neem-Azal $^{\circ}$ & $1,2 \% \mathrm{p} / \mathrm{v}$ & 48 & Agristar S.A \\
Piriproxifen & Epingle $^{\oplus}$ & $10 \% \mathrm{p} / \mathrm{v}$ & 75 & Summit-Agro S.A \\
Acetamiprid & Mospilan & $20 \% \mathrm{p} / \mathrm{p}$ & 200 & Summit-Agro S.A \\
Cipermetrina & Glextrin & $25 \% \mathrm{p} / \mathrm{v}$ & 25 & Gleba S.A \\
\hline
\end{tabular}

Tabla 5.2. MCRC y diluciones del $50 \%, 25 \%$ y $12,5 \%$ de los insecticidas empleados en los estudios de toxicidad sobre Harmonia axyridis. Concentración (ppm = mg i.a./L).

\begin{tabular}{lcccc}
\hline & \multicolumn{4}{c}{ mg i.a./L } \\
& $\mathbf{1 0 0 \%}$ & $\mathbf{5 0 \%}$ & $\mathbf{2 5 \%}$ & $\mathbf{1 2 , 5 0 \%}$ \\
& MCRC & MCRC & MCRC & MCRC \\
\hline Azadiractina & 48 & 24 & 12 & 6 \\
Piriproxifén & 75 & 37,5 & 18,75 & 9,37 \\
Acetamiprid & 200 & 100 & 50 & 25 \\
Cipermetrina & 25 & 12,5 & 6,25 & 3,12 \\
\hline
\end{tabular}

Se prepararon al inicio de cada experimento soluciones con agua destilada o acetona de grado analítico 80\% (Youn et al. 2003), según la vía de contaminación elegida. En el caso de aquellos experimentos en los que se utilizó acetona, los controles se realizaron con este compuesto. A través de la realización de bioensayos preliminares se ha demostrado que la acetona no afecta a H. axyridis.

Los bioensayos fueron realizados bajo condiciones controladas de temperatura ( $25 \pm$ $\left.5^{\circ} \mathrm{C}\right)$, humedad $(75 \pm 5 \% \mathrm{HR})$ y fotoperiodo $(16: 8 \mathrm{~h}, \mathrm{~L}: \mathrm{O})$. 
Bioensayos de toxicidad de los insecticidas sobre el estado de huevo

Los plastones de huevos, conteniendo entre 27 y 33 ejemplares, de $<24$ h de edad, fueron obtenidos de la colonia de coccinélidos para bioensayos. La vía de exposición elegida fue la de inmersión (Schneider et al. 2009) (Figura 5.1 B). La misma consistió en sumergir los plastones, durante 10 segundos, en una solución del compuesto y agua destilada. Se realizaron 3 réplicas por cada tratamiento, representada cada una de ellas por un plastón de huevos. Los controles se llevaron a cabo utilizando agua destilada. Una vez sumergidos los huevos, se los colocó en cápsulas de Petri de $6 \mathrm{~cm}$ de diámetro y 1,5 $\mathrm{cm}$ de alto, se los dejó bajo campana para su secado y luego se los dispuso en el bioterio.

Se registró la emergencia de larvas durante 6 días consecutivos, controlando a los huevos bajo lupa binocular. Con estos datos se calculó el porcentaje de emergencia de larvas, de la siguiente manera:

Emergencia de larvas $(\%)=\left(\mathrm{N}^{\circ}\right.$ de larvas emergidas $/ \mathrm{N}^{\circ}$ inicial huevos tratados $) \times 100$

De aquellas larvas emergidas, se seleccionaron al azar 30 por tratamiento. Las mismas se dispusieron en cajas de Petri de $6 \mathrm{~cm}$ de diámetro y $1,5 \mathrm{~cm}$ de alto y se le suministró como alimento Rhopalosiphum padi ad libitum y dieta artificial. Se controló a los individuos diariamente y se registró la supervivencia de cada estadio larval y estado de pupa.

Los adultos fueron sexados, siguiendo la metodología descripta por Mc Cornack et al. (2007). Se formaron 5 parejas por tratamiento, seleccionando al azar hembras y machos, y las mismas se colocaron en recipientes cilíndricos de plástico, de $6 \mathrm{~cm}$ de diámetro y $10 \mathrm{~cm}$ de alto, ventilados con tela de "voile". En cada arena, se colocaron trozos de papel como sustrato de oviposición, bebederos con agua, pulgón ad libitum y dieta artificial. Los individuos fueron observaron diariamente para registrar la supervivencia de los adultos, suministrarles el alimento y retirar los huevos. Los mismos fueron observados bajo lupa binocular durante 6 días para registrar la emergencia de larvas. Cuando la emergencia de adultos fue mayor al 50\%, se evaluó la fecundidad (no de 
huevos/hembra) y fertilidad (no de larvas emergidas/hembra) acumulada de las primeras 5 posturas.

Bioensayos de toxicidad sobre larvas del segundo y cuarto estadio larval y estado pupa

Individuos del segundo y cuarto estadio larval y estado de pupa, de $<24$ h de edad, fueron obtenidos de la colonia de coccinélidos para bioensayos. La vía de exposición elegida fue tópica y consistió en aplicar una gota de la solución de insecticida, de un volumen determinado, sobre la región dorsal de cada individuo (Schneider et al. 2004). Para dicho fin, se utilizó un microaplicador manual de precisión (Burkard ${ }^{\circledR}$, UK) (Figura 5.1 A, C y D). El tamaño de gota seleccionado fue de $0,5 \mu \mathrm{l}$ para el segundo estadio larval y de $1 \mu \mathrm{l}$ para el cuarto estadio larval y estado de pupa. Se utilizó como solvente acetona de grado analítico $80 \%$, la cual por sus características físico químicas, al evaporarse rápidamente facilita la deposición del insecticida sobre la cutícula del insecto. Se realizaron 30 réplicas por cada tratamiento, cada una de ellas representada por un individuo. Los controles se llevaron a cabo utilizando acetona $80 \%$.

Una vez tratados los individuos, los mismos fueron colocados individualmente en cajas de Petri de $6 \mathrm{~cm}$ de diámetro y 1,5 cm de alto. A las larvas se le suministró como alimento R. padi ad libitum y dieta artificial. Se observó a los individuos diariamente y se registró la supervivencia de cada estadio larval y estado de pupa. El porcentaje de eclosión de adultos se calculó de la siguiente manera:

Eclosión de adultos $(\%)=\left(\mathrm{N}^{\circ}\right.$ de adultos emergidos $/ \mathrm{N}^{\circ}$ de pupas tratadas $) \times 100$

Cuando la emergencia de adultos fue mayor al 50\%, se evaluó la fecundidad y fertilidad acumulada de las primeras 5 posturas, tal como se describió anteriormente para los bioensayos sobre el estado de huevo. 


\section{Análisis estadístico}

Los resultados de los diferentes bioensayos fueron comparados y analizados utilizando diferentes métodos estadísticos. Para todos los casos se utilizó el programa estadístico XLSTAT.exe 2014. El nivel de significancia elegido fue $\alpha=0,05$.

La emergencia de larvas y adultos y los parámetros de fecundidad y fertilidad fueron analizados en cada concentración por separado, es decir, se realizaron estadísticos para el 100\%, 50\%, 25\% y $12,5 \%$ de la MCRC. Para esto se utilizó el test paramétrico de Análisis de la Varianza (ANOVA), siempre y cuando se cumplieran con los supuestos de normalidad y homocedasticidad. Para comprobar los supuestos de normalidad y homocedasticidad, los datos fueron sometidos al test de Shapiro Wilk y de Levene, respectivamente. Cuando algunos de los supuestos de ANOVA no se alcanzó, los datos de conteo fueron transformados a $y=\log (x+1)$, y para el caso de datos expresados en proporciones se utilizó la transformación angular: $y=\sqrt{ }$ arcoseno $x$. Nuevamente, se comprobaron los supuestos de normalidad y homocedasticidad y en el caso que los mismos siguieron sin cumplirse se utilizó el test no paramétrico Kruskal Wallis. Para los datos analizados con ANOVA se realizó la separación de medias a través del test LSD de Fisher, para aquellos sometidos al test Kruskal Wallis se realizó la prueba bilateral de Dunn (Zar 2010).

Para el análisis de la supervivencia de las larvas emergidas, de los huevos tratados, y larvas del segundo y cuarto estadio se utilizó el estimador Kaplan Meier. Las curvas de proporción de individuos sobrevivientes, desde el primer día del experimeto hasta que los mismos alcanzaron el estado adulto, fueron comparadas a través del test Log Rank, con el análisis $\chi^{2}$. Aquellos individuos que alcanzaron el estado adulto fueron tratados como datos censurados. La elección de este método estadístico se realizó siguiendo la metodología de Tomé et al. (2013). 

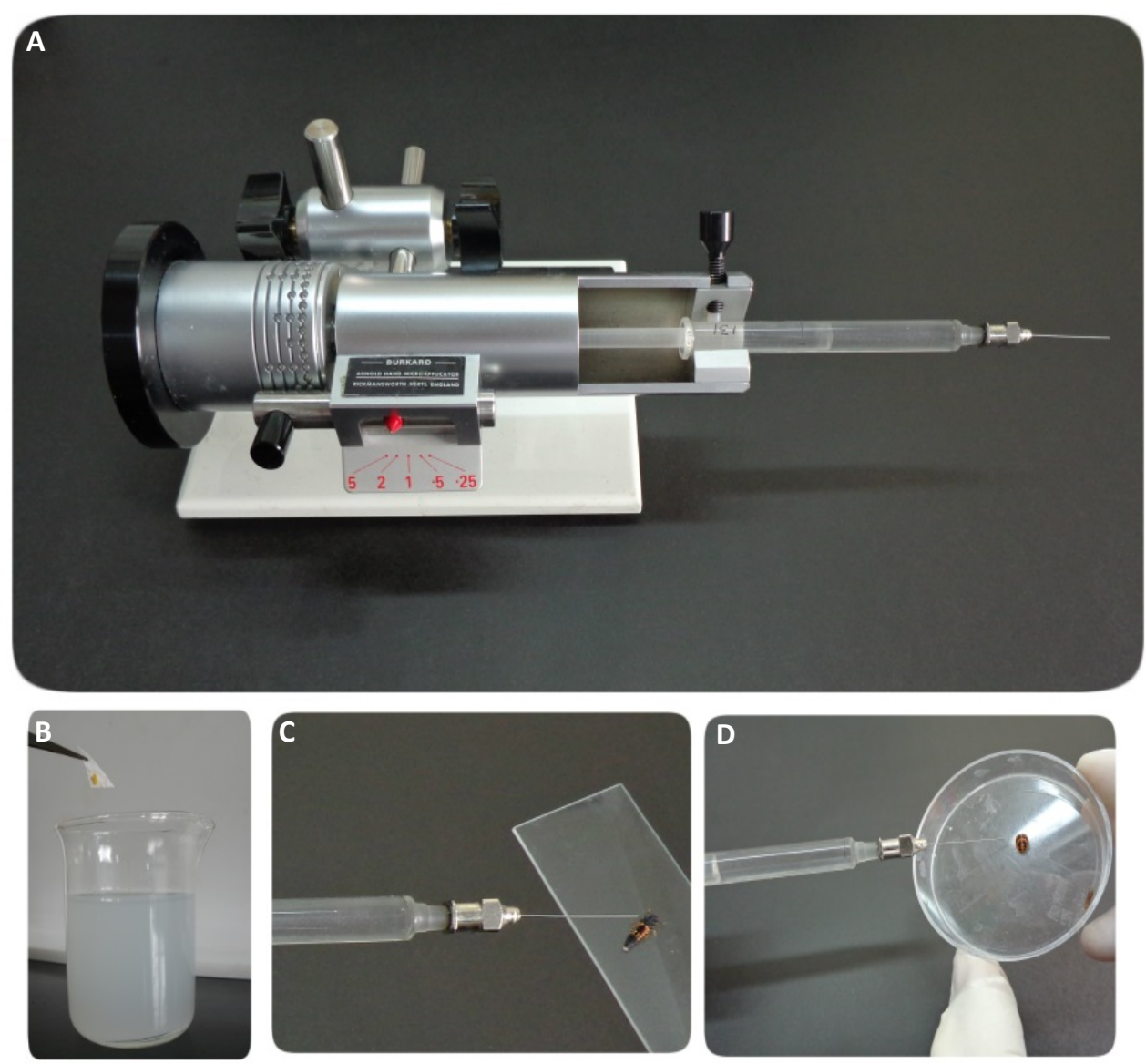

Figura 5.1. Exposición de Harmonia axyridis a insecticidas. A: Microaplicador manual de precisión, Burkard ${ }^{\circledR}$. B: Exposición por inmersión de huevos. C: Exposición tópica de larva del cuarto estadio. D: Exposición tópica de pupa.

\section{Resultados}

Bioensayos de toxicidad sobre el estado de huevo

\section{Emergencia de larvas expuestas en el estado de huevo}

En el tratamiento control, la emergencia de larvas registrada fue de $96,29( \pm 3,71) \%$. Se observaron diferencias significativas a todas las concentraciones evaluadas: $\mathrm{MCRC}(H=$ $13,42 ;$ g.l. $=4 ; P=0,009) ; 50 \% \operatorname{MCRC}(H=13,01 ;$ g.I. $=4 ; P<0,001) ; 25 \% \operatorname{MCRC}(H=13,06$; g.l. $=4 ; P<0,001) ; 12,5 \% \operatorname{MCRC}(F=10,98 ;$ g.l. $=4,10 ; P<0,001)$ (Figura 5.2). 
En los tratamientos realizados con azadiractina, la emergencia de larvas registrada varió entre el $54,21( \pm 13,44) \%$ y $43,33( \pm 15,75) \%$. Con acetamiprid estos valores variaron entre el $29,44( \pm 2,54) \%$ y $52,70( \pm 15,97) \%$. Los insecticidas piriproxifén y cipermetrina resultaron ser muy tóxicos. Al 12,5\% de la MCRC se registró un porcentaje de emergencia de larvas del $4,70( \pm 3,09) \%$ y 14,28 ( \pm 8,24)\% para piriproxifén y cipermetrina, respectivamente. A las demás concentraciones ensayadas, ambos insecticidas causaron un $100 \%$ de mortalidad de huevo.

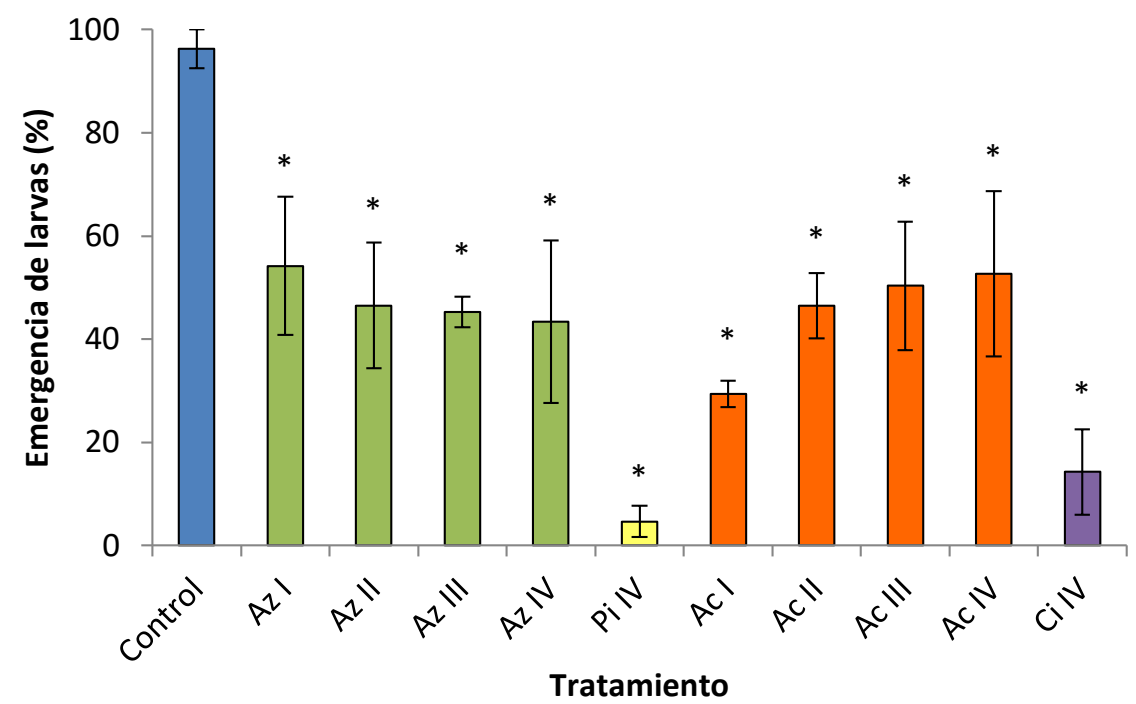

Figura 5.2. Emergencia de larvas de Harmonia axyridis expuestas en el estado de huevo a diferentes insecticidas. Las barras muestran media ( $\pm \mathrm{ES}) . *$ indica diferencias significativas con respecto al control. $(P<0,05)$. Az I, II, III y IV = azadiractina 48, 24, 12 y 6 mg i.a./L. Pi IV = piriproxifén 9,38 mg i.a./L. Ac I, II, III, IV = acetamiprid 200, 100,50 y $25 \mathrm{mg}$ i.a./L. Ci IV = cipermetrina $3,12 \mathrm{mg}$ i.a./L.

Supervivencia de larvas-pupas expuestas en el estado de huevo

Los tratamientos realizados con piriproxifén, acetamiprid y cipermetrina, si bien presentaron emergencia de larvas, el $100 \%$ de las mismas murieron durante las primeras 24 horas de eclosionados los huevos. Por este motivo, estos insecticidas no fueron incluidos en este análisis. 
El $70 \%$ de los individuos del tratamiento control alcanzaron el estado adulto. En los tratamientos con azadiractina la supervivencia de larvas registrada varió entre el $60 \%$ y 80\%. Ninguno de estos tratamientos mostraron diferencias significativas entre sí (Log Rank, $\chi^{2}=2,92 ;$ g.l. $=4 ; P=0,57$ ) (Figura 5.3).

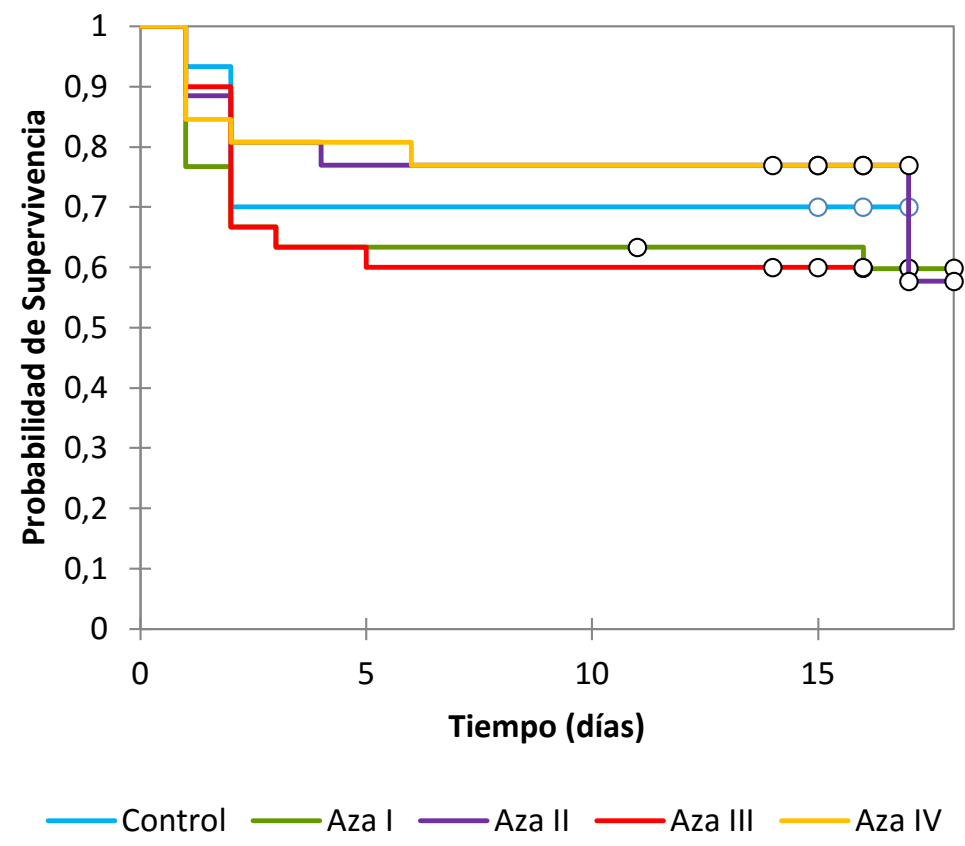

Figura 5.3. Toxicidad de azadiractina sobre la supervivencia de larvaspupas de Harmonia axyridis expuestas en el estado de huevo. Kaplan Meier, $\chi^{2}$. Test Log Rank $(P<0,05)$. Az I, II, III y IV = azadiractina 48, 24, 12 y $6 \mathrm{mg}$ i.a./L, respectivamente.

Fecundidad y fertilidad de hembras expuestas en el estado de huevo

En el tratamiento control se registró una fecundidad de 137,40 ( $\pm 16,54)$ huevos. La azadiractina no causó ningún efecto significativo en la fecundidad de los individuos expuestos en el estado de huevo $(F=0,67 ;$ g.l. $=4,20 ; P=0,62)$ (Figura 5.4).

La fertilidad del tratamiento control fue de $110,61( \pm 12,47)$ larvas. En este caso la azadiractina causó una reducción de este parámetro cuando se ensayaron las dos concentraciones mayores $(F=5,15 ;$ g.l. $=4,20 ; P<0,001)$ (Figura 5.4). 


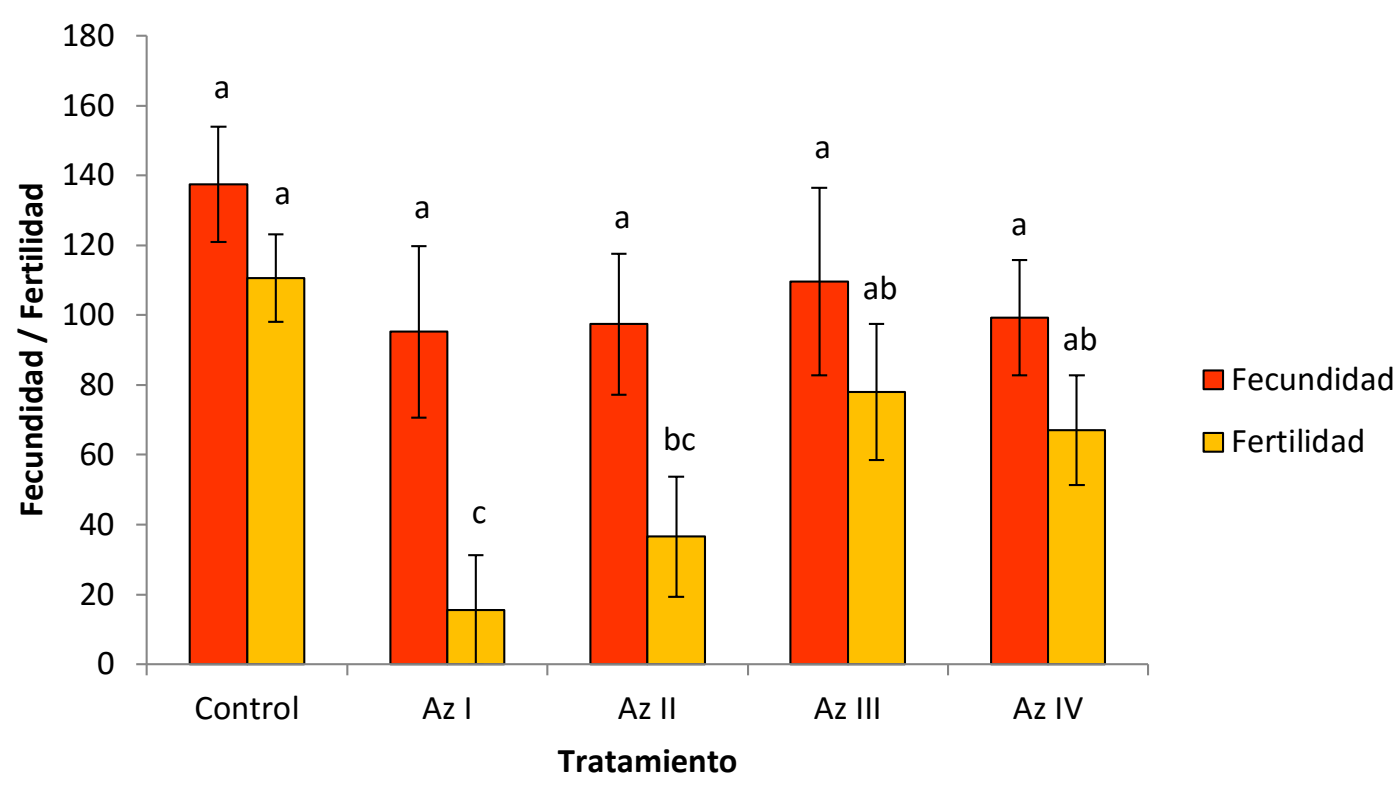

Figura 5.4. Toxicidad de azadiractina sobre la fecundidad y fertilidad acumulada de las primeras cinco posturas de individuos de Harmonia axyridis, expuestos en el estado de huevo. Las barras muestran media ( \pm ES). Para cada parámetro biológico diferentes letras indican diferencias significativas entre tratamientos $(P<0,05)$. Az I, II, III y IV = azadiractina $48,24,12$ y $6 \mathrm{mg}$ i.a./L, respectivamente.

Bioensayos de toxicidad sobre el segundo estadio larval

\section{Supervivencia de larvas-pupas expuestas en el segundo estadio larval}

El porcentaje de individuos que alcanzaron estado adulto en el tratamiento control fue del 96,70\%. La azadiractina a la MCRC ocasionó una reducción significativa de la supervivencia respecto del control y solo el $33,33 \%$ de los individuos completaron el desarrollo inmaduro (Tabla 5.5 A y Figura 5.5 A). Al 50\% de MCRC, el valor para este parámetro fue del $80 \%$, lo que resultó ser marginalmente significativo (Tabla 5.5 B y Figura 5.5 B). Por último, el $86,70 \%$ de los individuos se desarrollaron a adultos en los tratamientos con diluciones del $12,5 \%$ y $25 \%$ de la MCRC (Tabla 5.5 C y D, Figura 5.5 C y D).

En los tratamientos realizados con piriproxifén se observaron reducciones en la supervivencia a todas las concentraciones ensayadas (Tabla 5.5 A-D). A la MCRC y al 50\%, el 60\% de los individuos alcanzaron el estado adulto (Figura 5.5 A, B). En los tratamientos 
con diluciones del $25 \%$ y $12,5 \%$ de la MCRC, la supervivencia registrada fue de $56,70 \%$ y $63,30 \%$, respectivamente (Figura $5.5 \mathrm{D}$ y $\mathrm{C}$ ).

El insecticida acetamiprid ocasionó un $100 \%$ de mortalidad de larvas, a todas las concentraciones ensayadas (Tabla 5.5 A-D, Figura 5.5 A-D). Con cipermetrina, se registró un $100 \%$ de mortalidad para la MCRC y la dilución del $50 \%$ de la MCRC (Tabla 5.5 A y B, Figura 5.5 A y B). Al 25\% y 12,5\% de la MCRC, solo el $10 \%$ y 6,70\% de los individuos alcanzaron el estado adulto, respectivamente (Tabla 5.5 C y D, Figura 5.5 C y D).

Tabla 5.5. Toxicidad de los insecticidas sobre la supervivencia de larvas-pupas de Harmonia axyridis expuestas en el segundo estadio larval. Kaplan Meier, $\chi^{2}$. Test Log Rank $(P<0,05)$. A: $100 \%$ MCRC. B: $50 \%$ MCRC. C: $25 \%$ MCRC. D: $12,5 \%$ MCRC.

A

\begin{tabular}{lccr}
\hline & $\chi^{2}$ & g.l. & $\boldsymbol{P}$ \\
\hline Comparación global & 99,74 & 4 & $<0,001$ \\
Control - Azadiractina & 22,32 & 1 & $<0,001$ \\
Control - Piriproxifen & 11,85 & 1 & $<0,001$ \\
Control - Acetamiprid & 55,19 & 1 & $<0,001$ \\
Control - Cipermetrina & 55,19 & 1 & $<0,001$ \\
\hline
\end{tabular}

C

\begin{tabular}{lccc}
\hline & $\boldsymbol{\chi}^{2}$ & g.l. & $\boldsymbol{P}$ \\
\hline Comparación global & 103,79 & 4 & $<0,001$ \\
Control - Azadiractina & 1,89 & 1 & 0,16 \\
Control - Piriproxifen & 13,39 & 1 & $<0,001$ \\
Control - Acetamiprid & 55,19 & 1 & $<0,001$ \\
Control - Cipermetrina & 46,1 & 1 & $<0,001$ \\
\hline
\end{tabular}

B

\begin{tabular}{lccc}
\hline & $\boldsymbol{\chi}^{2}$ & g.l. & $\boldsymbol{P}$ \\
\hline Comparación global & 123,00 & 4 & $<0,001$ \\
Control - Azadiractina & 3,95 & 1 & 0,04 \\
Control - Piriproxifen & 11,51 & 1 & $<0,001$ \\
Control - Acetamiprid & 55,19 & 1 & $<0,001$ \\
Control - Cipermetrina & 55,19 & 1 & $<0,001$ \\
\hline
\end{tabular}

D

\begin{tabular}{lccc}
\hline & $\boldsymbol{\chi}^{2}$ & g.l. & $\boldsymbol{P}$ \\
\hline Comparación global & 103,18 & 4 & $<0,001$ \\
Control - Azadiractina & 1,92 & 1 & 0,16 \\
Control - Piriproxifen & 10,24 & 1 & $<0,001$ \\
Control - Acetamiprid & 55,19 & 1 & $<0,001$ \\
Control - Cipermetrina & 52,4 & 1 & $<0,001$ \\
\hline
\end{tabular}


A

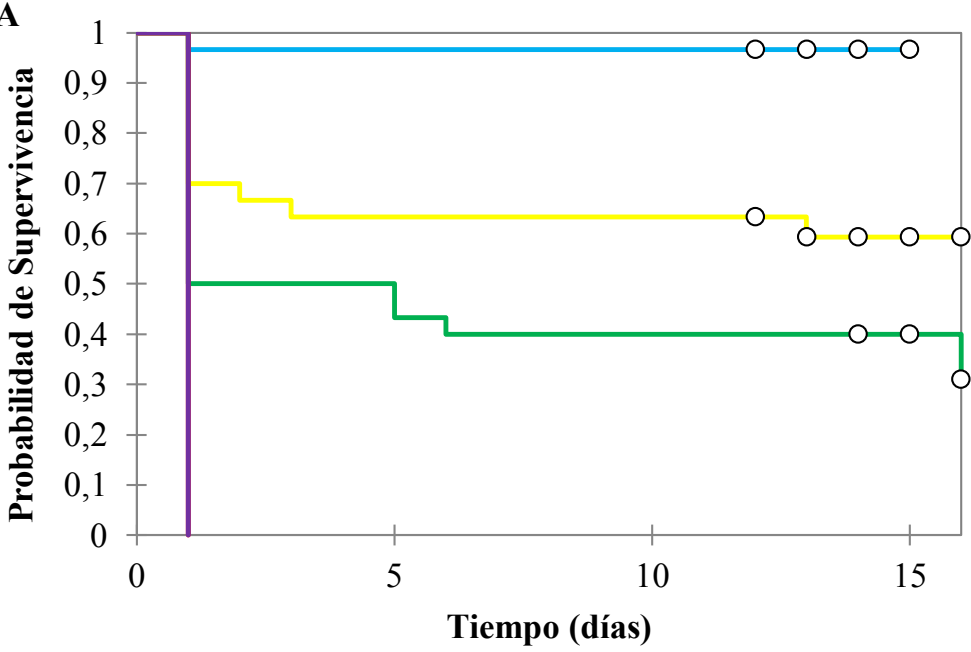

$\longrightarrow$ Control $\longrightarrow$ Az I $\longrightarrow$ Pi I $\longrightarrow$ Ac I $\longrightarrow$ Ci I

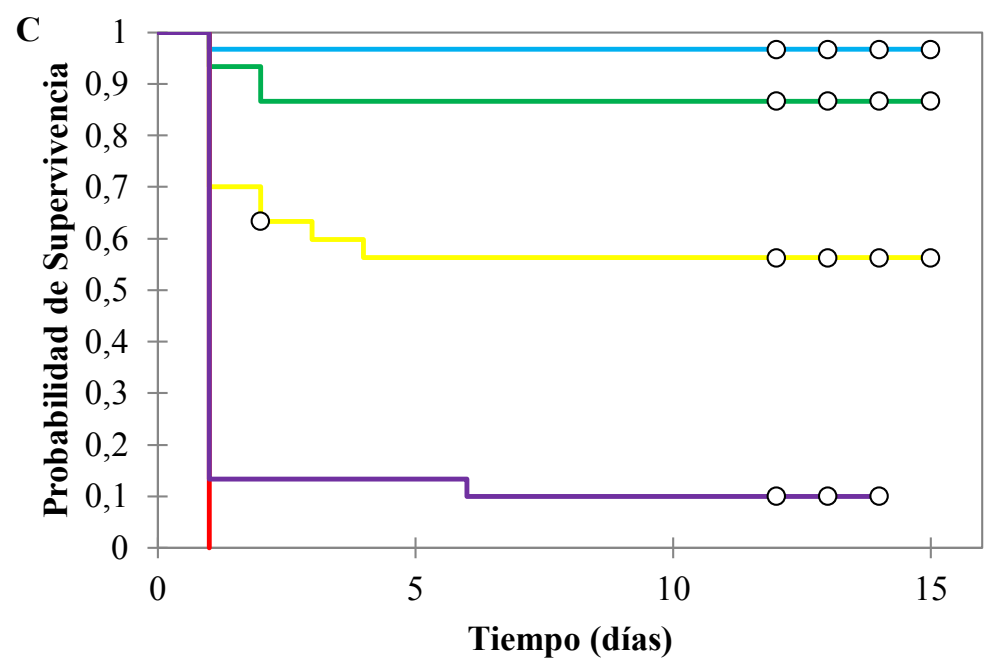

$\longrightarrow$ Control $\longrightarrow$ Az III $\longrightarrow$ Pi III $\longrightarrow$ Ac III $\longrightarrow$ Ci III
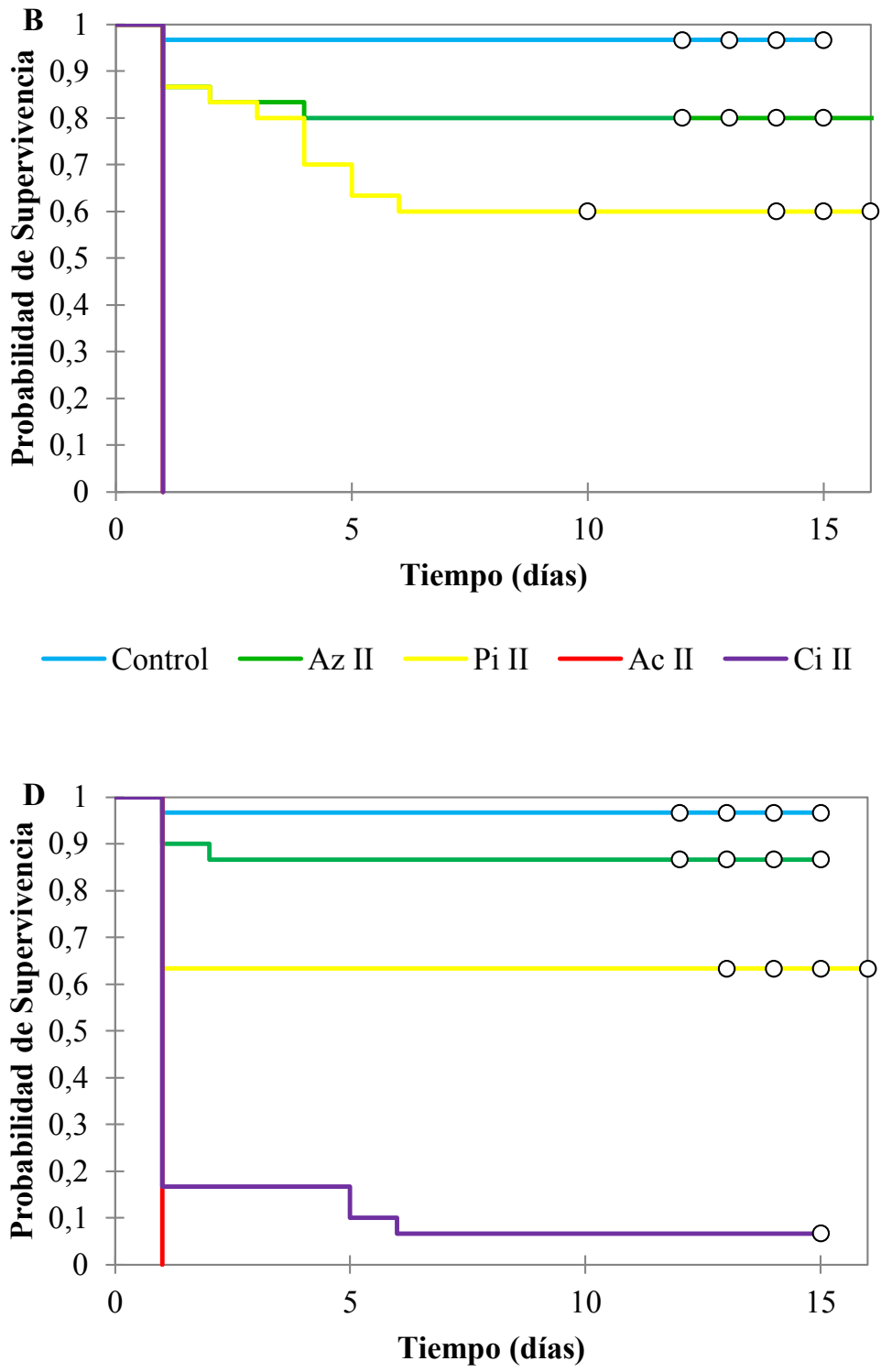

- Control $\longrightarrow$ Aza IV $\longrightarrow$ Pi IV $\longrightarrow$ Ac IV $\longrightarrow$ Ci IV

Figura 5.5. Toxicidad de los insecticidas sobre la supervivencia de larvas-pupas de Harmonia axyridis, expuestas en el segundo estadio larval. Kaplan Meier, $\chi^{2}$. Test Log Rank $(P<0,05)$. Az I, II, III y IV = azadiractina 48, 24, 12 y 6 mg i.a./L. Pi I, II, III, IV = piriproxifén 75; 37,5; 18,75 y 63 9,38 mg i.a./L. Ac I, II, III, IV = acetamiprid 200, 100, 50 y $25 \mathrm{mg}$ i.a./L. Ci I, II, III, IV = cipermetrina 25; 12,5; 6,25; 3,12 mg i.a./L. A: 100\% MCRC. B: 50\% MCRC. C: 25\% MCRC. D: 12,5\% MCRC. 
Fecundidad y fertilidad de hembras expuestas en el segundo estadio larval

En el tratamiento control obtuvo un valor de fecundidad de 143,61 ( $\pm 16,42)$ huevos. Ninguno de estos tratamientos mostró diferencias significativas con respecto al control $(H=5,25 ;$ g.l. $=4 ; P=0,63)$ (Figura 5.6).

La fertilidad observada para el control fue de $96,01( \pm 15,66)$ larvas. Nuevamente, ninguno de los tratamientos mostró diferencias significativas con respecto al control $(H=$ 2,$60 ;$ g.l. $=4 ; P=0,92$ ) (Figura 5.6).

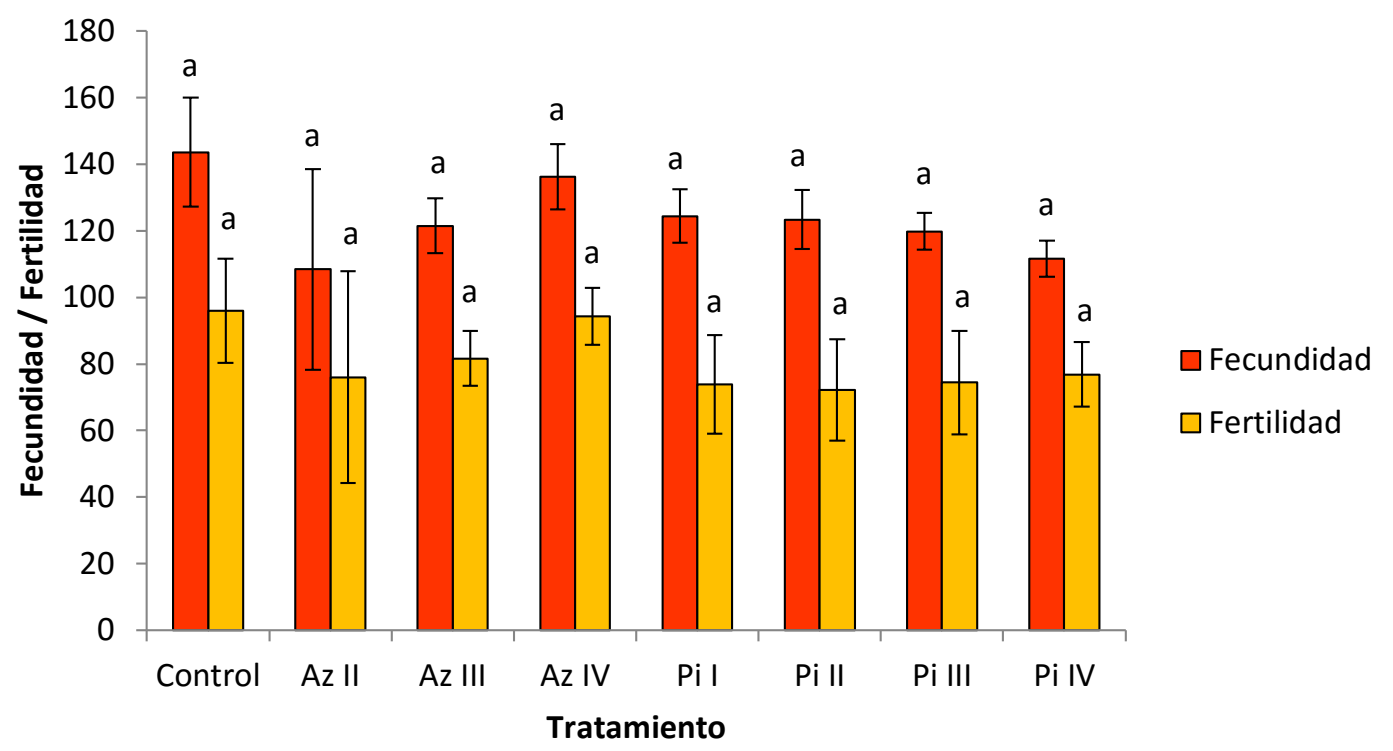

Figura 5.6. Toxicidad de azadiractina y piriproxifén sobre la fecundidad y fertilidad acumulada de las primeras cinco posturas de individuos de Harmonia axyridis, expuestos en el segundo estadio larval. Las barras muestran media ( \pm ES). Para cada parámetro biológico diferentes letras indican diferencias significativas entre tratamientos $(P<0,05)$. Az II, III y IV= azadiractina 24, 12 y 6 mg i.a./L. Pi I, II, III, IV = piriproxifén 75; 37,5; 18,75 y $9,38 \mathrm{mg}$ i.a./L , respectivamente. 
Bioensayos de toxicidad sobre el cuarto estadio larval

Supervivencia de larvas-pupas expuestas en el cuarto estadio larval

El porcentaje de individuos que alcanzaron el estado adulto en el tratamiento control fue del $93,30 \%$ (Figura 5.7). En el tratamiento con azadiractina a la MCRC se observó una supervivencia del 40\% (Figura 5.7 A), estos resultados mostraron diferencias significativas con respecto al control (Tabla 5.7 A). Al $50 \%$ y $25 \%$ de la MCRC de este insecticida, se registraron valores de supervivencia del $83,30 \%$ (Figura 5.7 B y C), y al 12,5\% de la MCRC se observó un valor del 96,70\% (Figura 5.7 D). En ninguno de estos últimos tratamientos se observaron diferencias significativas con respecto al control (Tabla 5.7 A-D).

El insecticida piriproxifén no resultó tóxico para larvas del cuarto estadio. Se observaron valores de supervivencia cercanos al control en todas las concentraciones ensayadas. A la MCRC, la supervivencia fue del $86,70 \%$ (Figura $5.7 \mathrm{~A}$ ), con diluciones del $50 \%$ y $25 \%$ de la MCRC los valores fueron de $96,70 \%$ y $90 \%$, respectivamente (Figura 5.7 B y C) y al $12,5 \%$ de la MCRC se registró una supervivencia del $93,30 \%$ de los individuos tratados (Figura 5.7 D). Ninguna de las concentraciones difirió significativamente del control (Tabla 5.7 A-D).

El acetamiprid fue el insecticida más tóxico y causó $100 \%$ de mortalidad en todas las concentraciones ensayadas (Tabla 5.7 A-D, Figura 5.7 A-D). Por otro lado, en aquellas larvas expuestas a cipermetrina se observó una marcada reducción de la supervivencia a todas las concentraciones ensayadas. A la MCRC se observó un $100 \%$ de mortalidad y cuando se utilizó una dilución del 50\% se registró un valor de este parámetro del 3,30\% (Figura 5.7 A y B). Por otro lado, solo el $10 \%$ y $20 \%$ de los individuos sobrevivieron cuando se los expuso a diluciones del $25 \%$ y $12,5 \%$ de la MCRC, respectivamente (Figura 5.7 C y D). Todos estos tratamientos mostraron diferencias significativas con respecto al control (Tabla 5.7 A-D). 
Tabla 5.7. Toxicidad de los insecticidas sobre la supervivencia de larvas-pupas de Harmonia axyridis, expuestos en el cuarto estadio larval. Kaplan Meier, $\chi^{2}$. Test Log Rank $(P<0,05)$. A: $100 \%$ MCRC; B: 50\% MCRC; C: 25\% MCRC; D: 12,5\% MCRC.

A

\begin{tabular}{lccc}
\hline & $\chi^{2}$ & g.l. & $\boldsymbol{P}$ \\
\hline Comparación global & 93,96 & 4 & $<0,001$ \\
Control - Azadiractina & 19,08 & 1 & $<0,001$ \\
Control - Piriproxifen & 0,70 & 1 & 0,40 \\
Control - Acetamiprid & 52,64 & 1 & $<0,001$ \\
Control - Cipermetrina & 49,98 & 1 & $<0,001$ \\
\hline
\end{tabular}

C

\begin{tabular}{lccc}
\hline & $\chi^{2}$ & g.l. & $\boldsymbol{P}$ \\
\hline Comparación global & 145,60 & 4 & $<0,001$ \\
Control - Azadiractina & 1,29 & 1 & 0,26 \\
Control - Piriproxifen & 0,16 & 1 & 0,68 \\
Control - Acetamiprid & 49,24 & 1 & $<0,001$ \\
Control - Cipermetrina & 40,46 & 1 & $<0,001$ \\
\hline
\end{tabular}

B

\begin{tabular}{lccc} 
& $\chi^{2}$ & g.l. & $\boldsymbol{P}$ \\
\hline Comparación global & 139,35 & 4 & $<0,001$ \\
Control - Azadiractina & 1,28 & 1 & 0,26 \\
Control - Piriproxifen & 0,36 & 1 & 0,55 \\
Control - Acetamiprid & 51,18 & 1 & $<0,001$ \\
Control - Cipermetrina & 46,5 & 1 & $<0,001$ \\
\hline
\end{tabular}

D

\begin{tabular}{lccc}
\hline & $\chi^{2}$ & g.l. & $\boldsymbol{P}$ \\
\hline Comparación global & 172,23 & 4 & $<0,001$ \\
Control - Azadiractina & 0,36 & 1 & 0,55 \\
Control - Piriproxifen & 0,01 & 1 & 0,98 \\
Control - Acetamiprid & 55,41 & 1 & $<0,001$ \\
Control - Cipermetrina & 30,72 & 1 & $<0,001$ \\
\hline
\end{tabular}



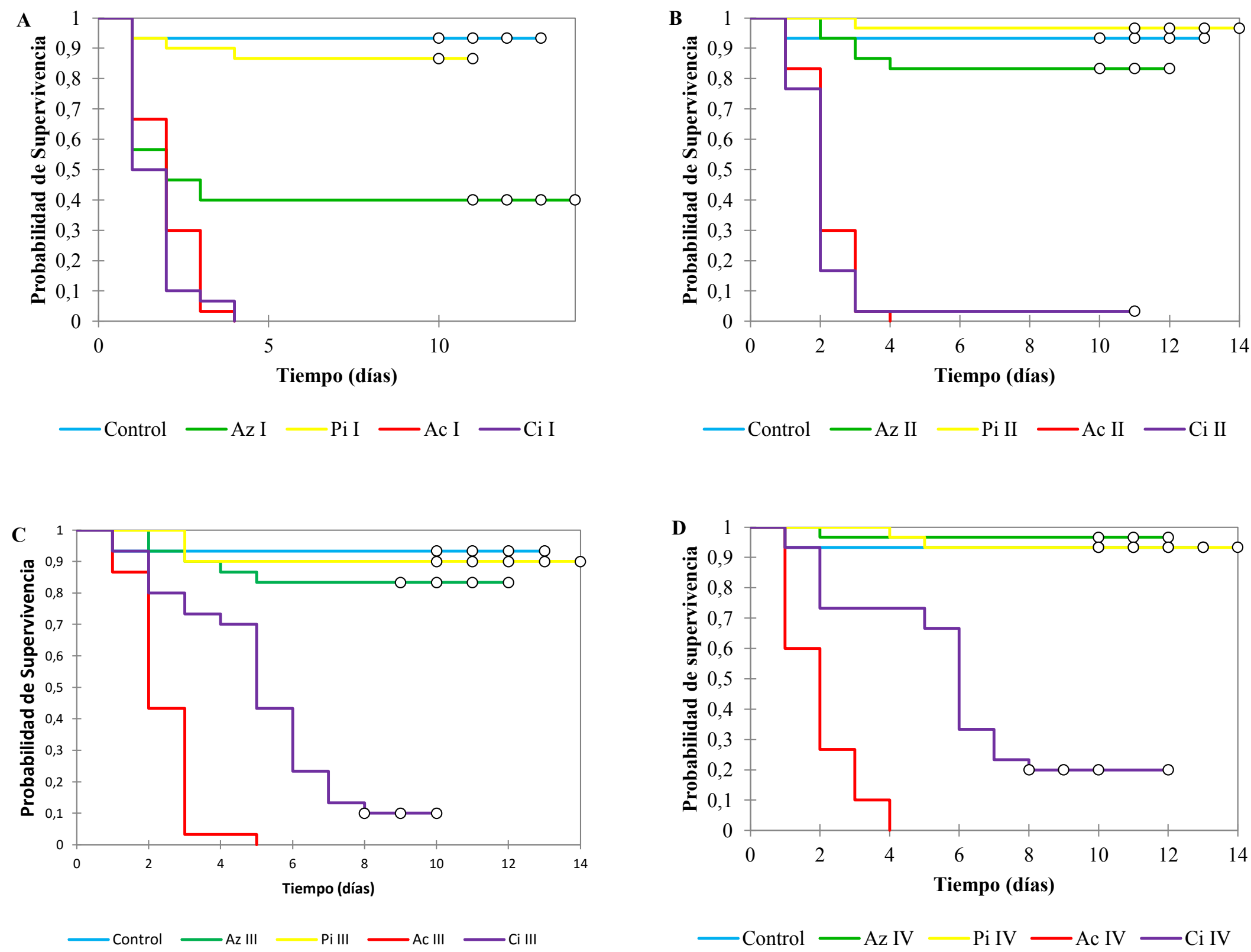

Figura 5.7. Toxicidad de los insecticidas sobre la supervivencia de larvas-pupas de Harmonia axyridis expuestas en el cuarto estadio larval. Kaplan Meier, X2. Test Log Rank (P < 0,05). Az I, II, III y IV = azadiractina 48, 24, 12 y 6 mg i.a./L. Pi I, II, III, IV = piriproxifén 75; 37,5; 18,75 y 9,38 mg i.a./L. AC I, II, III, IV = acetamiprid 200, 100, 50 y 25 mg i.a./L. Ci I, II, III, IV = cipermetrina 25; 12,5; 6,25; 3,12 mg i.a./L. A: 100\% MCRC. B: 50\% MCRC. C: $25 \%$ MCRC. D: $12,5 \%$ MCRC. 
Fecundidad y fertilidad de hembras expuestas en el cuarto estadio larval

El tratamiento control presentó una fecundidad de 138,81 ( $\pm 12,57)$ huevos. Se observaron diferencias significativas cuando los individuos fueron expuestos al insecticida azadiractina y piriproxifén $(H=20,39 ; g . l .=4 ; P=0,004)$. La azadiractina produjo una reducción de este parámetro en los tratamientos con diluciones del $50 \%$ y $25 \%$ de la MCRC. En cambio, ninguno de los tratamientos realizados con piriproxifén difirió significativamente con respecto al control (Figura 5.8).

La fertilidad observada para el control fue de $97,43( \pm 12,05)$ larvas. Nuevamente, se observaron diferencias significativas entre los tratamientos $(H=17,68 ; g . l .=4 ; P=0,01)$. Aquellos que presentaron diferencias, con respecto al control, fueron azadiractina al $50 \%$ y $25 \%$ de la MCRC (Figura 5.8).

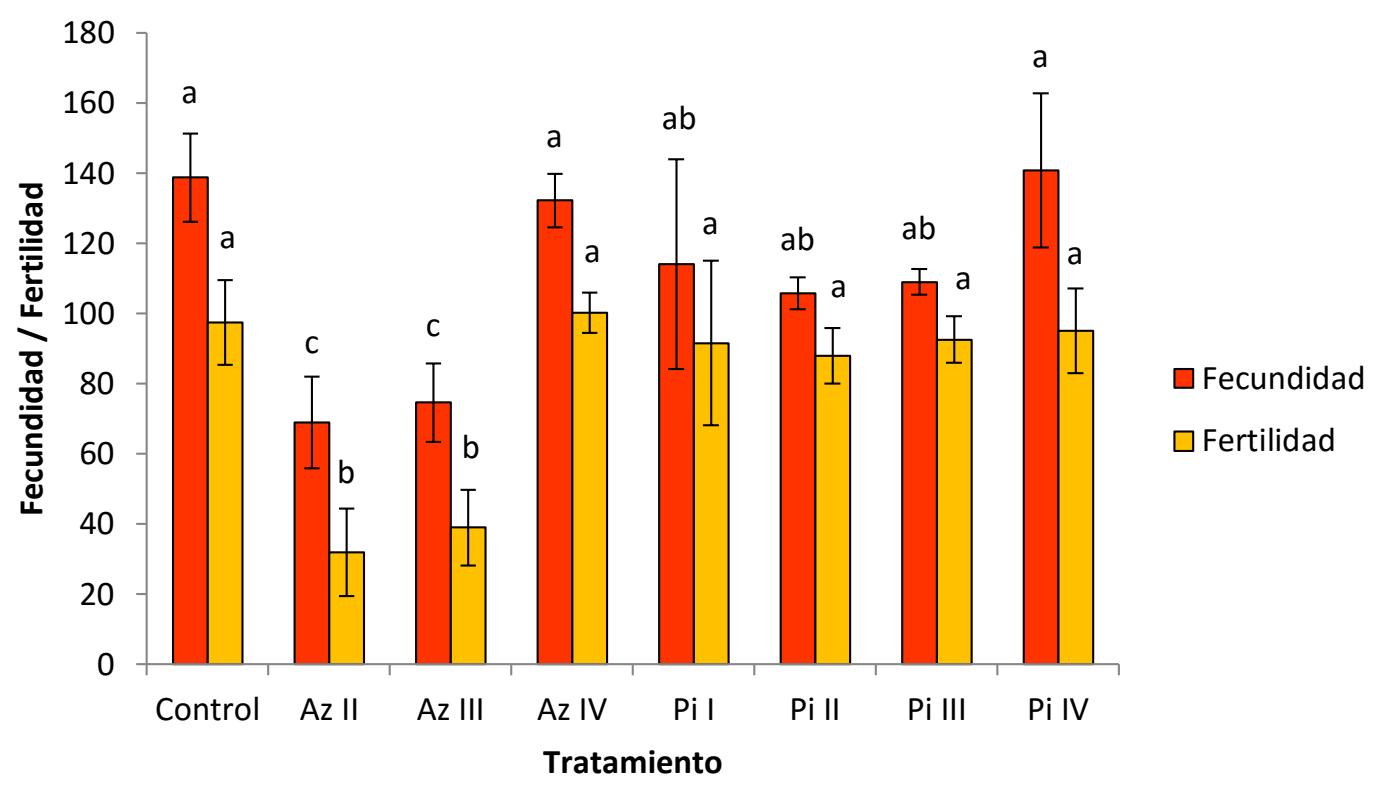

Figura 5.8. Toxicidad de azadiractina y piriproxifén sobre la fecundidad y fertilidad acumulada de las primero cinco posturas de individuos de Harmonia axyridis, expuestos en el cuarto estadio larval. Las barras muestran media ( \pm ES). Para cada parámetro biológico diferentes letras indican diferencias significativas entre tratamientos $(P<0,05)$. Az II, III y IV= azadiractina 24,12 y 6 mg i.a./L. Pi II II, III, IV = piriproxifén 75; 37,5; 18,75 y $9,38 \mathrm{mg}$ i.a./L, respectivamente. 
Bioensayos de toxicidad sobre el estado de pupa

Emergencia de adultos expuestos en el estado de pupa

El $100 \%$ de los ejemplares del tratamiento control alcanzaron el estado adulto. Se observaron diferencias significativas en todas concentraciones evaluadas: MCRC $(H=$ $13,78 ;$ g.l. $=4 ; P=0,008) ; 50 \% \operatorname{MCRC}(H=13,60 ;$ g.l. $=4 ; P=0,008) ; 25 \% \operatorname{MCRC}(H=13,14$; g.I. $=4 ; P=0,010) ; 12,5 \% \operatorname{MCRC}(F=12,88 ;$ g.I. $=4,10 ; P=0,012)$ (Figura 5.9).

La emergencia de adultos del tratamiento con azadiractina fue del $70( \pm 5,77) \%$ para la MCRC, este valor difirió significativamente con respecto al control. Los ejemplares que detuvieron su desarrollo en el estado de pupa mostraron anormalidades, observándose individuos con desarrollo incompleto de la cabeza y estructuras alares. De aquellos individuos que alcanzaron el estado adulto aproximadamente el 50\% de ellos presentaron anormalidades morfológicas. Se observaron ejemplares con el abdomen sin desarrollar y otros adheridos a la exuvia, por la región posterior del cuerpo. Las diluciones al 50\%, 25\% y $12.5 \%$ no mostraron diferencias significativas respecto al control (Figura 5.9 y 5.10 C-D).

El insecticida piriproxifén redujo significativamente la emergencia de adultos, en todas las concentraciones ensayadas. En el tratamiento a la MCRC, solo el $30( \pm 5,77) \%$ de los ejemplares alcanzaron el estado adulto. Además, algunos de ellos presentaron anormalidades, como ser, los élitros separados y las alas membranosas desplegadas y arrugadas. En todos los tratamientos, entre el $50 \%$ y $70 \%$ de los adultos presentaron anormalidades morfológicas, movimientos descoordinados, temblores y disposición del cuerpo invertida (región dorsal del cuerpo apoyada sobre la superficie) (Figura 5.9 y 5.10 $\mathrm{E}-\mathrm{G})$.

Cuando las pupas fueron expuestas al insecticida acetamiprid, ninguno de los individuos expuestos a la MCRC alcanzó el estado de adulto. En los tratamientos en los que se emplearon diluciones del $50 \%, 25 \%$ y $12,5 \%$ de la MCRC se observaron adultos adheridos a la exuvia y otros con desarrollo parcial de alas. Este insecticida también causó 
descoordinación motriz y temblores, y muchos ejemplares mostraron disposición del cuerpo invertida (Figura 5.9 y $5.10 \mathrm{H}-\mathrm{I})$.

En los tratamientos con cipermetrina se registró un $100 \%$ de mortalidad cuando los individuos fueros expuestos a la MCRC y diluciones del 50\%. En los tratamientos al $25 \%$ y $12,5 \%$ de la MCRC aproximadamente el $30 \%$ de estos individuos mostraron malformaciones y descoordinación motriz (Figura 5.9 y $5.10 \mathrm{~J}-\mathrm{K}$ ).

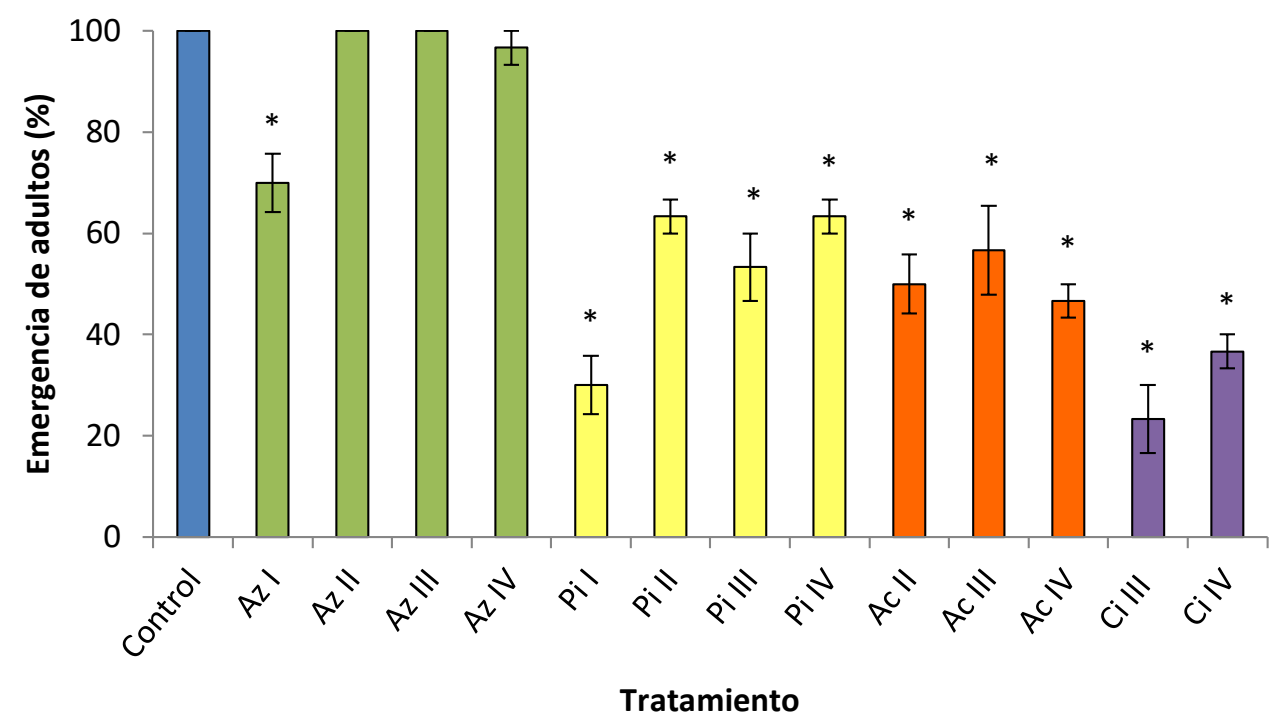

Figura 5.9. Emergencia de adultos de Harmonia axyridis expuestos en el estado de pupa. Las barras muestran media ( $\pm \mathrm{ES}) .{ }^{*}$ indica diferencias significativas con respecto al control $(P<0,05)$. Az I, II, III y IV = azadiractina $48,24,12$ y $6 \mathrm{mg}$ i.a/L. Pi I, II, III, IV = piriproxifén $75 ; 37,5 ; 18,75$ y 9,38 mg i.a/L. Ac II, III, IV = acetamiprid 100, 50 y $25 \mathrm{mg}$ i.a/L. Ci III, IV = cipermetrina $25,12,5 \mathrm{mg}$ i.a/L. 

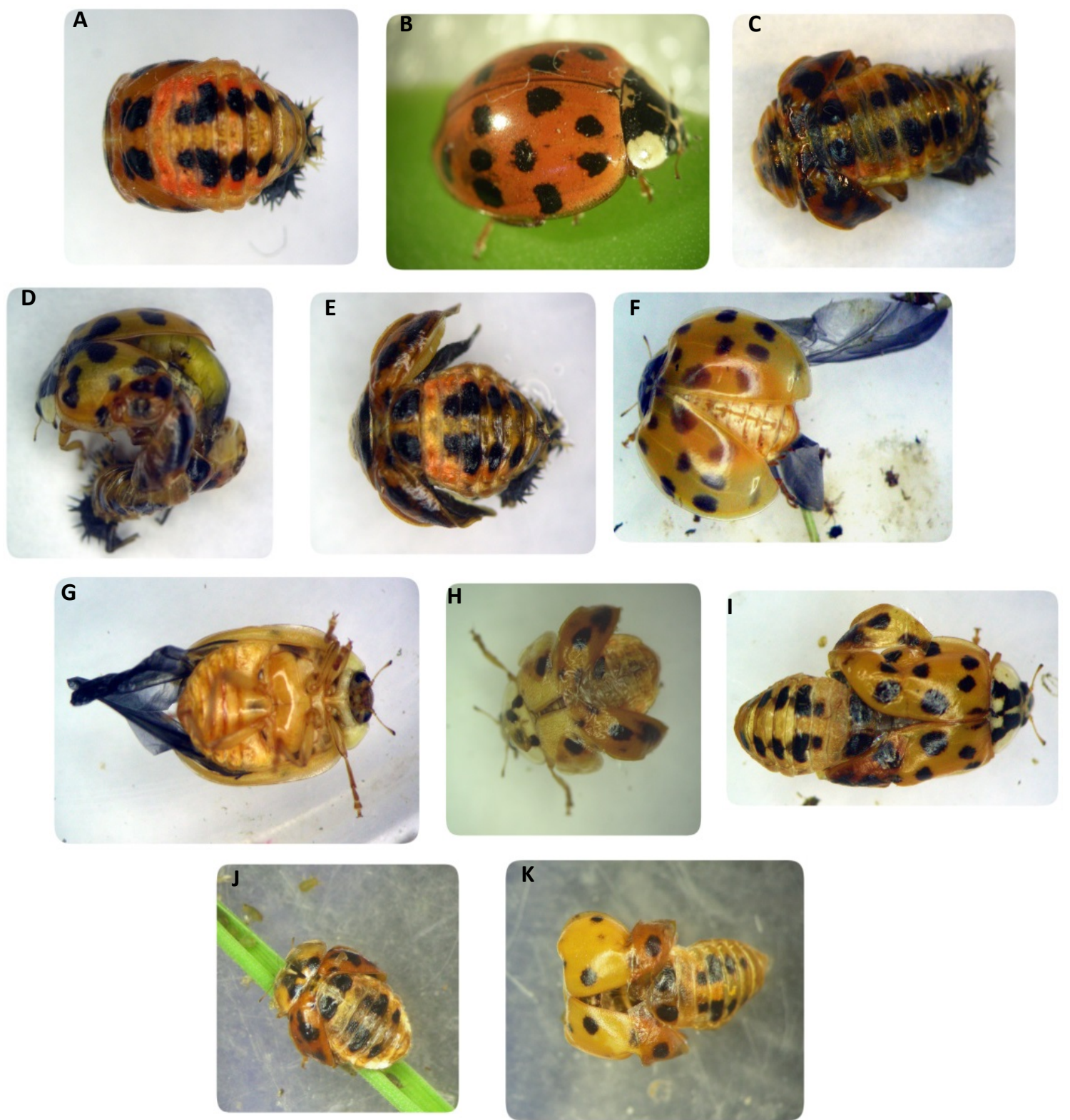

Figura 5.10. Anormalidades registradas en Harmonia axyridis expuesta a diferentes insecticidas en el estado de pupa. A: pupa control. B: adulto control. C, D: azadiractina 100\% MCRC (48 mg i.a./L). E, F: piriproxifén 100\% MCRC (75 mg i.a./L). G: piriproxifén 25\% MCRC (18,75 mg i.a./L). H: acetamiprid (100 mg i.a./L). I: acetamiprid 12,5\% MCRC (25 mg i.a./L). J, K: cipermetrina 50\% $\operatorname{MCRC}(12,5 \mathrm{mg}$ i.a./L). 
Fecundidad y fertilidad de hembras expuestas en el estado de pupa

Todos los individuos adultos de los tratamientos con piriproxifén y acetamiprid al $50 \%, 25 \%$ y $12,5 \%$ de la MCRC, murieron dentro los primeros siete días, por lo que no se pudieron obtener los parámetros reproductivos.

En el tratamiento control se obtuvo un valor de fecundidad de 149,41 $( \pm 11,76)$ huevos. En todos los tratamientos con azadiractina se observaron diferencias significativas con respecto al control $(F=8,78 ; g . l .=4,20 ; P<0,001)$ (Figura 5.11).

La fertilidad observada para el control fue de 115,21 $( \pm 9,17)$ larvas. Nuevamente, todos los tratamientos difirieron significativamente con respeto al control $(H=15,32 ;$ g.l.= 4; $P=0,004)$ (Figura 5.11).

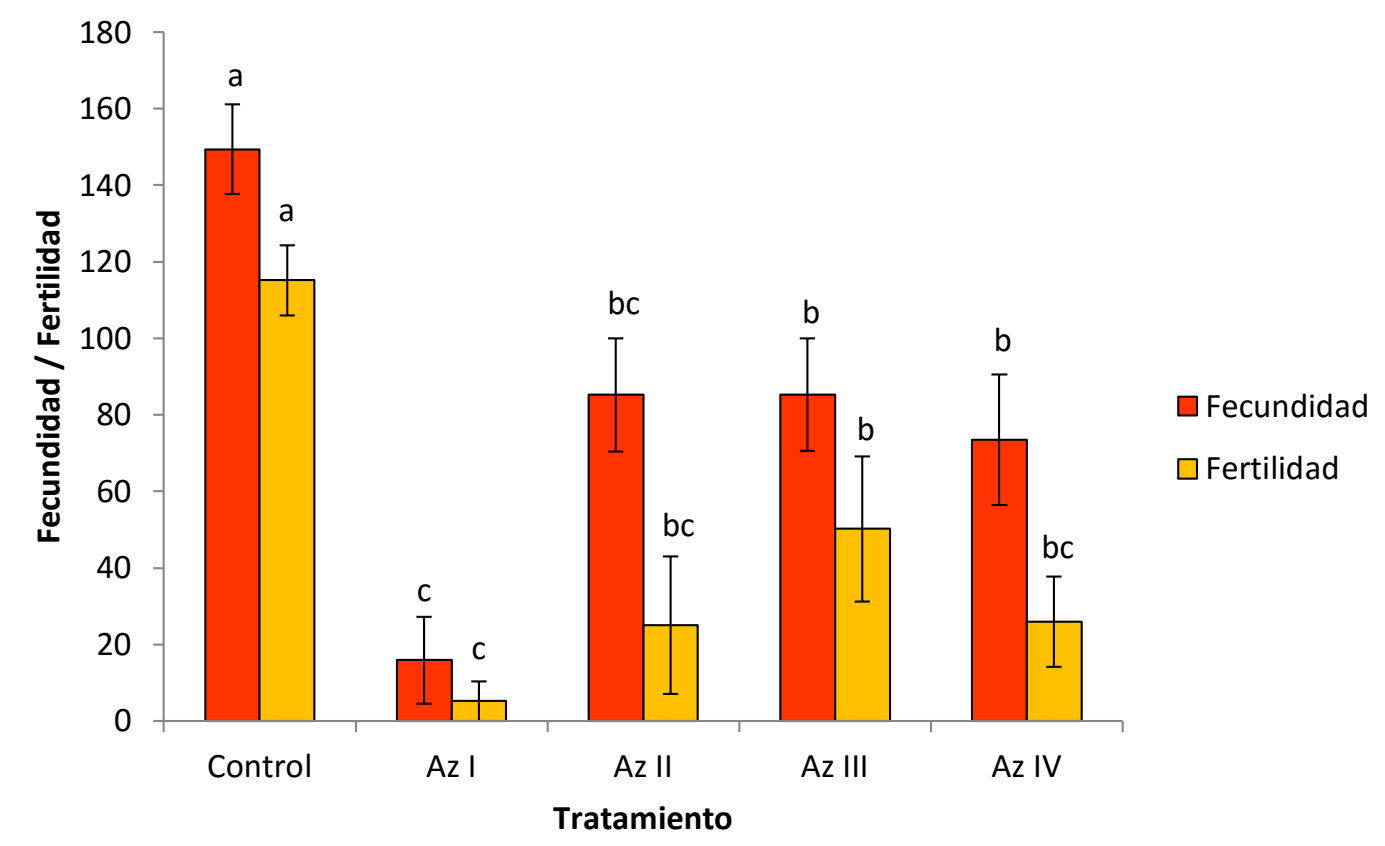

Figura 5.11. Toxicidad de azadiractina y piriproxifén sobre la fecundidad y fertilidad acumulada de las primeras cinco posturas de Harmonia axyridis expuesta en el estado de pupa. Las barras muestran media ( \pm ES). Para cada parámetro biológico diferentes letras indican diferencias significativas entre tratamientos $(P<0,05)$. Az I, II, III y IV= azadiractina 48, 24, 12 y $6 \mathrm{mg}$ i.a./L, respectivamente. 


\section{Discusión}

En los programas de MIP, se recomienda el uso de insecticidas biorracionales principalmente cuando el control biológico y otras estrategias de control no han logrado reducir los niveles poblacionales de la plaga por debajo del nivel de daño económico. Con el fin de maximizar la compatibilidad entre el control químico y control biológico, es relevante conocer la toxicidad y selectividad de los insecticidas sobre enemigos naturales (Galvan et al. 2005).

En los resultados de los bioensayos de toxicidad de los insecticidas sobre $H$. axyridis, obtenidos en este trabajo, se registraron diferencias entre los distintos insecticidas. Se observó una variación en dicho efecto según el estado de desarrollo y las concentraciones ensayadas. Esto último fue más notorio en los tratamientos con azadiractina y piriproxifén, tal como se discutirá más adelante.

En este trabajo, los efectos de la azadiractina sobre los individuos fueron más notorios al $100 \%$ y $50 \%$ de la MCRC. Esto indicaría que este insecticida podría atravesar el corion del huevo y cutícula del insecto, afectando al organismo. Otra vía de contaminación posible es la ingesta de residuos de insecticidas depositados sobre el corion del huevo, por parte de las neonatas quienes al emerger del huevo rompen el corion y se alimentan de él, causando algún desbalance fisiológico de la hormona ecdicsona (Desneux et al. 2007).

El insecticida azadiractina fue el que causó menor toxicidad sobre el estado de huevo, de todos los insecticidas evaluados. Si bien, se observó una reducción significativa de la emergencia de larvas que varió, según las concentraciones ensayadas, entre el $43 \%$ y $55 \%$ aproximadamente, este insecticida no afectó la supervivencia de la progenie de esos huevos. Cuando se trataron larvas del segundo y cuarto estadio y pupas, solo se observó una reducción significativa de la supervivencia a la MCRC ensayada. En otros estudios sobre individuos de $H$. axyridis expuestos a este insecticida (45 mg i.a./L) se observó una reducción de la supervivencia del primer y tercer estadio larval, sin embargo, las pupas y adultos no fueron afectados (Kraiss \& Cullen 2008). Por otro lado, Qi et al. (2001) evaluaron en laboratorio la tasa de consumo y supervivencia de adultos del 
coccinélido Harmonia conformis Boisduval y de larvas del crisópido Mallada signatus Schneider, utilizando presas contaminadas con extractos de neem (50 y 200 mg. i.a./L), cuyo principio activo principal es la azadiractina. $H$. conformis no fue afectada por este insecticida, sin embargo se registró una reducción en la supervivencia de los individuos de M. signatus.

Los efectos de la azadiractina sobre la fecundidad y fertilidad variaron según el estado/estadio de desarrollo del depredador evaluado. Cuando se expuso a huevos solo a la MCRC y con diluciones del $50 \%$ la fertilidad se vio afectada significativamente. Los parámetros reproductivos no se vieron afectados cuando se trataron larvas del segundo estadio. En cambio, se registraron valores significativamente diferentes al control cuando se expuso a larvas del cuarto estadio a la MCRC y diluciones del 50\% y a pupas a todas las concentraciones evaluadas. En estudios realizados sobre adultos de Blaptostethus pallescens Poppius (Hemiptera: Anthocoridae) se demostró que la azadiractina no causó efectos negativos sobre la supervivencia de este depredador, sin embargo produjo un descenso de los parámetros reproductivos (Celestino et al. 2014).

En general, se observa que la azadiractina afecta principalmente los estadios larvales. Esto podría explicarse a través del modo de acción de este insecticida. Por mecanismos no muy conocidos, la azadiractina inhibe la liberación de la hormona ecdicsona, cuya función principal es la de estimular las células epidérmicas para iniciar el proceso de muda (Mordue 2004). El suministro exógeno de un antiecdicsoide provocaría un desbalance hormonal en el cuerpo del insecto, ocasionando un desarrollo anormal y eventualmente la muerte. Por otro lado, la ecdicsona interviene en el desarrollo de los tejidos imaginales durante la fase de pupa. Esto podría explicar los efectos negativos que ocasionó este insecticida sobre los parámetros reproductivos (Cloyd 2006). A su vez, la mayor toxicidad observada en las del cuarto estadio y pupas podría relacionarse con el menor tiempo de degradación y/o excreción que presentaron estos individuos con respecto a los expuestos durante el estado de huevo y segundo estadio larval (Desneux et al. 2005). 
En este trabajo, el piriproxifén resultó ser tóxico en los ensayos sobre huevos de $H$. axyridis. De igual manera, este insecticida provocó un efecto negativo sobre huevos de Chrysoperla rufilabris Burmeister (Neuroptera: Chrysopidae), obteniéndose valores de supervivencia del 33,30\% y 6,70\% a concentraciones de 50 mg i.a. /L y 100 mg i.a. /L, respectivamente (Liu \& Chen 2001). En cambio, estudios de laboratorio realizados por Fonseca Moscardini et al. (2013) demostraron que este insecticida, a la concentración de 18,18 mg i.a. /L, no tuvo efecto sobre la supervivencia de los huevos ni el desarrollo embrionario del depredador Orius insidiosus.

Piriproxifén produjo una reducción de la supervivencia en larvas del segundo estadio a todas las concentraciones ensayadas, aunque no se observaron efectos negativos sobre los parámetros reproductivos. En larvas del cuarto estadio, piriproxifén no ocasionó ningún efecto letal o subletal. Resultados similares fueron obtenidos por Fonseca Moscardini et al. (2013), quienes demostraron una reducción mayor de la supervivencia de los primeros estadios ninfales de $O$. insidiosus, con respecto a los estadios avanzados. En otros estudios, piriproxifén (10 mg i.a./L) afectó la supervivencia solo del tercer estadio ninfal de C. rufilabris, indicando que este, es el estadio más vulnerable; además observaron un alargamiento en el tiempo de desarrollo hasta alcanzar el estado adulto (Chen \& Liu 2002).

El insecticida piriproxifén resultó ser altamente tóxico sobre el estado de pupa. La emergencia de adultos varió entre un $16 \%$ y 30\%, según la concentración ensayada. Además, la mayoría de los individuos que alcanzaron el estado adulto presentaron anormalidades morfológicas y estos individuos murieron antes de que se produzca la primera cópula. Fogel (2012) registró una menor toxicidad del piriproxifén sobre pupas del coccinélido Eriopis connexa, al evaluar la misma concentración empleada en este estudio (75 mg i.a./L). El 80\% de los individuos expuestos a este insecticida alcanzaron el estado adulto. Sin embargo, cerca de la mitad de ellos presentaron anormalidades morfológicas.

Piriproxifén resultó más tóxico sobre los estados de huevo y pupa con respecto a los estadios larvales. Este insecticida actúa como agonista de la hormona juvenil. En insectos 
holometábolos, los niveles de esta hormona disminuyen bruscamente previo al cambio de un estado a otro (huevo-larva, pupa-adulto) y son constantes durante los cambios de estadios larvales. Por lo tanto, la aplicación de un juvenoide exógeno puede provocar los resultados observados.

Piriproxifén no afectó la fecundidad y fertilidad de los individuos expuestos durante el segundo y cuarto estadio larval. Posiblemente, el efecto de los insecticidas IGRs sobre los parámetros reproductivos puede verse agravado cuando se exponen adultos, esto se debe a que los IGRs también pueden afectar la síntesis de vitelo y procesos de ovogénesis y espermatogénesis (Dhadialla et al. 1998; Hartfelder 2000). Liu \& Stansly (2004) evaluaron en el laboratorio los efectos letales y subletales de piriproxifén y buprofezín (100 y 200 mg i.a./L) sobre adultos del coccinélido Delphastus catalinae a través de la ingesta de huevos contaminados de Bemisia tabaci. El buprofezín redujo la supervivencia de los individuos y, además, produjo un alargamiento en el período de preoviposición. Mientras que con piriproxifén estos parámetros no se vieron afectados, este insecticida y buprofezín afectaron la fertilidad del coccinélido. Castro et al. (2012) examinaron la supervivencia y fertilidad de adultos de Podisus nigrispinus Dallas (Heteroptera: Pentatomidae) alimentados con presas contaminadas con diflubenzurón ( $35 \mathrm{mg}$ i.a./L). La supervivencia no se vio afectada, sin embargo, la fertilidad del depredador presentó valores muy bajos al inicio del periodo reproductivo. De esta manera, este insecticida podría afectar el desarrollo poblacional del pentatómido y, por lo tanto, comprometer su rol como agente de control biológico.

Los insecticidas cipermetrina y acetamiprid resultaron ser los más tóxicos para $H$. axyridis. El insecticida acetamiprid ocasionó una reducción de la emergencia de larvas, similar a la observada con azadiractina. Sin embargo, el total de esas larvas murieron dentro las primeras $24 \mathrm{~h}$ luego de la emergencia. El desarrollo embrionario pudo completarse y las neonatas emerger del huevo, esto podría indicar que el insecticida no intervino en este proceso. Sin embargo el residuo depositado sobre el corion del huevo podría haber actuado como vía de contaminación para las larvas, que al emerger se 
alimentaron de él. Este insecticida también afectó notablemente la supervivencia de larvas y pupas. En una gran proporción de los individuos sobrevivientes se observaron efectos subletales tales como descoordinación motriz e hiperexcitación que condujeron a la muerte de los adultos antes de que suceda la primera cópula. Youn et al. (2003) observaron en el laboratorio que el acetamiprid (40 mg i.a./L) causó un 100\% de mortalidad en huevo, estadios larvales y pupa de H. axyridis. Fogel et al. (2013) llegaron a resultados similares, mostrando la alta toxicidad de este neonicotinoide sobre diferentes estados de desarrollo de $E$. connexa.

La cipermetrina ocasionó graves efectos letales en todos los estados de desarrollo evaluados y a las cuatro concentraciones ensayadas. Además, en la mayoría de los individuos sobrevivientes expuestos en el estado de pupa se observaron efectos subletales propios de los insecticidas neurotóxicos como ser anormalidades morfológicas y descoordinación motriz. El bajo número de individuos sobrevivientes no permitió evaluar los parámetros reproductivos. Existen trabajos que demuestran una baja susceptibilidad de la fauna benéfica a insecticidas piretroides. Giolo et al. (2008) demostraron que el piretroide deltametrina (100 mg i.a./L) resultó ser inocuo o levemente tóxico para diferentes estados de Chrysoperla carnea Stephens (Neuroptera: Chrysopidae). Rimoldi et al. (2008) tampoco registraron efectos de la cipermetrina (25 mg i.a./L) en la supervivencia de larvas y pupas y la emergencia adulta del crisópido Chrysoperla externa Hagen. Sin embargo, la baja susceptibilidad de los crisópidos a piretroides podría explicarse a través de la mayor actividad de enzimas destoxificantes presentes en poblaciones de muchas especies del género Chrysoperla sp. (Pathan et al. 2010).

Por otro lado, un amplio número de trabajos demuestran la toxicidad de los insecticidas piretroides sobre enemigos naturales (Wakeling et al. 2012). Michaud et al. (2003) realizaron estudios de laboratorio evaluando la toxicidad de once insecticidas de amplio espectro sobre la supervivencia de varias especies de enemigos naturales de las familias Coccinellidae, Chrysopidae, Anthocoridae y Aphelinidae. Observaron una alta 
mortalidad de larvas y ninfas del primer estadio expuestas a los piretroides: bifentrín (500 mg i.a./L), fenproopatrín (309 mg i.a./L), zeta-cipermetrina (16 mg i.a./L), permetrina (384 mg i.a./L) y ciflutrín (500 mg i.a./L). Benamú et al. (2013) demostraron que la cipermetrina, a concentraciones de 25 mg i.a./L y diluciones menores, causó efectos letales y subletales sobre (Araneae: Araneidae), observándose una reducción en el consumo de presas, parámetros reproductivos y, además, se vieron afectados parámetros comportamentales como ser la construcción de la tela.

La alta toxicidad del acetamiprid y cipermetrina obtenida en este trabajo podría explicarse por el modo de acción de estos insecticidas. Los piretroides alteran el funcionamiento normal de los canales de sodio de las neuronas y los neonicotinoides se unen de manera persistente a los receptores de la acetilcolina causando sobre estimulación motora. Ambos insecticidas al tener su efecto sobre el sistema nervioso de los insectos, provocan una alteración de la transmisión del impulso nervioso, ocasionando descoordinación motriz, hiperexcitación y parálisis (Stenersen 2004; Casida \& Durkin 2013).

Durante más de una década, los neonicotinoides han sido considerados insecticidas biorracionales con baja toxicidad hacia organismos benéficos y, por lo tanto, su uso ha sido aceptado en programas de MIP (Hassan et al. 1994). Posiblemente, esto podría explicarse por la menor toxicidad que presentan estos compuestos frente a los insecticidas convencionales de amplio espectro. En un trabajo realizado en cultivos de algodón en condiciones de campo se demostró que los insecticidas neonicotinoides: acetamiprid, imidacloprid, nitenpirán y tiacloprid, en comparación con los insecticidas convencionales organofosforados y piretroides, ejercieron un control efectivo sobre insectos plagas sucsopicadores $y$, a su vez, presentaron menor toxicidad frente a enemigos naturales (Ahmed et al. 2014). Sin embargo, en numerosos estudios realizados en escala de laboratorio, semicampo y campo, se observó una alta toxicidad ejercida por los insecticidas neonicotinoides sobre los organismos benéficos de las familias: Miridae, Geocoridae, Coccinellidae, Chrysopidae, Phytoseiidae (Delbeke et al. 1997; Grafton 
Cardwell \& Gu 2003; Youn et al. 2003; Lucas et al. 2004; Cloyd \& Bethke 2010; Fogel et al. 2013). Además, estudios a nivel mundial han reportado una alta mortalidad de abejas y abejorros asociados a cultivos agrícolas. Se han identificado muchos factores potenciales entre los que se encuentran la exposición a neonicotinoides (Gill et al. 2012; Whitehorn et al. 2012; Boily et al. 2013). A raíz de esto, en muchos países se ha restringido o prohibido el uso de estos compuestos. La Comisión Europea encargada del uso y manejo sustentable de plaguicidas prohibió los insecticidas imidacloprid, clotianidina, tiametoxám para ciertos cultivos, entre los que se encuentra el girasol, algodón y el maíz, debido al daño que causan a poblaciones de polinizadores (Biondi et al. 2012).

Una vez más, se desea destacar la importancia de realizar bioensayos de toxicidad de los insecticidas sobre organismos benéficos, evaluando diferentes estados de desarrollo y vías de contaminación, tanto en escala de laboratorio, semicampo y campo. Estos estudios brindan información relevante que puede ser utilizada en programas de MIP y en evaluaciones de riesgo ambiental.

Estos tipos de estudios son importantes, ya que permiten evaluar las verdaderas consecuencias del uso de insecticidas en los agroecosistemas (Stark et al. 2007; Devine et al. 2008). Según los resultados obtenidos en el presente trabajo de tesis, se rechaza la hipótesis propuesta en este capítulo. Si bien $H$. axyridis muestra menor susceptibilidad a los insecticidas biorracionales, azadiractina y piriproxifén, el insecticida acetamiprid resultó ser altamente tóxico para todos los estados de desarrollo evaluados del depredador.

En base a lo dicho anteriormente se rechaza la hipótesis propuesta para el presente capítulo. Se concluye que acetamiprid y cipermetrina fueron los insecticidas que presentaron mayor toxicidad hacia todos los estados y estadios de desarrollo de $H$. axyridis evaluados. Estos estudios apoyan la reconsideración necesaria de los neonicotinoides dentro del grupo de los insecticidas biorracionales. El insecticida botánico azadiractina resultó ser más tóxico a la MCRC en la Argentina, sugiriendo que la aplicación de este compuesto empleando dicha concentración sería perjudicial para este 
depredador. Por último, el insecticida IGR piriproxifén presentó una mayor toxicidad sobre los estados de huevo y pupa del depredador, con respecto a los dos estadios larvales evaluados. 
Capítulo 6

\section{Interacción intragremio entre}

Harmonia axyridis y Eriopis connexa 


\section{Introducción}

El control biológico consiste en la utilización de enemigos naturales con el fin de reducir la densidad de una plaga, de forma temporal o permanente, por debajo del nivel de daño económico. Esta estrategia implementada en programas de MIP comprende entre otras técnicas el control biológico clásico, que involucra la importación de enemigos naturales para el control plagas exóticas, y el control biológico neoclásico, en el que se importan enemigos naturales para controlar plagas nativas (Van Driesche et al. 2007; Jacas \& Urbaneja 2009).

La elección de introducir un enemigo natural se basa en el principio ecológico que la especie de interés representaría un agente de control biológico más eficiente que aquellos presentes naturalmente en una región (O'Connel et al. 2012). Sin embargo, existen controversias respecto a esto. Si bien, numerosos casos de introducciones de enemigos naturales resultaron ser exitosos desde el punto de vista del control biológico, se han reportado efectos secundarios indeseados causado por las especies exóticas sobre las poblaciones de organismos benéficos nativos (van Lenteren 2008; Cock et al. 2010; Ragsdale et al. 2011).

Las nuevas interacciones que se generan entre especies exóticas y locales, tanto en ecosistemas antrópicos como naturales, pueden provocar desequilibrios afectando la estabilidad de las interacciones preexistentes (Heimpel et al. 2010; Jaworski et al. 2013). De esta manera, pueden generarse superposiciones de nichos entre especies introducidas y nativas favoreciendo la competencia por el espacio, presa u hospedero, etc. Además, las diferentes especies pueden interactuar directamente a través de la depredación intragremio (IGP) (Lucas et al. 1998; van Lenteren et al. 2003, 2006).

La depredación IGP ocurre cuando dos especies del mismo gremio, potencialmente competidoras, interactúan tróficamente (Polis et al., 1989; Lucas et al. 1998). En este tipo de interacción al menos tres especies están involucradas. La especie depredadora es llamada depredador intragremio, la especie que es depredada representa la presa intragremio y el recurso común es la presa extragremio (Lucas et al. 1998). En el caso que 
la depredación intragremio sea bidireccional las especies depredadoras pueden ocupar el rol de depredador o presa intragremio. Estas interacciones son comunes en redes tróficas de agentes de control biológico y han sido ampliamente estudiadas en gremios de especies afidófagas, entre los que se incluyen los coccinélidos como uno de los grupos más importantes (Phoofolo \& Obrycki 1998; Ware et al. 2009; Gagnon et al. 2011a; 2011b; Perdikis et al. 2014).

Existen una serie de factores que influyen en la simetría y grado de la interacción IGP, entre ellos, el tamaño relativo de los individuos es uno de los más importantes. En general, la interacción se lleva a cabo cuando el depredador IG ataca a presas de menor tamaño (Polis et al. 1989). La variación tamaño entre los protagonistas de la interacción IGP puede deberse a la variación natural existente entre individuos de diferentes especies o a variaciones de tamaño durante el desarrollo preimaginal. La interacción IGP entre individuos de diferentes estadios larvales y ninfales es más frecuente y esto estaría relacionado con el tamaño de los individuos (Lucas 2005).

La capacidad de movilidad y ciertos comportamientos de defensa frente a depredadores potenciales también son factores claves en la depredación IGP. Algunos coccinélidos responden agresivamente frente a individuos inter específicos. Otros presentan ciertos comportamientos relacionados con tácticas de huida, caída desde la planta, migración hacia nuevos sitios, etc. (Sato et al. 2009). Según Lucas (2005), los estados sésiles incluyendo huevo, larva en período de muda y pupa son más vulnerables a la depredación IG. Entre ellos, la pupa de los coccinélidos se caracteriza por presentar una cutícula gruesa que representaría una barrera más eficaz contra depredadores, con respecto a la cutícula más delgada de las larvas y el corion de los huevos.

Las defensas químicas son consideradas, también, una adaptación de defensa frente a depredadores. Ciertas especies de coccinélidos presentan sustancias alcaloides disuasorias en huevos, larvas y pupas que defenderían a los individuos de la depredación IG (Ware \& Majerus 2008). 
La presa EG es otro factor que influye en la ocurrencia de las interacciones IGP (Lucas et al. 1998; Lucas \& Rosenheim 2011). Además, el grado de especificidad alimenticia de las especies involucradas podría influir en la magnitud de dicha interacción. Un depredador generalista ataca y consume individuos de un gran número de especies. Por el contrario, un depredador especialista al presentar un menor rango de presas, estaría menos adaptado a alimentarse de presas alternativas, encontrándose en desventaja frente a una condición de baja o nula disponibilidad de alimento (Jacas \& Urbaneja 2009). Muchos estudios en laboratorio demuestran que un descenso de la densidad de presa EG se traduce en un aumento en la magnitud de la interacción. Esto indicaría que frente a la escasez o baja disponibilidad de presa, el depredador puede ampliar su dieta y alimentarse de un individuo del mismo gremio (Lucas et al. 1998; Nóia et al. 2008).

Como ya se mencionó en esta tesis, $H$. axyridis es una especie de coccinélido nativa de Asia que ha sido introducida en programas de control biológico clásico y neoclásico en muchos países del mundo (Koch et al. 2006; Brown et al. 2011). Esta especie ha sido estudiada ampliamente dentro de su gremio nativo y en aquellas áreas donde ha sido introducida. Muchos trabajos ubican a $H$. axyridis como un competidor interespecífico eficiente $\mathrm{y}$ demuestran los efectos negativos que esta especie ha causado sobre coccinélidos nativos y otros depredadores afidófagos, ya sea a través de competencia por el recurso o por depredación IGP (Michaud 2002; Cottrell 2004; Koch et al. 2008; van Lenteren et al. 2003; 2008; Alhmedi et al. 2010; Ingels \& De Clercq 2011).

En la Argentina, $H$. axyridis fue introducida, en el año 1996, en la provincia de Mendoza y actualmente se encuentra en varias regiones del país, entre las que se incluyen el Cinturón Hortiflorícola platense (CHFP) (Saini 2004; Tulli et al. 2013; Montero 2014; Strassera 2014). Desde la introducción de esta especie en nuestro país, no se ha realizado ningún estudio de riesgo ambiental para evaluar los posibles efectos de esta especie invasiva sobre organismos benéficos. El CHFP se caracteriza por presentar una diversa comunidad de enemigos naturales, entre los que se encuentra Eriopis connexa (Fogel 2012). Este coccinélido, considerado el más abundante en cultivos hortícolas y frutícolas 
de la región Neotropical, es un depredador generalista que se alimenta de varias especies fitófagas consideradas plagas, entre las que se encuentran, áfidos, lepidópteros, ácaros, etc. (López et al. 2003; De Almeida Sarmento et al. 2004; Duarte Gómez \& Zenner de Polanía 2009a). Además, por sus características destacadas como agente de control biológico, E. connexa ha sido comercializada y liberada en cultivos de Estados Unidos para el control del pulgón Diuraphis noxia Mordvilko (Reed \& Pike 1991).

Durante los muestreos que se han llevado a cabo en cultivos del CHFP para este trabajo de tesis, se observaron en cultivos de alcaucil larvas de $H$. axyridis alimentándose de larvas de E. connexa. La densidad poblacional de los diferentes áfidos era alta, esto indicó que si bien la densidad de presas podría influir en la dirección y magnitud de la interacción IGP, la presencia de áfidos no impidió la ocurrencia de la misma.

Los objetivos asociados a este capítulo fueron:

- Evaluar la interacción intragremio entre $H$. axyridis y $E$. connexa, en presencia y ausencia de presa.

- Analizar los efectos de los insecticidas biorracionales, azadiractina, piriproxifén y acetamiprid, y el insecticida convencional cipermetrina, sobre la interacción intragremio entre $H$. axyridis y E. connexa.

Las hipótesis propuestas fueron:

- Existe interacción intragremio entre $H$. axyridis y $E$. connexa y dicha interacción favorece al depredador exótico.

- Los insecticidas biorracionales, azadiractina, piriproxifén y acetamiprid, influyen en la interacción intragremio entre $H$. axyridis y $E$. connexa, favoreciendo al depredador exótico. 


\section{Materiales y métodos}

Condiciones generales de bioensayos de interacción IGP

Para evaluar la interacción IGP entre $H$. axyridis y $E$. connexa se realizaron diferentes bioensayos en condiciones de ausencia de presa, distinta densidad de presas y presas contaminadas previamente con insecticidas. Los mismos fueron diseñados siguiendo la metodología de Lucas et al. (1998), Ware \& Majerus (2008) y Moser \& Obrycki (2009).

En todos los casos se realizaron tratamientos en "condición de IGP" y en "condición de depredador individual". La primera consistió en colocar una larva de cada especie de coccinélido por arena. La segunda representó a los controles y las larvas de ambas especies de coccinélidos fueron dispuestas por separado. Los bioensayos fueron realizados bajo condiciones controladas de temperatura, humedad y fotoperiodo ( $25 \pm 5$ ${ }^{\circ} \mathrm{C}, 75 \pm 5 \% \mathrm{HR}$ y $16: 8 \mathrm{~h} \mathrm{L:} \mathrm{O)}$.

Los ejemplares de $H$. axyridis y $E$. connexa empleados fueron obtenidos de la colonia de coccinélidos para bioensayos. En todos los casos, la arena de experimentación consistió en un recipiente cilíndrico de plástico, de $8 \mathrm{~cm}$ de diámetro y $10 \mathrm{~cm}$ de alto, ventilados con tela de "voile". En cada arena se colocaron tiras de papel para mimetizar el follaje y servir de refugio a las larvas. Se utilizó como presa el pulgón Rhopalosiphum padi.

\section{Bioensayos de interacción IGP en ausencia de presa}

Se llevaron a cabo tratamientos en los que se combinaron diferentes estadios larvales de ambas especies de coccinélidos (Tabla 6.1). Se realizaron 20 réplicas por tratamiento.

Tabla 6.1. Tratamientos en condición de IGP, combinando diferentes estadios larvales de Harmonia axyridis y Eriopis connexa. $\mathrm{HA}=H$. axyridis. $\mathrm{EC}=E$. connexa L1, L3, L4 = primer, tercer, cuarto estadio larval, respectivamente.

Tratamientos

\begin{tabular}{ccccc}
\hline $\mathbf{1}$ & $\mathbf{2}$ & $\mathbf{3}$ & $\mathbf{4}$ & $\mathbf{5}$ \\
\hline HA L1 & HA L3 & HA L4 & HA L3 & HA L4 \\
ECL1 & EC L3 & EC L3 & EC L4 & EC L4 \\
\hline
\end{tabular}


Se emplearon larvas del primer estadio, de $<24 \mathrm{~h}$ de edad, mantenidas en ayuno desde su emergencia hasta su uso en los bioensayos. Cuando se utilizaron larvas del tercer y cuarto estadio, las mismas fueron individualizadas durante $24 \mathrm{~h}$ sin alimento, a partir del día que alcanzaron el estadio deseado.

Se registró la supervivencia de los individuos a las 24 h. Para cada par de larvas se identificó la ocurrencia de interacción IGP y los casos que $H$. axyridis actuó como depredador o presa IG. Con estos valores y siguiendo la metodología descripta por Lucas et al. (1998) se calculó el nivel de IGP y el índice de simetría de IGP, de la siguiente manera:

Nivel de IGP = n ocurrencia de IGP / n total

Donde, $n$ ocurrencia de IGP es la cantidad de réplicas en las que ocurrió la interacción y $n$ total es el número total de réplicas.

Índice de simetría de IGP = n HA depredador IG / n ocurrencia de IGP

Donde, $n$ HA depredador IG es la cantidad de réplicas en las que $H$. axyridis actuó como depredador IG y n ocurrencia de IGP es la cantidad de réplicas en las que ocurrió la interacción. Valores $>0,5$ indican IGP a favor de $H$. axyridis, mientras valores $<0,5$ indican valores a favor de E. connexa.

Además, para comparar el peso de $H$. axyris y E. connexa, y así demostrar de manera cuantitativa la diferencia de tamaño ambas especies de coccinélidos, antes de comenzar los bioensayos se pesó a las larvas; para esto, se utilizó una balanza analítica (Acculab ${ }^{\circledR}$ ) con una precisión de $10^{-4}$. El peso de las larvas del primer estadio se registró en grupos de 10 individuos; aquellas del tercer y cuarto estadio fueron pesadas individualmente. 
Bioensayos de interacción IGP con diferentes densidades de presas

Para la realización de este bioensayo se realizaron tratamientos con diferentes condiciones de presa: alta y baja densidad de presas. Para cada uno de los tratamientos, se realizaron 20 réplicas (Tabla 6.2).

Tabla 6.2. Tratamientos en condición de IGP y condición de depredador individual con diferentes densidades de presas. $\mathrm{HA}=H$. axyridis. $\mathrm{EC}=E$. connexa .

\begin{tabular}{l}
\hline Condición de IGP \\
HA y EC alta densidad de presas \\
HA y EC baja densidad de presas \\
\hline Condición de depredador individual \\
HA alta densidad de presas \\
HA baja densidad de presas \\
EC alta densidad de presas \\
EC baja densidad de presas \\
\hline
\end{tabular}

Los bioensayos fueron iniciados con individuos del primer estadio larval, de $<24 \mathrm{~h}$ de edad, mantenidos en ayuno desde su emergencia hasta su uso en los bioensayos. En los tratamientos con condición de alta densidad de presas, la cantidad de pulgones ofrecidos para el primer, segundo, tercer y cuarto estadio larval fue de 30, 60, 90 y 120 áfidos por larva, por día, respectivamente. En los tratamientos con condición de baja densidad de presas, la cantidad de pulgones ofrecidos para el primer, segundo, tercer y cuarto estadio larval fue de 10, 20, 30 y 40 áfidos, por larva, por día, respectivamente. La cantidad de presas mencionadas corresponden a la condición de depredador individual. En la condición de IGP siempre que ambas larvas se encontrasen vivas la cantidad de presas ofrecida por arena fue el doble. A su vez, esta elección se basó en estudios preliminares del requerimiento nutricional de larvas de ambos coccinélidos. La densidad de presas baja correspondió al número mínimo de áfidos necesarios para completar el ciclo de vida. La alta densidad de presas correspondió al triple de esta cantidad. 
Diariamente, cada arena fue controlada para registrar la supervivencia de los individuos y suministrar el alimento. Las pupas fueron pesadas con el fin de registrar la diferencia de tamaño entre ambas especies, en las dos condiciones de densidad de presas. Además, se calculó para cada especie de coccinélido la variación de peso de las pupas entre la condición de IGP y la condición de depredador individual. Se obtuvieron valores por separado para ambas condiciones de presas ensayadas (alta y baja de densidad de presas). Se calculó la variación de peso para cada individuo (VPi) de la siguiente manera:

$$
V P i=(X i p I G P-\bar{X} p D I) \div \bar{X} p D I \times 100
$$

Donde, XipIGP es el peso de un individuo en condiciones de IGP y $\bar{X} p D I$ es la media del peso pupal de los individuos de la misma especie en condiciones de depredador individual. Luego se calculó el valor medio (VPm) para cada tratamiento.

$$
V P m=\sum V P i / n
$$

Donde, $V P i$ es la variación de peso individual y $n$ es la cantidad de tratamientos en condiciones de IGP.

\section{Bioensayos de interacción IGP con presas contaminadas con insecticidas}

Para los bioensayos se utilizaron individuos del primer estadio larval, de $<24 \mathrm{~h}$ de edad. Las larvas fueron alimentadas, durante 48 h, con pulgón ad libitum contaminado con insecticidas. El primer día del experimento se les ofreció presas contaminadas ese mismo día y, el segundo día del experimento, presas con residuos de insecticidas de $24 \mathrm{~h}$. Se evaluaron las máximas concentraciones recomendadas a campo (MCRC) de los insecticidas: azadiractina (48 mg i.a./L), piriproxifén (75 mg i.a./L), acetamiprid (200 mg i.a./L) y cipermetrina (25 mg i.a./L) (CASAFE 2013-2015). Para cada uno de los tratamientos se realizaron 20 réplicas. 
Los áfidos fueron tratados por aspersión, utilizando soluciones de insecticidas con agua destilada. Para ello, se seleccionaron plantines de trigo infestados con pulgones y los mismos fueron rociados con la solución de insecticida durante $10 \mathrm{~s}$, hasta alcanzar el punto de goteo. Se dejó secar a los plantines, bajo campana, durante 15 min y luego los áfidos fueron suministrados como alimento. Los controles estuvieron representados por soluciones de agua destilada.

La cantidad de pulgones ofrecidos para el primer, segundo, tercer y cuarto estadio larval fue 30, 60, 90 y 120 áfidos por larva, por día, respectivamente. Esta cantidad correspondió a la mayor densidad de presas ofrecida en los bioensayos de interacción IGP con diferente densidad de presa.

Diariamente cada arena fue controlada para registrar la supervivencia de los individuos y suministrar el alimento. En el caso de encontrarse un individuo muerto, la cantidad de presas ofrecida se ajustó a la condición de depredador individual $(30,60,90$ y 120 áfidos por larva, por día).

\section{Análisis estadístico}

Los resultados de los diferentes bioensayos fueron comparados y analizados utilizando diferentes métodos estadísticos. Para todos los casos se utilizó el programa estadístico XLSTAT.exe 2014. El nivel de significancia elegido fue $\alpha=0,05$.

En los bioensayos de interacción IGP en ausencia de presa, el nivel de IGP y el índice de simetría de IGP entre los diferentes tratamientos fueron evaluados a través del análisis de tabla de contingencia, usando el test exacto de Fisher's (FE).

Para el análisis de supervivencia de los bioensayos de interacción IGP con diferente densidad de presas y presas contaminadas con insecticidas, se utilizó el estimador Kaplan Meier. Las curvas de proporción de individuos sobrevivientes fueron comparadas a través del test Log Rank, con el análisis $\chi^{2}$. Aquellos individuos que alcanzaron el estado adulto fueron tratados como datos censurados. 
En los bioensayos en ausencia de presas se comparó el peso de larvas de las diferentes especies para cada tratamiento. En los bioensayos con diferentes densidades de presas se comparó el peso de pupas de cada especie a alta y baja densidad de presas, se realizaron diferentes análisis para la condición de depredador individual y condición de IGP. Además, se comparó para cada especie la variación de peso medio (VPm) en condiciones de alta y baja densidad de presas. Para estos análisis se utilizó el test $t$ de Student para muestras apareadas cuando se contó con datos paramétricos y el test de Wilcoxon para datos no paramétricos. Para comprobar la normalidad de los datos y la homocedasticidad de las varianzas, los mismos fueron sometidos al test de Shapiro-Wilk y de Levene, respectivamente. Si alguna de los supuestos no se alcanzaron, los datos fueron transformados $a, y=\log (x+1)$. Los datos transformados fueron sometidos nuevamente a la comprobación de los supuestos de normalidad y homocedasticidad.

\section{Resultados}

Bioensayos de interacción IGP en ausencia de presa

\section{Supervivencia}

En la condición de depredador individual, los ejemplares de ambas especies de coccinélidos se encontraron vivos a las 24 h. Por lo tanto, en los tratamientos de condición IGP aquellos individuos encontrados muertos fueron considerados implicados en la interacción IGP.

Los valores del nivel de IGP demuestran que la proporción de réplicas en las que ocurrió interacción intragremio entre $H$. axyridis y $E$. connexa varió significativamente entre los distintos tratamientos $(F E=25,27 ; g . l .=4 ; P<0,001)$. El valor más alto fue igual a 1 y se obtuvo en los tratamientos 1,2 y 3 , es decir, cuando ambas especies estuvieron representadas por larvas del primer y tercer estadio y en el tratamiento que se combinaron larvas del tercer y cuarto estadio de $E$. connexa y $H$. axyridis, respectivamente. En el tratamiento 5, que involucró a larvas del cuarto estadio de ambas 
especies, el nivel de IGP fue de 0,95. Por último, este valor fue de 0,65 en el tratamiento 4, cuando se dispusieron larvas del tercer y del cuarto estadio de $H$. axyridis y $E$. connexa, respectivamente (tabla 6.3).

Los valores del índice de simetría de IGP indican que la proporción de réplicas en las que $H$. axyridis actuó como depredador IG, varió entre los tratamientos ( $F E=44,35 ;$ g.I.=4; $P<0,001)$. En los tratamientos 2,3 y 5, este índice indicó valores entre 0,95 y 1, a favor de la especie exótica. En todos los casos en los que $H$. axyridis actuó como depredador IG se encontraron a los ejemplares de $E$. connexa atacados y parcial o totalmente consumidos, observándose restos de patas, mandíbulas, tórax y abdomen. En el tratamiento 2 se registró un caso en el que $H$. axyridis actuó como presa IG, se encontró a ese individuo parcialmente consumido.

Cuando las larvas del primer estadio de ambas especies fueron ensayadas, se obtuvo un valor de índice de simetría de 0,60. En este tratamiento, solo en el $25 \%$ de los casos en los que $H$. axyridis actuó como depredador de IG se encontraron patas, mandíbulas y restos de organismos del depredador nativo; en el $75 \%$ de los casos restantes no pudieron observarse signos de ataque sobre E. connexa. En los casos en los que E. connexa actuó como depredador IG se observaron signos de ataque y consumo en el $37,35 \%$ de los individuos de $H$. axyridis.

Cuando se colocaron larvas del tercer estadio de $H$. axyridis y cuarto estadio de $E$. connexa, el valor del índice de simetría fue de 0,46. Esto si bien refleja una condición de IGP, a favor del coccinélido nativo, el valor fue muy cercano a 0,5 . Cuando $H$. axyridis actuó como depredador IG, el 50\% de los individuos de $E$. connexa presentaron signos de ataque; cuando el depredador exótico actuó como presa IG el 25,57\% de los individuos de esta especie se encontraron atacados y parcialmente consumidos (tabla 6.3). 
Tabla 6.3. Depredación intragremio (IGP) entre diferentes estadios larvales de Harmonia axyridis y Eriopis connexa. Nivel e índice de simetría de IGP. HA = H. axyridis. EC = E. connexa. L1, L3, L4 = primer, tercer, cuarto estadio larval.

\begin{tabular}{lccccc} 
& \multicolumn{5}{c}{ Tratamientos } \\
\cline { 2 - 6 } & $\mathbf{1}$ & $\mathbf{2}$ & $\mathbf{3}$ & $\mathbf{4}$ & $\mathbf{5}$ \\
\hline & HA L1 & HA L3 & HA L4 & HA L3 & HA L4 \\
& EC L1 & EC L3 & EC L3 & EC L4 & EC L4 \\
\hline HA actuó como depredador IG & 12 & 19 & 20 & 6 & 19 \\
HA actuó como presa IG & 8 & 1 & 0 & 7 & 0 \\
Nivel de IGP & 1 & 1 & 1 & 0,65 & 0,95 \\
Índice de simetría de IGP & 0,6 & 0,95 & 1 & 0,46 & 1 \\
\hline
\end{tabular}

Peso de larvas

H. axyridis presenta un mayor tamaño corporal con respecto a E. connexa. Esto es vio reflejado en los tratamientos 1,2 y 5 en los que ambas especies de coccinélidos estuvieron representadas por larvas del mismo estadio. En el tratamiento 3, la diferencia de peso a favor del depredador exótico fue muy notoria y solo en el tratamiento 4 , se registró un mayor peso en las larvas del cuarto estadio de $E$. connexa, con respecto a las larvas del tercer estadio de $H$. axyridis (tabla 6.4).

Tabla 6.4. Peso de larvas (mg) de Harmonia axyridis y Eriopis connexa. Los valores indican media ( $\pm \mathrm{ES}$ ). $\mathrm{HA}=H$. axyridis. $\mathrm{EC}=E$. connexa. $\mathrm{L} 1, \mathrm{~L} 3, \mathrm{~L} 4=$ primer, tercer, cuarto estadio larval, respectivamente.

\begin{tabular}{|c|c|c|c|c|}
\hline & & Peso de larvas & Estadístico & $P$ \\
\hline \multirow{2}{*}{1} & HA L1* & $2,96( \pm 0,11)$ & \multirow{2}{*}{$t=5,07$} & \multirow{2}{*}{$<0,001$} \\
\hline & EC L1* & $2,26( \pm 0,05)$ & & \\
\hline \multirow{2}{*}{2} & HA L3 & $2,99( \pm 0,12)$ & \multirow{2}{*}{$W=210$} & \multirow{2}{*}{$<0,001$} \\
\hline & EC L3 & $1,39( \pm 0,03)$ & & \\
\hline \multirow{2}{*}{3} & HA L4 & $23,4( \pm 5,93)$ & \multirow{2}{*}{$W=210$} & \multirow{2}{*}{$<0,001$} \\
\hline & EC L3 & $1,72( \pm 0,09)$ & & \\
\hline \multirow{2}{*}{4} & HA L3 & $4,13( \pm 0,93)$ & \multirow{2}{*}{$W=3$} & \multirow{2}{*}{$<0,001$} \\
\hline & EC L4 & $6,64( \pm 0,18)$ & & \\
\hline \multirow{2}{*}{5} & HA L4 & $26,97( \pm 6,25)$ & \multirow{2}{*}{$W=210$} & \multirow{2}{*}{$<0,001$} \\
\hline & EC L4 & $7,26( \pm 0,27)$ & & \\
\hline
\end{tabular}


Bioensayos de interacción IGP con diferente densidad de presas

\section{Supervivencia}

En la condición de depredador individual, los diferentes tratamientos mostraron diferencias significativas de supervivencia. Aquellos tratamientos que mostraron diferencias entre sí, fueron $H$. axyridis en condiciones de alta densidad de presas y $E$. connexa en condiciones de baja densidad de presas (Tabla 6.5 y Figura 6.1)

La supervivencia registrada para $H$. axyridis fue del $100 \%$ y $85 \%$ en condiciones de alta y baja densidad de presas, respectivamente. A baja densidad de presas el descenso de la curva se produjo los días 5 y 6 del ensayo, que correspondió a la mortalidad de individuos del segundo estadio larval. El día 19, se produjo una disminución adicional, ocasionado por la muerte de un individuo del cuarto estadio larval (Figura 6.1).

Eriopis connexa presentó un $85 \%$ de emergencia adulta en condiciones de alta densidad de presa. El descenso de la supervivencia se observó el día 6 y 9 y correspondió a la muerte de individuos del segundo y tercer estadio larval. En condiciones de baja densidad de presa, el $75 \%$ de los individuos alcanzaron el estado adulto. En este caso, la curva produjo el descenso entre los días 6 y 9 y el día 18 que correspondió a la muerte de individuos del segundo, tercer y cuarto estadio larval.

Cuando ambas especies fueron ensayadas en condiciones de IGP, la supervivencia registrada entre los tratamientos fue significativamente diferente (Tabla 6.5 y Figura 6.1).

H. axyridis a alta y baja densidad de presas mostró una supervivencia del $85 \%$ y $80 \%$, respectivamente. Estos tratamientos, si bien no difirieron significativamente entre sí, lo hicieron con los tratamientos de E. connexa a ambas densidades de presas. El descenso en la curva de supervivencia de $H$. axyridis en la condición de alta densidad de presas se produjo entre los días 5 y 9, registrándose la mortalidad de individuos del primer y segundo estadio larval. En la condición de baja densidad de presa, entre los días 8 y 15, se produjo el descenso de la curva, observándose la mortalidad de individuos del segundo al cuarto estadio larval. 
Eriopis connexa mostró una reducción marcada de la supervivencia a ambas densidades de presas. Estos tratamientos no mostraron diferencias significativas entre sí. La supervivencia fue del $35 \%$ en el tratamiento con alta densidad de presas. Entre los días 6 y 14 se registró la muerte de individuos del primer al cuarto estadio larval. En el tratamiento con baja densidad de presa, la supervivencia de $E$. connexa fue del $10 \%$. Entre los días 5 y 12 se produjo de la muerte de individuos de todos los estadios larvales.

Los valores de reducción de supervivencia de E. connexa en condición de IGP respecto a la condición de depredador individual indican que esta especie fue la más afectada por dicha interacción. A alta densidad de presa se encontró que el $70 \%$ de los individuos de $E$. connexa que se encontraron muertos fueron consumidos, encontrándose patas, mandíbulas y restos cuticulares; en el $30 \%$ restante no se observaron signos de ataque. A baja densidad de presa el total de los individuos del depredador nativo afectados fueron encontrados parcial o totalmente consumidos.

Tabla 6.5. Comparación de a pares de diferentes curvas de supervivencia de Harmonia axyridis y Eriopis connexa expuestas a diferentes densidades de presas Kaplan Meier, $\chi^{2}$. Test Log Rank $(P<$ $0,05) .{ }^{*}$ Indica diferencias significativas entre tratamientos. ADP $=$ alta de densidad de presa. BDP $=$ baja densidad de presa. A: condición de depredador individual; B: condición de IGP.

\begin{tabular}{lccc}
\hline A & $\boldsymbol{\chi}^{\mathbf{2}}$ & g.l. & $\boldsymbol{P}$ \\
\hline Comparación global * & 6,84 & 3 & 0,04 \\
H. axyridis (ADP) - H. axyridis (BDP) & 3,16 & 1 & 0,08 \\
H. axyridis (ADP) - E. connexa (ADP) & 3,16 & 1 & 0,08 \\
H. axyridis (ADP) - E. connexa (BDP) * & 7,04 & 1 & 0,04 \\
H. axyridis (BDP) - E. connexa (ADP) & 0,16 & 1 & 0,68 \\
H. axyridis (BDP) - E. connexa (BDP) & 1,24 & 1 & 0,26 \\
E. connxa (ADP) - E. connexa (BDP) & 4,1 & 1 & 0,08 \\
\hline B & $\boldsymbol{x}^{\mathbf{2}}$ & $\mathbf{g . l}$ & $\boldsymbol{P}$ \\
\hline Comparación global * & 33,94 & 3 & $<0,001$ \\
H. axyridis (ADP) - H. axyridis (BDP) & 0,09 & 1 & 0,75 \\
H. axyridis (ADP) - E. connexa (ADP) * & 8,95 & 1 & 0,03 \\
H. axyridis (ADP) - E. connexa (BDP) * & 19,01 & 1 & $<0,001$ \\
H. axyridis (BDP) - E. connexa (ADP) * & 9,02 & 1 & 0,01 \\
H. axyridis (BDP) - E. connexa (BDP) * & 21,04 & 1 & $<0,001$ \\
E. connxa (ADP) - E. connexa (BDP) & 3,59 & 1 & 0,60 \\
\hline
\end{tabular}



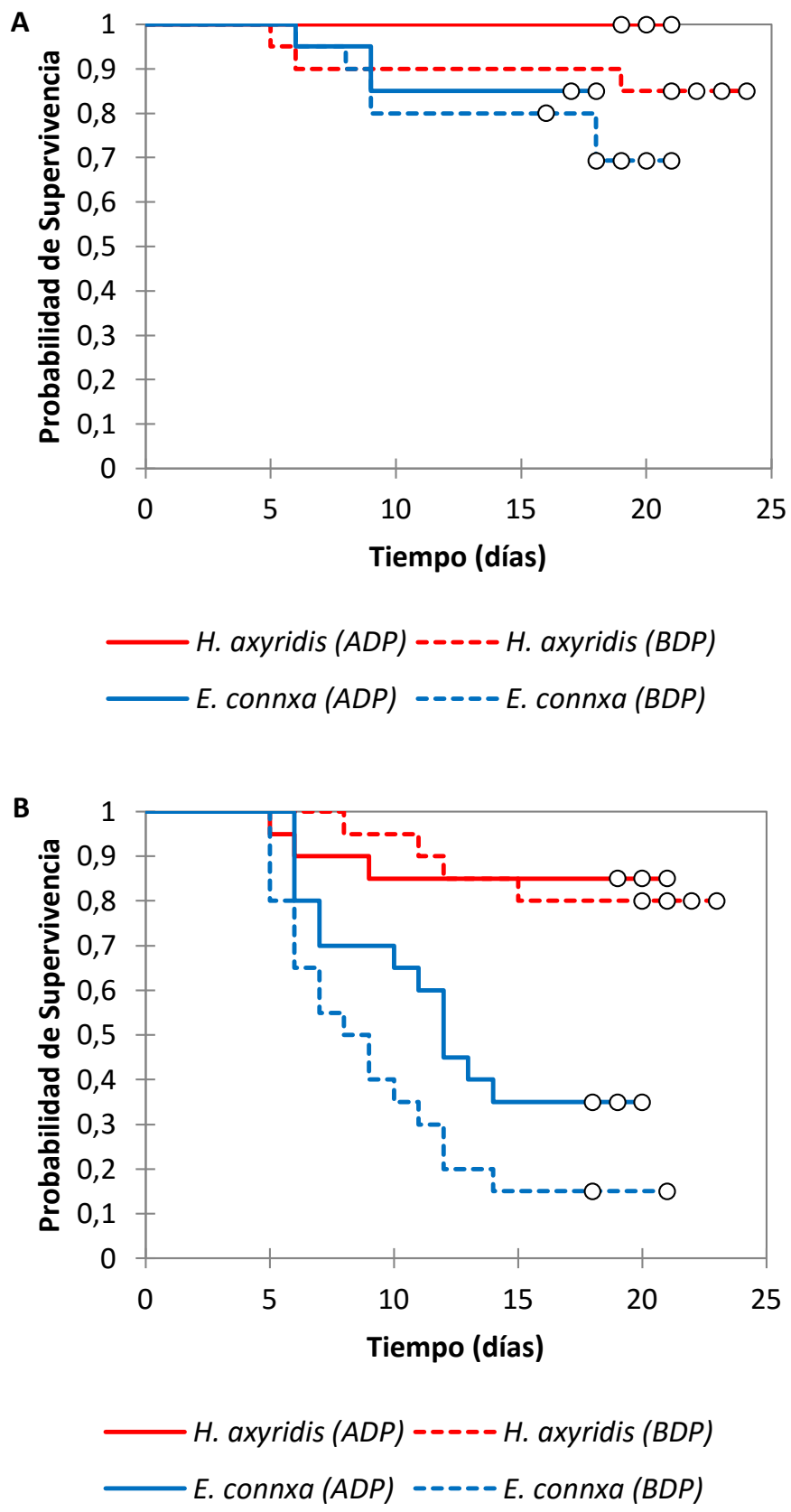

Figura 6.1. Supervivencia de Harmonia axyridis y Eriopis connexa expuestas a diferentes densidades de presas. Kaplan Meier, $\chi^{2}$. Test Log Rank $(P<0,05) . \quad A D P=$ alta de densidad de presa. $\mathrm{BDP}=$ baja densidad de presa. $\mathbf{A}$ : condición de depredador individual. B: condición de IGP. 


\section{Peso de pupas}

El mayor tamaño corporal de $H$. axyridis respecto de $E$. connexa, también, se vio reflejado en el peso de pupas. A su vez, este parámetro se vio afectado por la cantidad de presas ofrecida en los diferentes tratamientos (Figura 6.2).

En la condición de depredador individual, el peso medio de pupas de $H$. axyridis fue mayor cuando se le suministró una alta densidad de presas respecto a condición de densidad de presas baja $(t=2,10 ; P<0,001)$. Lo mismo ocurrió con $E$. connexa, el peso medio de pupas fue mayor en el tratamiento con alta densidad de presas respecto al tratamiento con menor densidad de presas $(t=2,14 ; P<0,001)$ (Figura 6.2).

En la condición de depredador IGP se observó el mismo patrón para $H$. axyridis, el peso medio de pupas fue mayor a alta densidad de presas que a baja densidad de presas $(W=0 ; P<0,001)$, mientras que para $E$. connexa el peso medio de pupas fue similar para los tratamientos de ambas densidades de presas ofrecidas $(t=4,30 ; P=0,92$ ) (Figura 6.2).

En los tratamientos a alta densidad de presas, $H$. axyridis presentó un aumento de variación de peso respecto a la condición de baja densidad de presas $(t=2,10 ; P=0,02)$. En cambio, E. connexa mostró una reducción de la variación del peso medio de pupa en los tratamientos con alta densidad de presas en comparación con la condición de baja densidad de presas $(t=3,72 ; P<0,001)$ (Figura 6.3). 

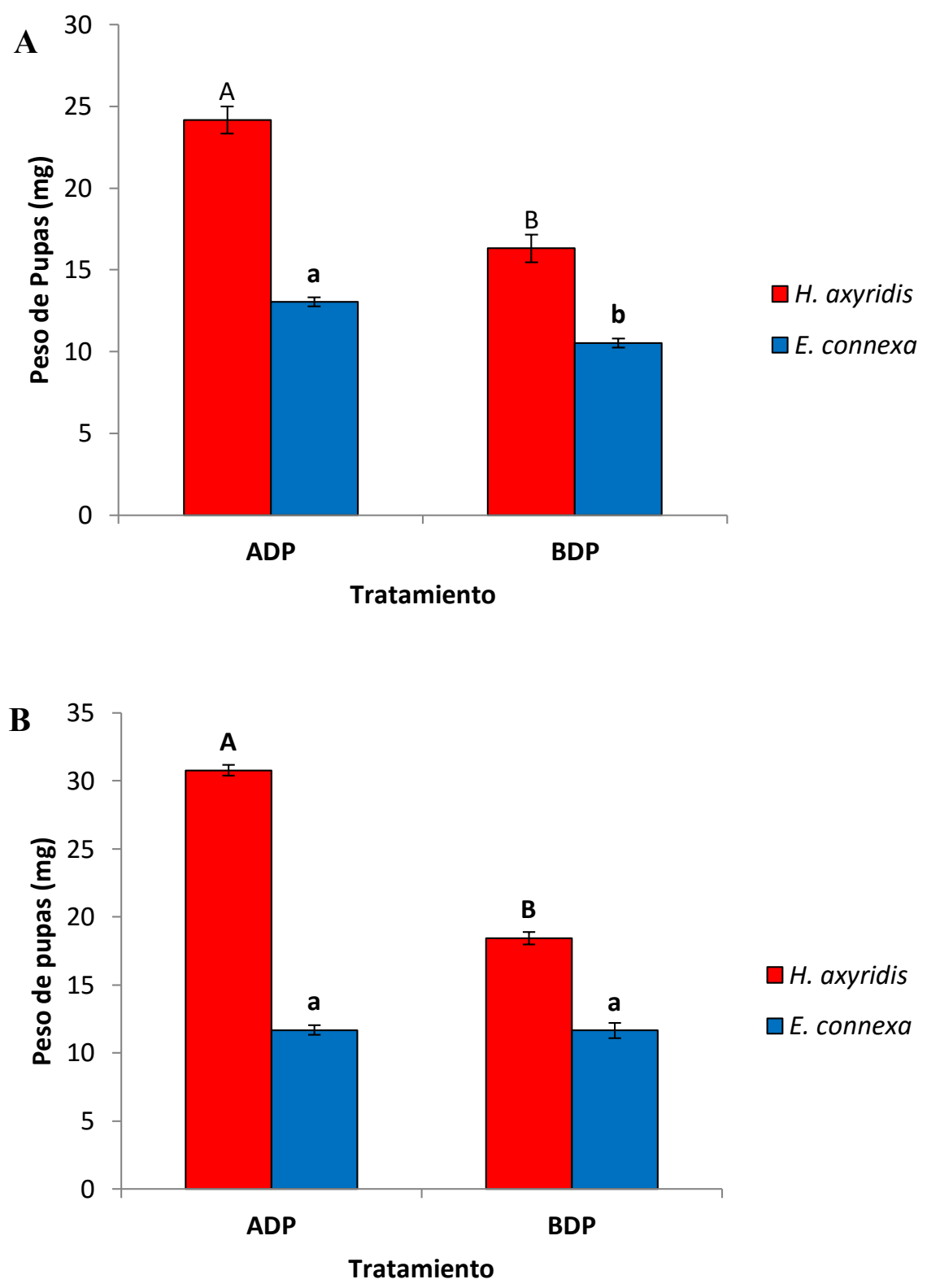

Figura 6.2. Peso de pupas de Harmonia axyridis y Eriopis connexa expuestas a diferentes densidades de presas. Las barras muestran media ( $\pm \mathrm{ES}$ ). Diferentes letras indican diferencias significativas. $\mathrm{ADP}=$ alta de densidad de presa. $\mathrm{BDP}=$ baja densidad de presa. A: condición de depredador individual; B: condición de IGP. 


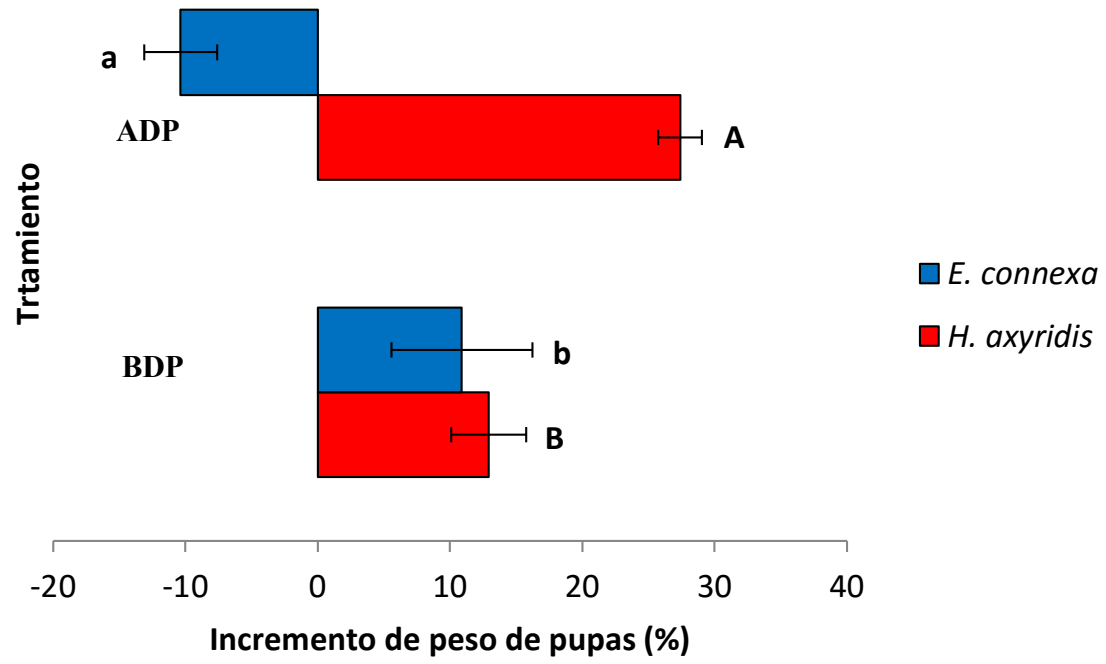

Figura 6.3. Variación de peso (VPm) de pupas de Harmonia axyridis y Eriopis connexa entre la condición de IGP y la condición de depredador individual. Las barras muestran media ( $\pm E S)$. Diferentes letras indican diferencias significativas. $A D P=$ alta de densidad de presa. $\mathrm{BDP}=$ baja densidad de presa.

Bioensayos de interacción IGP con presas contaminada con insecticidas

\section{Supervivencia}

En los tratamientos en los que se les ofreció a los coccinélidos presas tratadas con acetamiprid y cipermetrina, se registró un $100 \%$ de mortalidad de los individuos durante las primeras 24 horas, tanto en la condición de depredador individual como en la condición de IGP. Por este motivo, estos tratamientos no fueron incluidos en el análisis de supervivencia.

En la condición de depredador individual, la supervivencia registrada para el tratamiento control de $H$. axyridis y $E$. connexa fue de $100 \%$ y $93,30 \%$, respectivamente. Cuando los coccinélidos fueron expuestos a presas tratadas con azadiractina, presentaron en ambos casos un valor de supervivencia del $56,70 \%$. Los tratamientos de cada especie variaron significativamente con respecto a su control. En los tratamientos con piriproxifén, 
ambas especies de coccinélidos obtuvieron valores similares de supervivencia: 73,30\% para $H$. axyridis y $83,30 \%$ para E. connexa. El piriproxifén no afectó significativamente la supervivencia depredador nativo, sin embargo los valores obtenidos para el depredador exótico se vieron influenciados significativamente por este insecticida (Tabla 6.6 y Figura 6.4)

En condiciones de IGP $H$. axyridis obtuvo un valor de supervivencia del $86,70 \%$ y $E$. connexa de $43,30 \%$ en los tratamientos control. La marcada reducción en la supervivencia del depredador nativo con respecto a la condición de depredador individual se vio reflejada en la proporción de individuos afectados por la interacción IGP. El 80\% de los individuos de $E$. connexa que se encontraron muertos se encontraron parcialmente consumidos.

En los tratamientos con azadiractina se registró un valor del $76,70 \%$ de supervivencia para $H$. axyridis y un $100 \%$ de mortalidad en los individuos de $E$. connexa. En este caso se observó que solo el $20 \%$ de los ejemplares del depredador nativo fueron parcialmente consumidos; de los restantes la mayoría de ellos no presentaron signos de ataque.

Con el insecticida piriproxifén, $H$. axyridis obtuvo un valor de supervivencia del $70 \%$, que no difirió con respecto al control. El valor para E. connexa fue del 16,70\%, significativamente diferente al control. De los individuos del depredador nativo encontrados muertos el $50 \%$ se encontraron atacados (Tabla 6.6 y Figura 6.4). 
Tabla 6.6. Comparación de a pares de diferentes curvas de supervivencia de Harmonia axyridis y Eriopis connexa expuestas a presas tratadas con azadiractina (48 mg i.a. /L) y piriproxifén (75 mg i.a./L). Kaplan Meier, $\chi^{2}$. Test Log Rank $(P<0,05) .{ }^{*}$ Indica diferencias significativas. A: condición de depredador individual; B: condición de IGP.

\begin{tabular}{lccc} 
A & \multicolumn{3}{c}{} \\
\hline & $\boldsymbol{\chi}^{\mathbf{2}}$ & $\boldsymbol{g . l}$ & $\boldsymbol{P}$ \\
\hline Comparación global * & 28,11 & 5 & $<0,001$ \\
H. axyridis control - E. connexa control & 2,03 & 1 & 0,15 \\
H. axyridis control - H. axyridis azadiractina * & 16,55 & 1 & $<0,001$ \\
H. axyridis control - H. axyridis piriproxifén * & 9,1 & 1 & 0,003 \\
H. axyridis azadiractina - H. axyridis piriproxifén & 1,53 & 1 & 0,200 \\
H. axyridis control - E. connexa azadiractina * & 16,54 & 1 & $<0,001$ \\
H. axyridis control - E. connexa piriproxifén * & 5,37 & 1 & 0,02 \\
H. axyridis azadiractina - E. connexa control * & 10,51 & 1 & 0,01 \\
H. axyridis azadiractina - E. connexa azadiractina & 0,002 & 1 & 0,968 \\
H. axyridis azadiractina - E. connexa piriproxifén * & 4,68 & 1 & 0,03 \\
H. axyridis piriproxifén - E. connexa control * & 4,32 & 1 & 0,03 \\
H. axyridis piriproxifén - E. connexa azadiractina * & 1,61 & 1 & 0,20 \\
H. axyridis piriproxifén - E. connexa piriproxifén & 0,86 & 1 & 0,35 \\
E. connexa control - E. connexa azadiractina * & 10,58 & 1 & 0,002 \\
E. connexa control - E. connexa piriproxifén & 1,46 & 1 & 0,22 \\
E. connexa azadiractina - E. connexa piriproxifén * & 4,78 & 1 & 0,029 \\
\hline
\end{tabular}

B

\begin{tabular}{|c|c|c|c|}
\hline & $x^{2}$ & g.l. & $\boldsymbol{P}$ \\
\hline Comparación global * & 93,86 & 5 & $<0,001$ \\
\hline H. axyridis control - E. connexa control * & 11,42 & 1 & 0,001 \\
\hline H. axyridis control - H. axyridis azadiractina & 0,98 & 1 & 0,32 \\
\hline H. axyridis control - H. axyridis piriproxifén * & 2,33 & 1 & 0,12 \\
\hline$H$. axyridis azadiractina - $H$. axyridis piriproxifén & 0,31 & 1 & 0,57 \\
\hline H. axyridis control - E. connexa azadiractina * & 49,99 & 1 & $<0,001$ \\
\hline H. axyridis control - E. connexa piriproxifén * & 30,45 & 1 & $<0,001$ \\
\hline H. axyridis azadiractina - E. connexa control * & 5,80 & 1 & 0,016 \\
\hline H. axyridis azadiractina - E. connexa azadiractina * & 41,32 & 1 & $<0,001$ \\
\hline H. axyridis azadiractina - E. connexa piriproxifén * & 22,64 & 1 & $<0,001$ \\
\hline H. axyridis piriproxifén - E. connexa control & 3,22 & 1 & 0,07 \\
\hline H. axyridis piriproxifén - E. connexa azadiractina * & 38,30 & 1 & $<0,001$ \\
\hline H. axyridis piriproxifén - E. connexa piriproxifén * & 18,95 & 1 & $<0,001$ \\
\hline E. connexa control - E. connexa azadiractina * & 38,30 & 1 & $<0,001$ \\
\hline E. connexa control - E. connexa piriproxifén * & 9,92 & 1 & 0,002 \\
\hline E. connexa azadiractina - E. connexa piriproxifén * & 5,91 & 1 & 0,01 \\
\hline
\end{tabular}




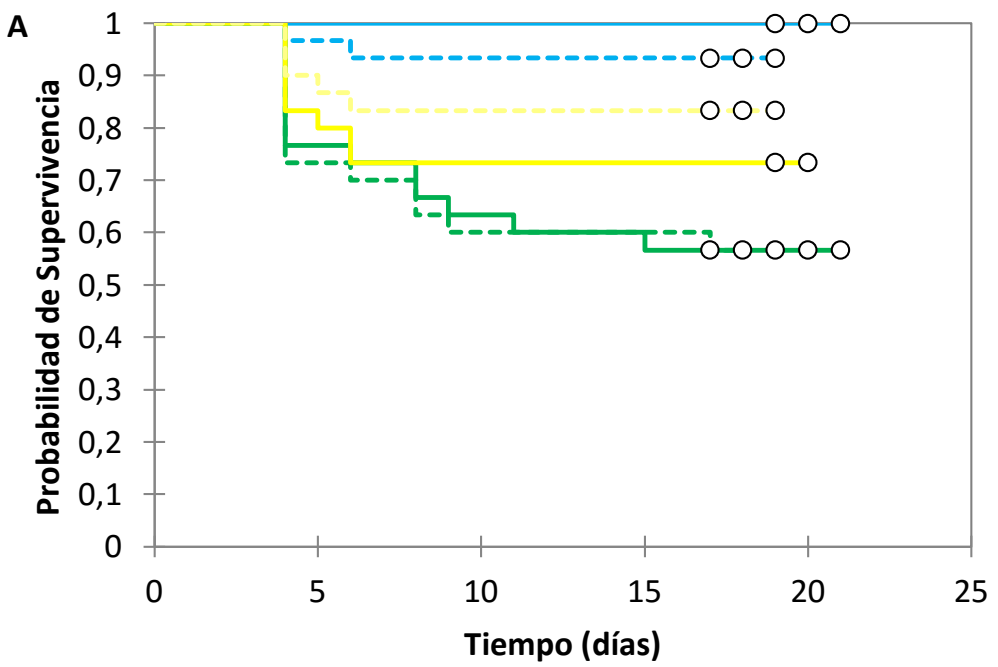
H. axyridis control
-----E. connexa control
H. axyridis azadiractina
E. connexa azadiractina
H. axyridis piriproxifén
E. connexa piriproxifén

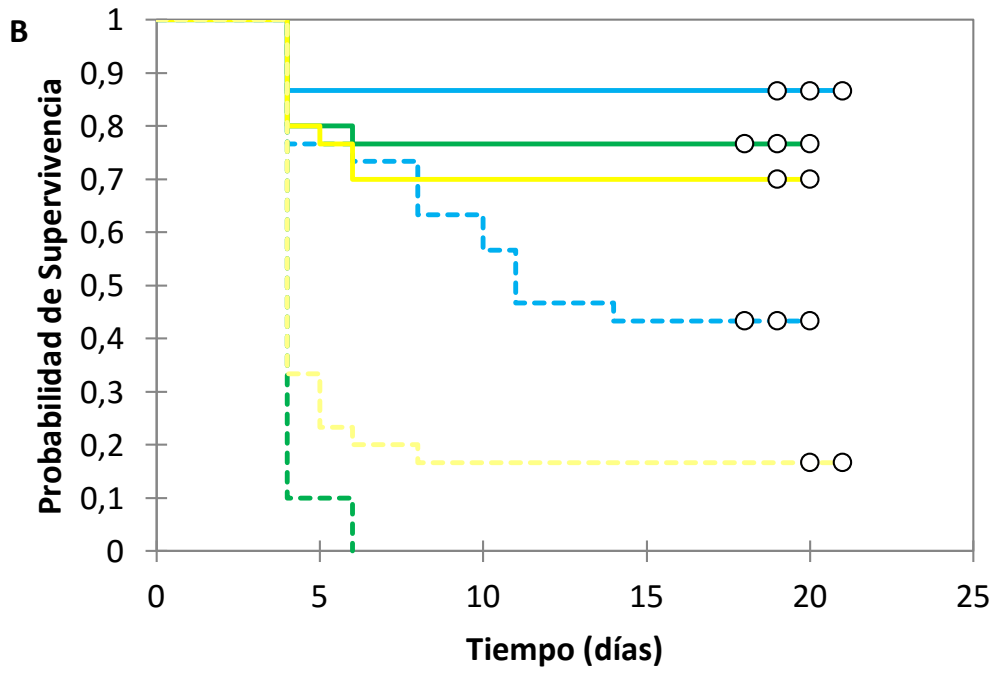
H. axyridis control
-----E. connexa control
H. axyridis azadiractina
E. connexa azadiractina
H. axyridis piriproxifén
E. connexa piriproxifen

Figura 6.4. Supervivencia de Harmonia axyridis y Eriopis connexa expuestas a presas tratadas con azadiractina (48 $\mathrm{mg}$ i.a./L) y piriproxifén (75 mg i.a./L). Kaplan Meier, $\chi^{2}$. Test Log Rank $(P<0,05)$. A: condición de depredador individual; B: condición de IGP. 


\section{Discusión}

En este trabajo ha quedado demostrado la ocurrencia de la depredación intragremio entre $H$. axyridis y $E$. connexa en condiciones de laboratorio. El mayor tamaño de la especie exótica con respecto a la nativa representaría uno de los factores claves que intervino en la magnitud y dirección de la interacción IGP, a favor de la primera. En los bioensayos en ausencia de presa, $H$. axyridis actuó preferentemente como depredador IG, excepto en el tratamiento en el que la especie exótica y nativa estuvieron representadas por larvas del tercer y cuarto estadio, respectivamente. Este fue el único caso en el que las larvas de $E$. connexa presentaron un mayor peso, que se tradujo en un mayor tamaño corporal. La menor diferencia de peso, entre las larvas de ambas especies, se registró en el tratamiento en el que se ensayaron larvas del primer estadio; para este caso el valor del índice de simetría fue cercano al valor medio.

Numerosos estudios destacan el mayor tamaño de $H$. axyridis frente a coccinélidos nativos y sus consecuencias sobre las interacciones IGP (Cottrell \& Yeargan 1998; Yasuda et al. 2001; Michaud 2002). Esta especie, además, se caracteriza por presentar una alta voracidad, comportamientos agresivos y espinas cuticulares que le servirían de defensa ante el ataque de un depredador IG (Katsanis et al. 2012). Yasuda et al. 2004 realizaron estudios de laboratorio evaluando la interacción IGP entre diferentes especies de coccinélidos presentes en Norteamérica. Dos especies introducidas, H. axyridis y Coccinella septempunctata, y dos especies nativas de la región, Coccinella transversoguttata e Hippodamia convergens. En general, la magnitud de la interacción IGP fue más acentuada entre larvas de estadios avanzados y entre estadios larvales de diferente edad. Además, $H$. axyridis presentó comportamientos más agresivos y causó un mayor impacto con respecto a $C$. septempunctata sobre los coccinélidos nativos.

En los bioensayos en los que se evaluó la interacción IGP con diferente densidad de presas, $H$. axyridis actuó como depredador IG en ambas condiciones. Sin embargo la magnitud de la interacción se vio acentuada en condiciones de baja densidad de presas. Este resultado se condice con lo encontrado por Lucas et al. (1998), Yasuda et al. (2004) y 
Nóia et al. (2008), quienes observaron que la densidad de presa EG afecta la ocurrencia, dirección y magnitud de las interacciones IGP.

En la condición de depredador individual, la densidad de presas ocasionó una variación en la supervivencia de los individuos de ambas especies de coccinélidos, registrándose valores menores cuando se ofreció una baja densidad. Sin embargo, los únicos tratamientos que variaron significativamente entre sí fueron $H$. axyridis a alta densidad de presas y $E$. connexa a baja densidad de presa. Esto posiblemente se debe a que $\mathrm{H}$. axyridis, respecto a E. connexa, presenta una mayor plasticidad con respecto al requerimiento de alimento para completar su ciclo de vida.

En condiciones de interacción IGP, tanto la densidad de presas como la interacción entre especies, afectaron la supervivencia de los coccinélidos. Si bien, $H$. axyridis presentó valores menores de supervivencia con respecto a la condición de depredador individual, se observó una reducción mayor de la supervivencia de los individuos de $E$. connexa. Esto indica que la supervivencia del coccinélido nativo se vio afectada por la presencia de $H$. axyridis. Estos resultados concuerdan con estudios de laboratorio sobre la interacción IGP entre $H$. axyridis y Coccinella undecimpunctata. Los resultados ubicaron a $H$. axyridis como el depredador IG y se observaron niveles mayores de IGP en condiciones de menores densidad de presas (Nóia et al. 2008). Snyder et al. (2004) no encontraron una relación entre el tamaño corporal y las interacciones IGP entre varias especies de coccinélidos. Este autor sugiere que el éxito de $H$. axyridis se debe a las mayores habilidades para capturar presas IG y escapar de los depredadores IG.

El peso de las pupas de los coccinélidos reflejó la diferencia de tamaño entre ambas especies de coccinélidos. En condiciones de alta densidad de presa, se produjo una diminución en el peso medio de pupas de $E$. connexa y un aumento en pupas de $H$. axyridis. Esto podría explicarse a través de la alta voracidad que presenta el coccinélido exótico, al aumentar la cantidad de presas disponibles, los individuos se habrían alimentado de un mayor número de áfidos. 
En los bioensayos de interacción IGP con presas contaminadas con los diferentes insecticidas, el acetamiprid y la cipermetrina resultaron ser altamente tóxicos. En cambio, si bien los insecticidas azadiractina y piriproxifén causaron reducción de la supervivencia de los coccinélidos, la interacción IGP pudo ser evaluada.

Tanto $E$. connexa como $H$. axyridis presentaron valores menores de supervivencia en la condición de IGP cuando se les ofreció presas no tratadas. Por otro lado, en condiciones de depredador individual el efecto del piriproxifén fue menor, en comparación con la azadiractina, en ambas especies. En condiciones de IGP, ambos insecticidas causaron un aumento en la magnitud de la interacción a favor al depredador exótico.

La diferencia de toxicidad de los insecticidas azadiractina y piriproxifén sobre $H$. axyridis y E. connexa, podría asociarse al efecto fagodisuasivo causado por la azadiractina. Posiblemente, los ejemplares de ambas especies expuestos a este insecticida no se alimentaron de los áfidos ofrecidos, o lo hicieron en menor medida, y esto produjo que se agudice la voracidad de $H$. axyridis, ocasionando una mayor reducción de la supervivencia de E. connexa. Carton et al. (2003) observaron valores de supervivencia cercanos al 50\%, cuando larvas del cuarto estadio de $H$. axyridis fueron alimentadas con presas tratadas con los insecticidas IGRs metoxifenocida y halofenocida (50 y $100 \mathrm{mg}$ i.a./L). En otros estudios, la supervivencia de ninfas del cuarto estadio y adultos del antocórido Orious laevigatus no se vio afectada cuando se le ofreció presas contaminadas con piriproxifén (1000 mg i.a./L). Sin embargo, este parámetro se vio reducido cuando los individuos fueron expuestos al neonicotinoide imidacloprid (Delbeke et al. 1997).

En base a todo lo dicho anteriormente, se acepta la hipótesis y se demuestra que, en condiciones de laboratorio, existe interacción IGP entre $H$. axyridis y $E$. connexa, y dicha interacción favorece al depredador exótico. El tamaño de los coccinélidos y la densidad de presas ofrecidas fueron factores que intervinieron en dicha interacción. Por otro lado, se rechaza la segunda hipótesis. Si bien azadiractina y piriproxifén intervinieron en la interacción IGP en favor de $H$. axyridis, el acetamiprid causó un $100 \%$ de mortalidad en todos los individuos ensayados, no pudiéndose evaluar su influencia sobre dicha interacción. 
Capítulo 7

Conclusiones 
En base a resultados obtenidos en el presente trabajo de tesis doctoral, se desprenden las siguientes conclusiones:

\section{Parámetros biológicos y demográficos de Harmonia axyridis}

Cuando se evaluaron en conjunto la tasa de supervivencia específica por estado y edad (Sxj) y expectativa de vida por estado y edad (exj), el estado de huevo y el primer estadio larval de $H$. axyridis presentaron los mayores valores de reducción de supervivencia.

En los adultos, las hembras de $H$. axyridis presentaron valores menores de longevidad y supervivencia con respecto a los machos.

Harmonia axyridis presenta atributos biológicos y demográficos que le permitirían competir y desplazar al coccinélido nativo E. connexa.

\section{Susceptibilidad de Harmonia axyridis a los insecticidas biorracionales, azadiractina, piriproxifén y acetamiprid, $y$ al insecticida convencional cipermetrina}

Los insecticidas biorracionales, azadiractina y piriproxifén presentaron menor toxicidad hacia $H$. axyridis con respecto a los insecticidas neurotóxicos, acetamiprid y cipermetrina.

La toxicidad de azadiractina y piriproxifén varió según el estado de desarrollo expuesto y la concentración ensayada.

El insecticida botánico azadiractina resultó ser levemente tóxico sobre el estado de huevo. Solo la Máxima Concentración Recomendada a Campo (MCRC) y diluciones del 50\% (24 mg ia./L) afectaron la fertilidad de la progenie de los huevos tratados.

La azadiractina a la MCRC produjo una reducción en la supervivencia de larvas del segundo estadio de $H$. axyridis. A todas las concentraciones evaluadas, los parámetros reproductivos no se vieron afectados.

La azadiractina a la MCRC afectó la supervivencia del cuarto estadio larval. Cuando se emplearon concentraciones menores no se registraron efectos letales significativos, sin embargo al $50 \%$ y $25 \%$ de la MCRC, al se produjo una reducción de los parámetros reproductivos.

La azadiractina afectó la supervivencia de pupas de $H$. axyridis, cuando se evaluó la MCRC. Los parámetros reproductivos se vieron afectados a todas las concentraciones ensayadas.

El insecticida IGR, piriproxifén, resultó ser altamente tóxico sobre huevos y pupas de $H$. axyridis.

El insecticida piriproxifén redujo la supervivencia de larvas del segundo estadio a todas las concentraciones evaluadas, sin embargo no se observaron efectos negativos sobre los parámetros de fecundidad y fertilidad de los organismos sobrevivientes. 
El insecticida piriproxifén resultó inocuo sobre larvas del cuarto estadio.

El insecticida neonicotinoide acetamiprid resultó ser altamente tóxico para los diferentes estados/estadio evaluados de $H$. axyridis a todas las concentraciones ensayadas.

Según los resultados obtenidos se recomienda reconsiderar la categorización del acetamiprid dentro del grupo de los insecticidas biorracionales.

El insecticida convencional cipermetrina presentó una alta toxicidad sobre los diferentes estados/estadios de $H$. axyridis evaluados a las cuatro concentraciones ensayadas.

\section{Evaluación de la depredación intragremio (IGP) entre Harmonia axyridis y Eriopis connexa}

En los bioensayos realizados en ausencia de presa ocurrió depredación intragremio y la dirección se mantuvo en la mayoría de los casos a favor de $H$. axyridis.

Solo cuando las larvas del tercer estadio de $H$. axyridis fueron combinadas con larvas del cuarto estadio de $E$. connexa, el depredador nativo se vio favorecido.

En los bioensayos con diferentes densidad de presas, la supervivencia de $E$. connexa se redujo en presencia de $H$. axyridis. A baja densidad de presas, esta reducción fue mayor.

El peso de larvas y pupas de ambas especies de coccinélidos demuestra que $H$. axyridis presenta un mayor tamaño corporal con respecto a E. connexa. Además, el peso de pupas de ambas especies se vio afectado por la cantidad de presa ofrecida.

$H$. axyridis presenta una variación de peso mayor, entre la condición de IGP y de depredador individual, respecto de E. connexa. Esta diferencia fue más notoria en condiciones de alta densidad de presa. Esto indicaría un mayor consumo de alimento por parte del depredador exótico.

En los bioensayos con presa tratada con insecticidas, en condiciones de depredador individual, azadiractina (48 mg ia./L) y piriproxifén (75 mg ia./L) afectaron la supervivencia de ambas especies. Sin embargo, la toxicidad registrada para la azadiractina fue mayor.

En condiciones de IGP, tanto piriproxifén (75 mg ia./L) como azadiractina (48 mg ia./L) influyeron sobre la magnitud de la interacción, favoreciendo al depredador exótico.

Los insecticidas acetamiprid (200 mg ia./L) y cipermetrina (25 mg ia./L) presentaron una alta toxicidad sobre los individuos de $H$. axyridis y E. connexa. Ambos causaron $100 \%$ de mortalidad sobre las larvas, tanto en la condición de depredador individual como en la condición IGP. 
Referencias 
Abdel Salam A.H. \& Abdel Baky N.F. 2001. Life table and biological studies of Harmonia axyridis Pallas (Col., Coccinellidae) reared on the grain moth eggs of Sitotroga cerealella Olivier (Lep., Gelechiidae). Journal of Applied Entomology. 125: 455-462.

Adriaens T., San Martin G. \& Maes D. 2008. Invasion history, habitat preferences and phenology of the invasive ladybird Harmonia axyridis in Belgium. Biological Control. 53: 69-88.

Ahmad M., Muhammad M.R., Arif M.A. \& Sayyed A.H. 2011. Toxicity of some commonly used insecticides against Coccinella undecimpunctata (Coleoptera: Coccinellidae). Zoological Society Of Pakistan. 43: 1161-1165.

Ahmed Azmi M \& Naqvi S.N.H. 2011. Pesticide pollution, resistance and health hazards. En: Stoytcheva M. (Ed.). The impacts of Pesticides exposure, pp 1-25. Intech.

Ahmed S., Nisar M. S., Shakir M. M., Imran M. \& Iqbal K. 2014. Comparative efficacy of some neonicotinoids and traditional insecticides on sucking insect pests and their natural enemies on BT-121 cotton crop. The Journal of Animal \& Plant Sciences. 24: $660-663$

Alhmedi A., Haubruge E. \& Francis F. 2010. Intraguild interactions implicating invasive species: Harmonia axyridis as a model species. Biotechnology, Agronomy, Society and Environment. 14: 187-201.

Altieri M. \& Nicholls C. I. 2000. Agroecología. Teoría y práctica para una agricultura sustentable, pp 13-44. Programa de las Naciones Unidas para el Medio Ambiente. Red de Formación Ambiental para América Latina y el Caribe.

Alyokhin A. \& Sewell G. 2004. Changes in a lady beetle community following the establishment of three alien species. Biological Invasions. 6: 463-471.

Arias A.H., Buzzi N.S., Pereira M.T. \& Marcovecchio J.E. 2011. Pesticides reaching the environment as a consequence of inappropriate agricultural practices in Argentina. En: Stoytcheva M. (Ed.). Pesticides - formulations, effects, fate, pp 313-332. Intech.

Atlihan R. \& Chi H. 2008. Temperature-dependent development and demography of Scymnus subvillosus (Coleoptera: Coccinellidae) reared on Hyalopterus pruni (Homoptera: Aphididae). Journal of Economic Entomology. 10: 325-333. 
Awasthi N.S., Barkhade U.P., Patil S.R. \& Lande G.K. 2013. Comparative toxicity of some commonly used insecticides to cotton aphid and their safety to predatory coccinellides. The Bioscan. 8: 1007-1010.

Bezzerides A.L., McGraw K.J., Parker R.S. \& Husseini J. 2007. Elytra color as a signal of chemical defense in the Asian ladybird beetle Harmonia axyridis. Behavioral Ecology and Sociobiology. 6: 1401-1408.

Benamú M.A., Schneider M.I., Gozález A. \& Sánchez N.E. 2013. Short and long-term effects of three neurotoxic insecticides on biological and behavioural attributes of the orbweb spider Alpaida veniliae (Araneae, Araneidae): implications for IPM Programs. Ecotoxicology. 22: 1155-64.

Birch L.C. 1948. The intrinsic rate of natural increase in an insect population. Journal of Animal Ecology. 17: 15-26.

Biondi A., Desneux N., Siscaro G. \& Zappalá L. 2012. Using organic-certified rather than synthetic pesticides may not be safer for biological control agents: Selectivity and side effects of 14 pesticides on the predator Orius laevigatus. Chemosphere. 87: 803-812.

Boller E.F., Heidrun V., Ternes P. \& Malavoltai C. 2005. Working document on selectivity of pesticides. IOBCwprs "Commission on IP guidelines" and the IOBCwprs working group on "pesticides and beneficial organisms".

Borges I., Hemptinne J.L. \& Soares A.O. 2013. Contrasting population growth parameters of the aphidophagous Scymnus nubilus and the coccidophagous Nephus reunioni. BioControl. 58: 351-357.

Boily M., Sarrasin B., DeBlois C., Aras P. \& Chagnon M. 2013. Acetylcholinesterase in honey bees (Apis mellifera) exposed to neonicotinoids, atrazine and glyphosate: laboratory and field experiments. Environmental Science and Pollution Research. 20: 56035614.

Bozsik A. 2006. Susceptibility of adult Coccinella septempunctata (Coleoptera: Coccinellidae) to insecticide with different mode of action. Pest Management Science. 62: 651-654. 
Brown P.M.J., Thomas C.E., Lombaert E., Jeffries D.L., Estoup A. \& Handley L.J.L. 2011. The global spread of Harmonia axyridis (Coleoptera: Coccinellidae): distribution, dispersal and routes of invasión. Biological Control. 56: 623-641.

Brown P.M.J., Adriaens T., Bathon H., Cuppen J., Goldarazena A., Hägg T., Kenis M., Klausnitzer B.E.M., Kovár I., Loomans A.J.M., Majerus M.E.N., Nedved O., Pedersen J., Rabitsch W., Roy H.E., Ternois V., Zakharov I.A. \& Roy D.B. 2008. Harmonia axyridis in Europe: spread and distribution of a non-native coccinellid. Biological Control. 53: 5-21.

Bulacio L.G., Giuliani S.L., Panelo M.S. \& Giolito I. 2007. Seguridad en la aplicación de productos fitosanitarios en cultivos hortícolas y frutícolas. Acta Toxicológica Argentina. 15: 1-7.

Castro A.A., Lacerda M.C., Zanuncio T.V., Ramalho F., Polanczyk R.A., Serraõ J.E. \& Zanuncio J.C. 2012. Effect of the insect growth regulator diflubenzuron on the predator Podisus nigrispinus (Heteroptera: Pentatomidae). Ecotoxicology. 21: 96-03.

Carton B., Smagghe G. \& Tirry L. 2003. Toxicity of two ecdysone agonists, halofenozide and methoxyfenozide, against the multicoloured Asian lady beetle Harmonia axyridis (Col., Coccinellidae). Journal of Applied Entomology. 127: 240-242.

CASAFE. 2013-2015. Guía de productos fitosanitarios para la República Argentina. Cámara de Sanidad Agropecuaria y Fertilizantes. Buenos Aires, Argentina.

Casida J.E. \& Durkin K.A. 2013. Neuroactive insecticides: targets, selectivity, resistance, and secondary effects. Annual Review of Entomology. 58: 99-117.

Celestino D., Braoios G.I., Ramos R.S., Gontijo L.M. \& Guedes R.N.C. 2014. Azadirachtinmediated reproductive response of the predatory pirate bug Blaptostethus pallescens. BioControl. 59: 697-705.

Chen T.Y. \& Liu T.X. 2002. Susceptibility of immature stages of Chrysoperla rufilabris (Neurop., Chrysopidae) to pyriproxyfen, a juvenile hormone analog. Journal of Applied Entomology. 126: 125-129. 
CHFB. Censo Hortiflorícola de la provincia de Buenos Aires. 2005. Dirección provincial de Estadística. Dirección general de estadística y programas especiales, Municipalidad de La Plata.

Chi H. 1988. Life-table analysis incorporating both sexes and variable development rates among individuals. Environmental Entomology. 17: 26-34.

Chi H. 2012. TWOSEX-MSChart: Computer Program for Age-stage, Two-Sex Life Table Analysis. http://140.120.197.173/Ecology/prod02.htm

Chi H. \& Liu H. 1985. Two new methods for the study of insect population ecology. Bulletin of the Institute of Zoology Academia Sinica. 24: 225-240.

Chi H. \& Yang T.C. 2003. Two-sex life table and predation rate of Propylaea japónica Thunberg (Coleoptera: Coccinellidae) fed on Myzus persicae (Sulzer) (Homoptera: Aphididae). Environmental Entomology. 32: 327-333.

Chi H. \& Su H.Y. 2006. Age-stage, two-sex life tables of Aphidius gifuensis (Ashmead) (Hymenoptera: Braconidae) and its host Myzus persicae (Sulzer) (Homoptera: Aphididae) with mathematical proof of the relationship between female fecundity and the net reproductive rate. Environmental Entomology. 35: 10-21.

Cock M.J.W., van Lenteren J.C., Brodeur J., Barratt B.I.P., Bigler F., Bolckmans K., Consoli F.L., Haas F., Mason P.G. \& Parra J.R.P. 2010. Do new access and benefit sharing procedures under the convention on biological diversity threaten the future of biological control? Biological Control. 55: 199-218.

Cloyd R.A. 2006. Indirect effects of pesticides on natural enemies. En: Soundararajan R.P. Ed.). Pesticides - Advances in chemical and botanical pesticides, pp 128-150. Intech.

Cloyd R.A \& Bethke J.A. 2010. Impact of neonicotinoid insecticides on natural enemies in greenhouse and interiorscape environments. Pest Managment Science. 67: 3-9.

Cloyd R.A \& Dickinson A. 2006. Effect of insecticides on mealybug destroyer (Coleoptera: Coccinellidae) and parasitoid Leptomastix dactylopii (Hymenoptera: Encyrtidae), natural enemies of citrus mealybug (Homoptera: Pseudococcidae). Biological and Microbial Control. 99: 1596-1604. 
Colombo J.C., Cappelletti N., Barreda A., Migoya M.C. \& Skorupka C.N. 2005. Vertical fluxes and accumulation of PCBs in coastal sediments of the Río de la Plata estuary, Argentina. Chemosphere. 61: 1345-1357.

Colombo J.C., Cappelletti N., Williamson M., Migoya M.C., Speranza E., Sericano J. \& Muir D.C.G. 2011. Risk ranking of multiple-POPs in detritivorous fish from the Río de la Plata. Chemosphere. 83: 882-889.

Colunga Garcia M. \& Gage S.H. 1998. Arrival, establishment, and habitat use of the multicolored Asian lady beetle (Coleoptera: Coccinellidae) in a Michigan landscape. Environmental Entomology 27: 1574-1580.

Cosme L.V., Carvalho G.A. \& Moura A.P. 2007. Efeitos de inseticidas botânico e sintéticos sobre ovos e larvas de Cycloneda sanguinea (Linnaeus) (Coleopotera: Coccinellidae) em laboratório. Arquivos do Instituto Biológico. 74: 251-258.

Cottrell E.T. 2004. Suitability of exotic and native lady beetle eggs (Coleoptera:

Coccinellidae) for development of lady beetle larvae. Biological Control. 31: 362-371.

Cottrell T.E. \& Yeargan K.V. 1998. Intraguild predation between an introduced lady beetle, Harmonia axyridis (Coleoptera: Coccinellidae), and a native lady beetle, Coleomegilla maculata (Coleoptera: Coccinellidae). Journal of the Kansas Entomological Society. 71: 159-163.

de Almeida L.M. \& da Silva V.B. 2002. First record or Harmonia axyridis (Pallas) (Coleoptera: Coccinellidae): a lady beetle native to the Palaearctic region. Revista Brasileira de Zoologia. 19: 941-944.

De Almeida Sarmento R., Gomes de Oliveira H., Holtz A.M., Marques da Silva S., Serrão J.E. \& Pallini Â. 2004. Fat body morphology of Eriopis connexa (Coleoptera, Coccinelidae) in function of two alimentary sources. Brazilian Archives of Biolgy and technology. 47: 07-411.

De Clercq P., Mason, P.G \& Babendreier D. 2011. Benefits and risks of exotic biological control agents. Biological Control. 56: 681-698.

Deevey E.S. 1947. Life Tables for Natural Populations of Animals. The Quarterly Review of Biology 22: 283-314. 
Delbeke E., Vercruyssel L., Tirry P., De Clercq P. \& Degheele D. 1997. Toxicity of diflubenzuron, pyriproxyfen, imidacloprid, and diafenthiuron to rhe predatory bug Orious laevigatus (Het: Anthocoridae). Entomophaga. 42: 349-358.

Desneux N., Decourtye A. \& Delpuech J.M. 2007. The sublethal effects of pesticides on beneficial arthropods. Annual Review of Entomology. 52: 81-106.

Desneux N., Fauvergue X., Dechaume Moncharmont F.X., Kerhoas L., Ballanger Y. \& Kaiser L. 2005. Diaeretiella rapae limits Myzus persicae populations after applications of deltamethrin in oilseed rape. Journal of Economic Entomology. 98: 9-17.

Devine G.J., Eza D., Ogusuku E. \& Furlong M.J. 2008. Uso de insecticidas: contexto y consecuencias ecológicas. Revista Peruana de Medicina Experimental y Salud Pública. 25: 74-100.

Dhadialla S.T., Carlon G.R. \& Le D.P. 1998. New insecticides with ecdysteroidal and juvenil hormone activity. Annual Reviews of Entomology. 43: 545-69.

DNIyCA-SENASA. Dirección Nacional de Inocuidad y Calidad Agroalimentaria Dirección de Calidad Agroalimentaria. Coordinación de productos ecológicos. 2015. Situación de la producción orgánica en la Argentina durante el año 2015.

Duarte Gómez W. \& Zenner de Polanía I. 2009 a. Efecto de la temperatura sobre el desarrollo de Eriopis connexa connexa (Germar) (Coleoptera: Coccinellidae). Revista U.D.C.A Actualidad \& Divulgación Científica. 12: 135-145.

Duarte Gómez W. \& Zenner de Polanía I. 2009 b. Tabla de vida del cucarrón depredador Eriopis connexa connexa (Germar) (Coleoptera: Coccinellidae). Revista U.D.C.A Actualidad \& Divulgación Científica. 12: 147-155.

Duarte Gómez W., Zenner de Polanía I. \& Arévalo H. 2013. Influence of three aphid species used as prey on some biological aspects of the predator Eriopis connexa. Open Journal of Animal Sciences 3: 193-199.

Eilenberg J. 2006. Concepts and visions of biological control. En: Eilenberg J. \& Hokkanen H.M.T. (Eds.). An ecological and societal approach to biological control, pp. 1- 12. Springer. 
El-Sebaey I.I.A. \& El-Gantiry A.M. 1999. Biological aspects and description of different stages of Harmonia axyridis (Pallas) (Coleoptera: Coccinellidae). Bulletin of the Faculty of Agriculture, Cairo University. 50: 87-97.

Environmental Protection Agency (EPA). www. epa.org. Consultado 14/07/2015.

FAO. 2000. Las negociaciones comerciales multilaterales sobre la agricultura III. Acuerdo sobre la Aplicación de Medidas Sanitarias y Fitosanitarias y Acuerdo sobre Obstáculos Técnicos al Comercio. Módulo 5.

Farhadi R., Allahyari H. \& Chi H. 2011. Life table andpredation capacity of Hippodamia variegata (Coleoptera: Coccinellidae) feeding on Aphis fabae (Hemiptera: Aphididae). Biological Control. 59: 83-89.

Fernández D.G., Mancipe L.C. \& Fernández D.C. 2010. Intoxicación por organofosforados. Revista Med. 18: 84-92.

Fiedler A.K., Landis D.A. \& Wratten S.D. 2008. Maximizing ecosystem services from conservation biological control: The role of habitat management. Biological Control. 45: 254-271.

Fogel M.N. 2012. Selectividad de insecticidas utilizados en cultivos hortícolas del Cinturón Hortícola Platense sobre el depredador Eriopis connexa en el marco del Manejo Integrado de Plagas. Trabajo de tesis de la carrera de Doctor en la Facultad de Ciencias Exactas, Universidad Nacional de La Plata.

Fogel M.N., Schneider M.I., Desneux N., González B. \& Ronco A.E. 2013. Impact of the neonicotinoid acetamiprid on immature stages of the predator Eriopis connexa (Coleoptera: Coccinellidae). Ecotoxicology. 22: 1063-1071.

Fonseca Moscardini V., Gontijo P.C., Carvalho G.A., Lopes de Oliveira R., Braga Maia J. \& Fonseca de Silva F. 2013. Toxicity and sublethal effects of seven insecticides to eggs of the flower bug Orius insidiosus (Say) (Hemiptera: Anthocoridae). Chemosphere. 92: 490-496.

Francesena N., Stadler T. \& Schneider M.I. 2013. Toxicidad de diferentes Insecticidas sobre pupas de Eretmocerus mundus (Hymenoptera:Aphelinidae) parasitoide de Bemisia tabaci (Hemiptera:Aleyrodidae). Acta zoológica Lilloana. 57: 40-42. 
Gagnon A.V., Heimpel G.E. \& Brodeur J. 2011a. The ubiquity of intraguild predation among predatory Arthropods. PLoS ONE. 6:e28061.

Gagnon A.E., Doyon J., Heimpel G.E. \& Brodeur J. 2011b. Prey DNA detection success following digestion by intraguild predators: influence of prey and predator species. Molecular Ecology Resources. 11: 1022-1032.

Galvan T.L., Burkness EC., Koch I. \& Hutchison W.D. 2009. Multicolored asian lady beetle (Coleoptera: Coccinellidae) activity and wine grape phenology: implications for pest management. Environmental Entomology. 38: 1563-1574.

García M. 2011. El Cinturón Hortícola Platense: ahogándonos en un mar de plásticos. Un ensayo acerca de la tecnología, el ambiente y la política. Theoma. 23: 35-53.

Gentz M.C., Murdoch G. \& Kingm G.F. 2010. Tandem use of selective insecticides and natural enemies for effective, reduced-risk pest management. Biological Control 52: 208-215.

Gill R.J., Ramos Rodriguez O. \& Raine N.E. 2012. Combined pesticide exposure severely affects individual and colony level traits in bees. Nature. 491: 105-109.

Giolo F.P., Grützmacher A.D., Manzoni C.G., Nörnberg S.D, da Roza Härter W. \& Castilhos R.V. 2008. Seletividade de produtos fitossanitários utilizados na cultura do pessegueiro nos estágios imaturos de Trichogramma atopovirilia Oatman \& Platner, 1983 (Hymenoptera: Trichogrammatidae). Ciência Rural. 38: 1220-1226.

Gliessman S.R., Rosado May F.J., Guadarrama Zugasti C., Jedlicka J., Cohn A., Mendez C.R., Trujillo L., Bacon C. \& Jaffe R. 2007. Agroecología: promoviendo una transición hacia la sostenibilidad. Ecosistemas. 16: 13-23.

González G.F. \& Kondo T. 2012. Primer registro de la especie invasora Harmonia axyridis (Pallas) (Coleoptera: Coccinellidae) en Ecuador. Boletín de la Sociedad Entomológica Aragonesa. 51: 310.

Gordon R.D. 1985. The Coccinellidae (Coleoptera) of America north of Mexico. Journal of the New York Entomological Society. 93: 1-912. 
Grafton Cardwell E.E. \& Gu P. 2003. Conserving vedalia beetle, Rodolia cardinalis (Mulsant) (Coleoptera: Coccinellidae), in Citrus: A continuing challenge as new insecticides gain registration. Journal of Economic Entomology. 96: 1388-1398.

Grez A., Zaviezo T., Gónzalez G. \& Rothmann S. 2010. Harmonia axyridis in Chile: a new threat. Ciencia e investigación agraria. 37: 145-149.

Gugole Ottaviano M.F., Sánchez N.E., Roggiero M.F. \& Grecco N.M. 2013. Performance of Tetranychus urticae and Neoseiulus californicus on strawberry cultivars and assessment of the effect of glandular trichomes. Arthropod Plant Interactions. 7: 747-754.

Gupta C.R. 2006. Toxicology of organophosphate \& carbamate compounds. Elsevier Haramboure M., Mirande L. \& Schneider M.I. 2016. Improvement of the mass rearing of larvae of the neotropical lacewing Chrysoperla externa through the incorporation of a new semiliquid artificial diet. Biological Control. 61: 69-78.

Haramboure M., Mirande L., Smagghe G., Pineda S. \& Schneider M.I. 2009. Compartibility of melia azedarach extract with Eriopis connexa (Coleoptera: Coccinellidae). Communications in agricultural and applied biological sciences. 75: 373-378.

Hartfelder J. 2000. Insect juvenile hormone: from "status quo" to high society. Brazilian Journal of Medical and Biological Research. 33: 157-177.

Hassan S.A., Bigler F., Bogenschotz H., Boller E., Brun J., Calis J.N.M., Coremans Pelseneer J., Duso C., Grove A., Heimbach U., Helyer N., Hokkanen H., Lewis G.B., Mansour F., Moreth L., Polgar L., Samsoe Petersen B., Sauphanor B., Ubli A., Sterk G., Vainio A., van de Veme M., Viogiani G. \& Vogt H. 1994. Results of the sixth joint pesticides programme of the IOBC/WPRS-Working Group "Pesticides and benefical organisms". Entomophaga. 39: 107-119.

Heimpel G.E., Frelich L.E., Landis D.A., Hopper K.R., Hoelmer K.A., Sezen Z., Asplen M.K. \& Wu K.M. 2010. European buckthorn and Asian soybean aphid as components of an extensive invasional meltdown in North America. Biological Invasions. 12: 29132931. 
Horowitz A.R., Ellsworth P.C. \& Ishaaya I. 2009. Biorational pest control - An overview. En: Ishaaya I. \& Horowitz A.R. (Eds). Biorational control of arthropod pests. Application and resistance management, pp 1-20. Springer.

Hoy A. 2000. The David Rosen lecture: biological control in citrus. Crop Protection 19: 657664.

Ingels B. \& De Clercq P. 2011. Effect of size, extraguild prey and habitat complexity on intraguild interactions: a case study with the invasive ladybird Harmonia axyridis and the hoverfly Episyrphus balteatus. BioControl. 56: 871-882.

Isman M.B. 2008. Perspective botanical insecticides: for richer, for poorer. Pest Management Science. 64: 8-11.

Jacas J.A. \& Urbaneja A. 2009. Origen de las plagas e historia de control biológico. En: Jacas J.A. \& Urbaneja A (Eds.). Control biológico de plagas agrícolas, pp. 3-14. Phytoma.

Jaworski C.C., Bompard A., Genies L., Amiens Desneux E. \& Desneux N. 2013. Preference and prey switching in a generalist predator attacking local and invasive alien pests. PLOS ONE 8: e82231.

Jha R.K., Tuan S.J., Chi H. \& Tang L.C. 2014. Life table and consumption capacity of corn earworm, Helicoverpa armigera, fed asparagus, Asparagus officinalis. Journal of Insect Science. 14: 1-17.

Kaakeh N., Kaakeh W. \& Bennett G.W. 1996. Topical toxicity of imidacloprid, fipronil, and seven conventional insecticides to the adult convergent lady beetle (Coleoptera: Coccinellidae). Journal of Entomological Science: 31: 315-322.

Kairo M.T.K., Pollard G.V., Peterkin D.D. \& Lopez V.F. 2000. Biological control of the hibiscus mealybug, Maconellicoccus hirsutus Green (Hemiptera: Pseudococcidae) in the Caribbean. Integrated Pest Management Reviews 5: 241-254.

Katsanis A., Babendreier D., Nentwig W. \& Kenis M. 2012. Intraguild predation between the invasive ladybird Harmonia axyridis and non-target European coccinellid species. Biocontrol. 58: 73-83. 
Katsoyannos P., Kontodimas D.C., Stathas G.J. \& Tsartsalis C.T. 1997. Establishment of Harmonia axyridis on citrus and some data on its phenology in Greece. Phytoparasitica. 25: 183-191.

Kraiss H. \& Cullen E.M. 2008. Insect growth regulator effects of azadirachtin and neem oil on survivorship, development and fecundity of Aphis glycines (Homoptera: Aphididae) and its predator, Harmonia axyridis (Coleoptera: Coccinellidae). Pest Management Science. 64: 660-668.

Koch L.R. 2003. The multicolored Asian lady beetle, Harmonia axyridis: A review of its biology, uses in biological control, and non-target impacts. Journal of Insect Science. 3: $32-48$.

Koch L.R. \& Tederson, L.D. 2008. Bad side of a good beetle: the North American experience with Harmonia axyridis. Biological Control. 53: 23-35.

Koch R.L., Venette R.C. \& Hutchison W.D. 2006. Invasions by Harmonia axyridis (Pallas) (Coleoptera: Coccinellidae) in the western hemisphere: implications for South America. Neotropical Entomology. 35: 421-434.

Kogan M. 1998. Integrated pest management: historical perspectives and contemporary developments. Annual Review of Entomology. 43: 243-270.

Kogan M. \& Waheed I.B. 1999. Forum integrated pest managment: a glogal reality? Anais da Sociedade Entomológica do Brasil. 28: 1-25.

Kondo T. \& González G.F. 2013. The multicolored Asian lady beetle, Harmonia axyridis (Pallas, 1773) (Coleoptera: Coccinellidae), a not so new invasive insect in Colombia and South America. Insecta Mundi. 283: 1-7.

Lanzoni A., Accinelli G., Bazzocchi G.G. \& Burgio G. 2004. Biological traits and life table of the exotic Harmonia axyridis compared with Hippodamia variegata and Adalia bipunctata (Col., Coccinellidae). Journal of Applied Entomology. 128: 298-306.

Leslie P.H. 1945. On the use of matrices in certain population mathematics. Biometrika. 33: 183-212. 
Li P., Chen Q.Z. \& Liu T.X. 2015. Effects of a juvenile hormone analog, pyriproxyfen, on Serangium japonicum (Coleoptera: Coccinellidae), a predator of Bemisia tabaci (Hemiptera: Aleyrodidae). Biological Control. 86: 7-13.

Liu T.X. \& Chen T.Y. 2001. Efectos del insecticida regulador del crecimiento fenoxycarb on immature Chrysoperla rufilabris (Neuroptera: Chrysopidae). Florida Entomolgist. 84: 628-633.

Liu T.X. \& Stansly P.A. 2004. Lethal and sublethal effects of two insect growth regulators on adult Delphastus catalinae (Coleoptera: Coccinellidae), a predator of whiteflies (Homoptera: Aleyrodidae). Biological Control 30: 298-305.

Lombaert E., Guillemaud T., Cornuet J.M., Malausa T., Facon B. \& Estoup A. 2010. Bridgehead effect in the worldwide invasion of the biocontrol harlequin ladybird. PLOS ONE 5: e9743.

López O., Salto C. \& Luiselli S. 2003. Foeniculum vulgare Miller como hospedera de pulgones y sus enemigos naturales en otoño. Revista FAVE - Ciencias Agrarias. 2: 1-2.

Lorenzatti E.A., Maitre M.I. \& Lenardon A. 2003. Evaluación de la contaminación con plaguicidas en productos lácteos. Revista FAVE - Ciencias Veterinarias 2.

Lotka A.J. 1913. Evolution form the standpoint of physics, the principle of the persistence of stable forms. Scientifc American. 75: 345-379.

Lucas E. 2005. Intraguild predation among aphidophagous predators. European Journal of Entomology. 102: 351-364.

Lucas E. \& Rosenheim J.A. 2011. Influence of extraguild prey density on intraguild predation by heteropteran predators: A review of the evidence and a case study. Biological Control. 59: 61-67.

Lucas E., Coderre D. \& Brodeur J. 1998. Intraguild predation among aphid predators: characterization and influence of extraguild prey density. Ecology. 79: 1084-1092.

Lucas E., Giroux S., Demougeot S., Duchesne R.M. \& Coderre D. 2004. Compatibility of a natural enemy, Coleomegilla maculata lengi (Col., Coccinellidae) and four insecticides used against the colorado potato beetle (Col., Chrysomelidae). Journal of Applied Entomology. 128: 233-239. 
Mackauer M. 1976. Genetic problems in the production of biological control agents. Annual Review Entomology. 21: 369-385.

Majerus M.E.N., Strawson V. \& Roy H.E. 2006. The potential impacts of the arrival of the harlequin ladybird. Ecological Entomology. 31: 207-215.

Maleki N. \& Damavandian M.R. 2015. Determination of economic injury level for first and second generations of Pulvinaria aurantii (Hem: Coccidae) in thomson navel orange orchards. Arthropods. 4: 13-21.

Manfrino R.G., Salto C.E. \& Zumoffen L. 2011. Estudio de las asociaciones áfidosentomófagos sobre Foeniculum vulgare (Umbelliferae) y Conyza bonariensis (Asteraceae) en la región central de Santa Fe, Argentina. Revista de la Sociedad Entomológica Argentina. 70: 99-109.

Mc Cornack B.P., Koch L.R \& Ragsdale D.W. 2007. A simple method for in-field sex determination of the multicolored Asian lady beetle Harmonia axyridis. Journal of Insect Science. 7: 1-12.

Michaud J.P. 2002. Invasion of the Florida citrus ecosystem by Harmonia axyridis (Coleoptera: coccinellidae) and asymmetric competition with a native species, Cycloneda sanguinea. Environmental Entomology. 31: 827-835.

Michaud J.P. \& Grant A.K. 2003. IPM compatibility of foliar insecticides for citrus: Indices derived from toxicity to beneficial insects from four orders. Journal of Insect Science. 3: $1-10$.

Montero G.A. 2014. Ecología de las interacciones entre malezas y artrópodos. En: Fernandez O.A., Acciaresi H.A. \& Leguizamón E.S. (Eds). Malezas e invasoras de la Argentina: ecología y manejo, pp. 267-305. Universidad Nacional del Sur.

Moser S.E. \& Obrycki J.J. 2009. Competition and intraguild predation among three species of coccinellids (Coleoptera: coccinellidae). Annals of the Entomological Society of America. 102: 419-425.

Mordue A.J. 2004. Present concepts of the mode of action of azadirachtin from neem. En: Koul O. \& Wahab S. Neem: Today and in the new millennium, pp. 229-242. Springer. 
Nauen R. \& Denholm I. 2005. Resistance of insect pests to neonicotinoid insecticides: current status and future prospects. Insect Biochemistry and Physiology. 58: 200215.

Nedvěd O. \& Honěk A. 2012. Life History and Development. En: Hodek H.F., van Emden A. \& Honěk A. (Ed.). Ecology and Behaviour of the Ladybird Beetles (Coccinellidae), pp 54-109. Wiley Online Library.

Nedvěd O. \& Kovář I. 2012. Phylogeny and Classification. En: Hodek H.F., van Emden A. \& Honěk A. (Ed.). Ecology and Behaviour of the Ladybird Beetles (Coccinellidae), pp 112. Wiley Online Library.

Nóia M., Borges I. \& Soares A. 2008. Intraguild predation between the aphidophagous ladybird beetles Harmonia axyridis and Coccinella undecimpunctata (Coleoptera: coccinellidae): the role of intra and extraguild prey densities. Biological Control. 46: 140-146.

O'Connel D.M., Wratten S.D., Pugh A.R. \& Barnes A.M. 2012. New species association biological control? Two coccinellid species and an invasive psyllid pest in New Zealand. Biological Control. 62: 86-92.

O’Farril Nieves H. \& Gaud S.M. 2007. Las plagas comunes del jardín. Identificación y manejo integrado, pp 59-65. Servicio de extensión agrícola, Universidad de Puerto Rico. Us Environmental Protection Agency. Pesticide environmental Stewardship Program, EPA Region 2.

Olsen C.E., Pike I.K.S., Boydton L. \& Allison D. 1993. Keys for identification of apterous viviparae and immatures of six small grain aphids (Homoptera: Aphididae). Journal Economic Entomology. 86: 137-148.

Pathan A.K., Ali H., Sayyed A.H., Aslam M., Liu T.X., Razzaq M. \& Gillani W.A. 2010. Resistance to pyrethroids and organophosphates increased fitness and predation potential of Chrysoperla carnea (Neuroptera: Chrysopidae). Journal of Economic Entomology. 103: 823-34. 
Pell. J.K., Baverstock J., Roy H.E., Ware R.L. \& Majerus M.E.N. 2008. Intraguild predation involving Harmonia axyridis: a review of current knowledge and future perspectives. BioControl. 53: 147-168.

Pervez A. \& Omkar. 2006. Ecology and biological control application of multicoloured asian ladybird, Harmonia axyridis: a review. Biocontrol Science and Technology. 16: 112128.

Phoofolo M.W. \& Obrycki J.J. 1998. Potential for intraguild predation and competition among predatory Coccinellidae and Chrysopidae. Entomologia Experimentalis et Applicata. 89: 47-55.

Phoofolo M.W., Giles K.L. \& Elliott N.C. 2008. Larval life history responses to food deprivation in three species of predatory lady beetles (Coleoptera: Coccinellidae). Environmental Entomology. 37: 315-322.

Pianka E.R. 1983. Evolutionary Ecology, pp 416. Harper and Row.

Pickering G.J., Lin Y., Reynolds A., Soleas G., Riesen R. \& Brindle I. 2005. The influence of Harmonia axyridis on wine composition and aging. Journal of Food Science. 70: 128135.

Perdikis D., Lucas E., Garantonakis N., Giatropoulos A., Kitsis P., Maselou D., Panagakis S., Lampropoulos P., Paraskevopoulos A., Lykouressis D. \& Fantinou A. 2014. Intraguild predation and sublethal interactions between two zoophytophagous mirids, Macrolophus pygmaeus and Nesidiocoris tenuis. Biological Control. 70: 35-41.

Polis G.A. \& Mc Cormick S.J. 1989. Intraguild predation and competition among desert scorpions. Ecology. 68: 332-343.

Pórfido O.D. 2014. Los plaguicidas de la República Argentina. Temas de salud ambiental № 14. Departamento de salud Ambiental. Ministerio de Salud de la Nación.

Qi B., Gordon G. \& Gimme W. 2001. Effects of neem-fed prey on the predacious insects Harmonia conformis (Boisduval) (Coleoptera: Coccinellidae) and Mallada signatus (Schneider) (Neuroptera: Chrysopidae). Biological Control. 22: 185-190.

Rabinovich J.E. 1980. Introducción a la ecología de poblaciones animales, pp. 114. Compañía Editorial Continental. 
Ragsdale D.W., Landis D.A., Brodeur J., Heimpel G.E. \& Desneux N. 2011. Ecology and management of the soybean aphid in North America. Annual Review of Entomology. 56: 375-99.

Reed D.K. \& Pike K.S. 1991. Summary of an exploration trip to South America. International Organization for Biological Control. Nearctic Region. 36: 16-17.

Rimoldi F., Schneider M.I. \& Ronco A.E. 2007. Short and long-term effects of endosulfan, cypermethrin, spinosad and methoxyfenozide on adults of Chrysoperla externa (Neuroptera: Chrysopidae). Journal of Economic Entomology. 105: 1982-1987.

Rimoldi F., Schneider M.I. \& Ronco A.E. 2008. Susceptibility of Chrysoperla externa eggs (Neuroptera: Chrisopidae) to conventional and biorational insecticides. Environmental Entomology. 37: 1252-1257.

Rimoldi F., Schneider M.I. \& Ronco A.E. 2012. Short and long-term effects of endosulfan, cypermethrin, spinosad, and methoxyfenozide on adults of Chrysoperla externa (Neuroptera: Chrysopidae). Journal of economic entomology. 105: 1982-1987.

Ringuelet R. 2008. La complejidad de un campo social periurbano centrado en las zonas rurales de La Plata. Mundo Agrario. Centro de Estudios Histórico Rurales. Facultad de Humanidades y Ciencias de la Educación. Universidad Nacional de La Plata. vol. 9, no 17.

Rouaux J. 2015. Coleopterofauna epígea de importancia agrícola en cultivos de lechuga (Lactuca sativa L.) y tomate (Lycopersicum esculentum Mill.), con diferente manejo sanitario, en el Cinturón Flori-Hortícola Platense. Trabajo de tesis de la carrera de Doctor en Ciencias Naturales. Facultad de Ciencias Naturales y Museo, Universidad Nacional de La Plata.

Saini E.D. 2004. Presencia de Harmonia axyridis (Pallas) (Coleoptera: Coccinelidae) en la provincia de Buenos Aires. Aspectos biológicos y morfológicos. Revista de Investigaciones Agropecuarias. 33: 151-160.

Sato S., Kushubuchi K. \& Yasuda H. 2009. Effect of reflex bleeding of a predatory ladybird beetle, Harmonia axyridis (Pallas) (Coleoptera: Coccinellidae), as a means of avoiding intraguild predation and its cost. Applied Entomology and Zoology. 44: 203-206. 
Schneider M.I., Smagghe G., Pineda S. \& Viñuela E. 2004. Action of insect growth regulator insecticides and spinosad on life history parameters and absorption in third-instar larvae of the endoparasitoid Hyposoter didymator. Biological Control. 31: 189-198.

Schneider M.I., Smagghe G., Pineda S. \& Viñuela E. 2007. The ecological impact of four IGR insecticides in adults of Hyposoter didymator (Hym., Ichneumonidae): pharmacokinetics approach. Ecotoxicology. 17: 181-188.

Schneider M.I., Sanchez N., Pineda S., Chi H. \& Ronco A. 2009. Impact of glyphosate on the development, fertility and demography of Chrysoperla externa (Neuroptera: Chrysopidae): Ecological approach. Chemosphere. 76: 1451-1455.

Sijm D.T.H.M., Rikken M.G.J., Rorije E., Traas T.P., MClachlan M.S. \& Peijnenburg W.J.G.M. 2007. Transport, accumulation and tansformation processes. En: van Leeuwen C.J. \& Vermeire T.G. (Eds.). Risk Assessment of chmicals, pp 73-158. Springer.

Silva R.B., Cruz I, Zanuncio J.C., Figueiredo M.L.C., Canevari G.C., Pereira A.G. \& Serrão J.E. 2013. Biological aspects of Eriopis connexa (Germar) (Coleoptera: Coccinellidae) fed on different insect pests of maize (Zea mays L.) and sorghum [Sorghum bicolor L. (Moench.)]. Brazilian Journal of Biology. 73: 419-424.

Snyder E.W., Clevenger G.M. \& Eigenbrode S.D. 2004. Intraguild predation and successful invasion by introduced ladybird beetles. Oecologia. 140: 559-565.

Stark J.D. \& Banks J.E. 2003. Population-level effects of pesticides and other toxicants on arthropods. Annual Review of Entomology. 48: 505-519.

Stark J.D., Vargas R. \& Banks J.E. 2007. Incorporating ecologically relevant measures of pesticides effect for estimating the compatibility of pesticides and biocontrol agents. Journal of Economic Entomology. 100: 1027-1032.

Stenersen J. 2004. Chemmical pesticides. Mode of actions and toxicology, pp. 1-14. CRC Press.

Strassera M.E. 2009. Análisis de la sustentabilidad de diferentes sistemas de producción comercial de tomate bajo cubierta para el manejo de las plagas Trialeurodes vaporariorum y Tuta absoluta en el Cinturón Hortícola Platense. Trabajo de tesis de la carrera de Magister en Protección Vegetal con orientación en manejo de plagas 
animales. Facultad de Ciencias Agrarias y Forestales, Universidad Nacional de La Plata.

Strassera M.E., Schneider M.I., Pretti Slanco V., Caballero E., Kuzmanich R., Mirande L., Haramboure M., Fogel M., Scarano P., Acosta N. \& May P. 2013. Enemigos naturales determinados en el cultivo de alcaucil en el Cinturón Hortícola Platense. XXXVI Congreso Argentino de Horticultura ASAHO. II Congreso Internacional de Plásticos Agrícolas. Tucumán, pp. 342.

Tauber M.J. \& Tauber C.A. 1993. Adaptations to temporal variation in habitats: categorizing, predicting, and influencing their evolution in agroecosystems. En: Kim K.C. \& McPheron B.A. (Eds.). Evolution of insect pests: patterns of variation, pp. 103127. Wiley.

Tommasini M.G., Burgio G., Mazzoni F., \& Maini S. 2002. On intra-guild predation and cannibalism in Orius insidiosus and Orius laevigatus (Rhynchota Anthocoridae): laboratory experiments. Bulletin of Insectology. 55: 49-54.

Tomizawa M. \& Casida J.E. 2003. Selective toxicity of neonicotinoids attributetable to spececity on insect ans mammalian nicotinireceptors. Annual Review of Entomology. 48: 339-364.

Tomé H.V.V., Martins J.C., Corrêa A.S., Galdino T.V.S., Picanço M.C. \& Guedes R.N.C. 2013. Azadirachtin avoidance by larvae and adult females of the tomato leafminer Tuta absoluta. Crop Protection. 46: 63-69.

Tulli M.C., Carmona D.M. \& Vincini A.M. 2013. Influence of plant diversity on the numerical response of Eriopis connexa (Coleoptera: Coccinellidae) to changes in cereal aphid density in wheat crops. International Journal of Ecology. 2013: 1-8.

Van Driesche R.G., Hoddle M.S. \& Center T.D. 2007. Control de plagas y malezas por enemigos naturales, pp. 1-70. USDA Forest Service Forest Health Technology Enterprise Team.

van Lenteren J.C., Loomans A.J.M., Babendreier D. \& Bigler F. 2008. Harmonia axyridis: an environmental risk assessment for Northwest Europe. Biological Control. 53: 37-54. 
van Lenteren J.C., Bale J., Bigler F., Hokkanen H.T.M. \& Loomans A.J.M. 2006. Assessing risks of releasing exotic biological control agents of arthropods pests. Annual Review Entomology. 51: 609-634.

van Lenteren J.C., Babendreier D., Bigler F., Burgio G., Hokkanen H.M.T., Kuske S., Loomans A.J.M., Menzler- Hokkanen I., Van Rijn P.C.J., Thomas M.B., Tommasini M.G. \& Zeng Q.Q. 2003. Environmental risk assessment of exotic natural enemies used in inundative biological control. Biological Control. 48: 3-38.

Wakeling E.N., Neal A.P. \& Atchison W.D. 2012. Pyrethroids and their effects on ion channels. En: Soundararajan R.P. (Ed.) Pesticides. Advances in chemical and botanical pesticides, pp. 39-66. Intech.

Ware R. \& Majerus E.N.M. 2008. Intraguild predation of immature stages of british and japanese coccinellids by the invasive ladybird Harmonia axyridis. BioControl. 53: 169-188.

Ware R., Yguel B. \& Majerus M. 2009. Effects of competition, cannibalism and intra-guild predation on larval development of the European coccinellid Adalia bipunctata and the invasive species Harmonia axyridis. Ecological Entomolog. 34: 12-19.

Weber D.C. \& Lundgren J.G. 2009. Assessing the trophic ecology of the Coccinellidae: their roles as predators and as prey. Biological Control. 51: 199-214.

Whitehorn P.R., O'Connor S., Wackers F.L. \& Goulson D. 2012. Neonicotinoid pesticide reduces bumble bee colony growth and queen production. Science. 36: 351-352.

www.coccinellidae.cl. Coccinelidae de Chile. Consultado 12/06/2015.

Yasuda H., Kikuchi T., Kindlmann P. \& Sato S. 2001. Relationships between aAttack and escape rates, cannibalism, and intraguild predation in larvae of two predatory ladybirds. Journal of Insect Behavior. 14: 373-384.

Yasuda H., Evans E.W., Kajita Y., Urakawa K. \& Takizawa T. 2004. Asymmetric larval interactions between introduced and indigenous ladybirds in North America. Oecologia. 141: 722-731. 
Youn Y.N., Seo M.J., Shin J.G., Jang C. \& Yu Y.M. 2003. Toxicity of greenhouse pesticides to multicolored Asian lady beetles, Harmonia axyridis (Coleoptera: Coccinellidae). Biological Control. 28: 164-170.

Yu J.Z., Chi H. \& Chen B.H. 2005. Life table and predation of Lemnia biplagiata (Coleoptera: Coccinellidae) fed on Aphis gossypii (Homoptera: Aphididae) with a proof on relationship among gross reproduction rate, net reproduction rate, and preadult survivorship. Annals of the Entomological Society of America. 98: 475-482.

Yu J.Z., Chi H. \& Chen B.H. 2013. Comparison of the life tables and predation rates of Harmonia dimidiata (F.) (Coleoptera: Coccinellidae) fed on Aphis gossypii Glover (Hemiptera: Aphididae) at different temperaturas. Biological Control 64: 1-9.

Zar J.H. 2010. Biostatistical anlisys. Pearson.

Zhang L., Greenberg S.M., Zhang Y. \& Liu T.X. 2011. Effectiveness of thiamethoxam and imidacloprid seed treatments against Bemisia tabaci (Hemiptera: Aleyrodidae) on cotton. Pest Management Science. 67: 226-232.

Zumoffen L., Salto C. \& Signorini M. 2010. Alfalfa (Medicago Sativa L.) como reservorio de insectos entomófagos. Revista FAVE - Ciencias Agrarias 9: 1-2. 